\title{
Spots before the eyes: revision of the saxicoline geckos of the Gehyra punctata (Squamata: Gekkonidae) species complex in the Pilbara region of Western Australia
}

\author{
Paul Doughty 1, ${ }^{,}$Aaron M. Bauer ${ }^{2}$, Mitzy Pepper ${ }^{3}$ and J. Scott Keogh ${ }^{3}$ \\ ${ }^{1}$ Department of Terrestrial Zoology, Western Australian Museum, Locked Bag 49, Welshpool DC, \\ Western Australia 6986, Australia. \\ 2 Department of Biology, Villanova University, 800 Lancaster Avenue, Villanova, Pennsylvania 19085, \\ U.S.A. \\ ${ }^{3}$ Division of Evolution, Ecology \& Genetics, Australian National University, Canberra, ACT 0200, \\ Australia. \\ * Corresponding author: paul.doughty@museum.wa.gov.au
}

\begin{abstract}
The Gehyra punctata species complex in the Pilbara and surrounding regions of Western Australia has long been known for its confused taxonomy. Recent collections in the region have enabled a reassessment of specimens currently referable to G. punctata. We assessed populations genetically using newly generated mitochondrial DNA data in conjunction with recently published phylogenomic data and an unpublished allozyme analysis. In addition, we carried out a detailed morphological examination involving hundreds of specimens across this taxon's range. Many possible candidate species were recovered from these analyses, and the re-examination of morphology indicated two major clades: one small-bodied and one large-bodied, each comprising multiple divergent lineages within them. A syntype of Peropus variegatus punctatus Fry, 1914, believed to have been lost at the time of Mitchell's revision in 1965, was recently found in the Western Australian Museum collections, and is here designated as the lectotype of G. punctata sensu stricto.

In addition to $G$. punctata from the Pilbara craton, the large-bodied clade comprises several species: G. macra sp. nov. - sister to G. punctata and confined to the northern Pilbara, and two more southerly distributed species, G. punctulata sp. nov. and G. polka sp. nov.; and a small-bodied species restricted to the south-western Pilbara region in the Hamersley Range, G. fenestrula sp. nov. Within the small-bodied clade a slightly larger-sized species is described as G. media sp. nov. For the other highly structured small-bodied lineage, one of the groups diverged morphologically and was recovered as the basal group in the phylogenomic data, despite being nested within the small-bodied lineage in the mitochondrial dataset. As this population is also geographically restricted to the Burrup Peninsula, we describe it as G. peninsularis sp. nov., based on the combined evidence. The remaining very small-bodied lineages we describe as G. micra sp. nov.
\end{abstract}

The new species are diagnosable on the basis of morphology, colour and patterns of pale and dark spots. The revision of the G. punctata species complex adds seven new species to the western arid zone, and further establishes the Pilbara as the region with the highest gecko diversity and endemism in Australia.

KEYWORDS: Gehyra fenestra, Gehyra fenestrula sp. nov., Gehyra macra sp. nov., Gehyra media sp. nov., Gehyra micra sp. nov., Gehyra peninsularis sp. nov., Gehyra polka sp. nov., Gehyra punctulata sp. nov., mtDNA, ND2.

urn:Isid:zoobank.org:pub:2D94A224-4604-4AF5-9436-4F8629A23746 


\section{INTRODUCTION}

The rock-dwelling spotted forms have proved as difficult to classify as the variegated tree-dwelling species.

- F.J. Mitchell on Gehyra (1965, p. 302)

Gehyra is a 'taxonomist's nightmare'...

- M. King (1979, p. 376)

Geckos of the genus Gehyra are among the most taxonomically confusing within the Australian herpetofauna owing to their conservative body form, widely varying characters within taxa, remote locations for many species complexes and poor preservation of colour patterns in museum specimens (King 1983; Sistrom et al. 2009, 2014; Doughty et al. 2012, 2018; Kealley et al. 2018). Recently, progress has been made resolving the affinities of Gehyra to other gekkonine geckos (Heineke et al. 2011; Gamble et al. 2012; Sistrom et al. 2014) and delimiting species boundaries (Horner 2005; Sistrom et al. 2009, 2013; Oliver et al. 2010, 2016; Doughty et al. 2012, 2018; Hutchinson et al. 2014). As King (1983) pointed out 35 years ago, taxonomic progress on Gehyra has been particularly hindered by the loss of colour patterns in preservative and that 'too few specimens from too few localities have been examined' (p. 739).

The wide variation within recognised forms has characterised work on Gehyra throughout its history. In a taxonomic treatment of the genus in Australia over 50 years ago, Bustard (1965a) noted the wide range of variation within $G$. australis Gray, 1845 and G. variegata (Duméril \& Bibron, 1836), concluding that, despite this variation, the two taxa were indeed full species and not mere subspecies as asserted by Mitchell (1955) (n.b. no mention was made of G. dubia [Macleay, 1877], indicating Bustard was unaware of this name). In the late 1970s and early 1980s, work on documenting the karyotypes of widely distributed Gehyra taxa in Australia by King and Moritz began to reveal the true confusion in the genus and resulted in many species descriptions (reviewed in King 1979, 1983; Moritz 1986; Sistrom et al. 2009, 2013). Based on widely varying karyotypes across the region, new species were erected to accommodate several chromosomally and morphologically divergent populations, i.e. G. nana Storr, 1978, G. montium Storr, 1982, G. purpurascens Storr, 1982, G. pamela King, 1982a, G. minuta King, 1982b, G. borroloola King, 1984a, G. robusta, King, 1984a and $G$. occidentalis King, 1984b, including the resurrection of $G$. dubia. In addition, other distinctive forms were also described based on morphology, i.e. G. catenata Low, 1978 and G. xenopus Storr, 1978. After this active period in Gehyra systematics, no further species were recognised for over 20 years until the description of G. koira Horner, 2005 (with two subspecies, koira and ipsa) based on morphology. Recent work drawing from combined genetic and morphological data has resulted in many new species descriptions from the Australian Monsoonal Tropics (Doughty et al. 2012, 2018; Oliver et al. 2016; Bourke et al. 2017) and Central Ranges (Hutchinson et al. 2014), and the first proper descriptions of G. lazelli Wells \& Wellington, 1983 (Sistrom et al. 2009) and G. kimberleyi Börner \& Schüttler, 1983 (Oliver et al. 2016).

One of the most recalcitrant groups within Gehyra is the G. punctata (Fry, 1914) species complex from the Pilbara, Gascoyne and eastern Murchison regions of Western Australia (WA), and sometimes reported from the southern Kimberley (Storr et al. 1990; Wilson \& Swan 2008; but see King 1981; Doughty et al. 2018). In his assessment in the 1910s of collections from the Western Australian Museum (WAM), Fry originally described this taxon as a 'variety' of G. variegata based on a small female from the 'Strelley River, Pilbara' that corresponded with Central Ranges specimens from the Horn Expedition (see Ellis et al. 2018) stating that: 'In all structural characters it agrees with the variable $P$. [Peropus] variegatus, but the color pattern is so different that I propose to distinguish it under the varietal name of punctatus' (p. 178). He then went on to describe in a few sentences the 'russet brown' colouration marked with many spots to distinguish it from Peropus variegatus variegatus (i.e. G. variegata and the eastern G. versicolor Hutchinson, Sistrom, Donnellan \& Hutchinson, 2014). Zietz (1920) later synonymised punctata with variegata, only for this to be reversed by Loveridge (1934), who retained punctata as a subspecies of $G$. variegata, and also considered its distribution to be restricted to Western Australia (excluding the Central Ranges). In a comment on a nomenclatural note on Gehyra, including G. punctata, by Chrapliwy et al. (1961), Bustard (1965b) raised this taxon to full species status based on his collections of sympatric $G$. 'variegata' ( $=G$. versicolor or $G$. montium) on trees and G. 'punctata' (= G. minuta, G. moritzi Hutchinson, Sistrom, Donnellan \& Hutchinson, 2014 or G. pulingka Hutchinson, Sistrom, Donnellan \& Hutchinson, 2014) on rocks in central Australia, believing G. punctata occurred as far as northern Queensland (n.b. his detailed treatment of Gehyra mentioned in Bustard [1965a, b] was never published, possibly owing to the appearance of Mitchell's own detailed revision published later that year).

In a review of the genus that emphasised osteological differences, Mitchell (1965) redescribed all Australian forms recognised at that time, including G. punctata. Unfortunately, he could not examine the type specimen as it could not be located by the staff of the WAM or the Australian Museum, Sydney (AMS) when searching through material that Fry likely consulted (Mitchell 1965, pp. 301-302; n.b. Fry died in World War I shortly after the publication of his 1914 work; Adler 2007). When focussing on material from the Pilbara region in WA, Mitchell found evidence for four species: $G$. variegata, G. punctata, G. fenestra Mitchell, 1965 and $G$. pilbara Mitchell, 1965, the latter two of which 
he described as new species in his review. Key to Mitchell's concept of Fry's G. punctata was that it was a small-bodied species, based on Fry's statement that 'in all structural characters it agrees with the variable P. variegatus' (p. 178, and also quoted by Mitchell 1965, p. 303). Despite presenting data that $G$. fenestra was larger than $G$. punctata (mean snout-vent length [SVL] of 61 vs. $46 \mathrm{~mm}$, respectively) and had a more strongly depressed head and body, Mitchell found that many characters overlapped between the two taxa, stating '...the present study clearly indicates that no characters can be employed as absolute criteria for species identification...' (p. 308). Based on the material listed for G. punctata and also the map shown in his fig. 10, it is clear that this taxon included other species from the Shark Bay area in WA and also the Northern Territory. He also cited ecological differences from collectors' notes indicating that $G$. 'punctata' had been collected from under rocks adjacent to rocky pools whereas $G$. fenestra had been collected from boulders and crevices (p. 303). Thus, although acknowledging outstanding issues in the delimitation of species boundaries between the two taxa, he stood by the osteological differences he found, particularly a single fenestra in the pubis of his small-bodied 'punctata' and two in fenestra (hence the specific name), and differences in the mesosternal ribs.

After Mitchell's (1965) revision, most small-bodied Gehyra with a reddish background colour, spots and an association with rocks had been referred to as $G$. punctata, including those from the northern tropics from the Kimberley to Queensland, and also the Central Ranges. Workers in the 1970s and 1980s left the Pilbara region and its reddish, spotted forms of Gehyra relatively uninvestigated, and instead focussed on describing forms elsewhere (see above). However, the two species of reddish-brown spotted Gehyra from the Pilbara were synonymised by Storr (1982) in his description of $G$. purpurascens and G. montium from the Central Ranges. The reddish, spotted G. montium presumably had been previously referred to G. punctata as early as Fry's 1914 publication and so necessitated a redescription (although recent work has found the Central Ranges to contain several more Gehyra species, as well as discovering that $G$. montium extends across the western deserts and is widespread in the Pilbara [Sistrom et al. 2013; Hutchinson et al. 2014; Kealley et al. 2018]). Without commenting on the type specimens of either taxa, Storr (1982) synonymised G. fenestra with $G$. punctata based on an overlap of characters, concluding his characteristically brief paper with: 'I suspect that Mitchell's concept of G. punctata was partly based on Pilbara specimens of $G$. variegata and/or $G$. pilbara. At any rate I believe that only three species of Gehyra occur in the Pilbara' (p. 59).

Recently, however, R.J. Ellis reidentified the specimens in the WAM collections that were loaned to Fry in the 1910s, including the female specimen that Fry (1914) referred to as the 'type' (see detailed account in Ellis et al. 2018). As Fry also referred to an illustration of a spotted gecko from the Horn Expedition to the Central Ranges in his description, this necessitates a lectotype designation as the specimen upon which the illustration is based constitutes a second syntype in addition to the rediscovered female in the WAM collection. Although the sub-adult female syntype is in quite poor condition, it is recognisable as the largebodied form of $G$. punctata from the Pilbara (Ellis et al. 2018). Coupled with examination of the G. fenestra types, which are in reasonable condition, this has greatly facilitated assignment of names to the G. punctata species complex. See the Taxonomy section below and Ellis et al. (2018) for resolution of the type specimens of $G$. punctata and G. fenestra.

Despite the confusion in the past, new collections of Gehyra from the western rocky areas of the Pilbara and regions to the south have resulted in an increase in material to assess Gehyra diversity from this area. In particular, environmental impact assessments carried out by biological consultants required for mining proposals and the WA Department of Environment \& Conservation's (now Department of Biodiversity, Conservation \& Attractions) Pilbara Biodiversity Survey (PBS) (McKenzie et al. 2009; Doughty et al. 2011) resulted in the collection of a large series of $G$. punctata sensu lato specimens, most of which had tissue samples taken for genetic analysis. Therefore it is timely to reassess the status of the many forms of G. punctata from the region using evidence from morphology, mtDNA, distribution and habitat preferences. We also draw on a recent phylogenomic analysis of Gehyra (Ashman et al. 2018) and an unpublished pilot study using allozyme electrophoresis (M. Adams and P. Doughty, unpublished data). The combined genetic and morphological evidence indicates that G. punctata as currently conceived is paraphyletic, with two major clades: one with four larger-bodied species and one small-bodied species, and a second clade with three smaller-bodied species, resulting in the description of seven new species from the Pilbara region herein.

\section{METHODS}

\section{APPROACH AND MATERIAL EXAMINED}

We undertook an integrated approach and used both morphological and genetic data to determine species boundaries within the G. punctata species complex based on recently collected specimens from the Pilbara and rocky regions to the south, including the eastern Gascoyne, eastern Murchison and Yalgoo bioregions (Thackway and Cresswell 1995). We initially grouped specimens into several different morphologies, then ran select specimens for allozyme profiles in the mid2000s (M. Adams and P. Doughty, unpublished data). The resulting groups recovered from the allozyme analysis then guided further mtDNA sequencing and morphological examinations. New specimens and tissues for genetic analyses were integrated into the revision, and recently the missing type of Fry was located to help 
resolve the application of names. Preliminary mtDNA phylograms generated by Sistrom et al. (2013) and for this study informed the study of Ashman et al. (2018), who drew samples from within mtDNA lineages and used exon capture techniques to carry out a detailed phylogenomic assessment of nearly all Gehyra species that firmly established independently-evolving lineages. Similar to Kealley et al. (2018), we use the findings of Ashman et al. (2018) based on few individuals per lineage and coupled them with our expanded mtDNA sampling to provide sufficient genotyped specimens for morphological analyses and for mapping distributions.

Almost all specimens examined had tissue samples taken and some were photographed during specimen preparation to document the dorsal colours and patterns that typically fade in preservative. Most specimens are from the WAM collections, supplemented by tissues from the South Australian Museum, Adelaide (SAMA) and the Museum and Art Gallery of the Northern Territory (NTM). Appendix 1 lists specimens examined, and whether their mtDNA, allozymes, nDNA and/or morphology were analysed.

\section{MITOCHONDRIAL DNA}

\section{Taxonomic sampling, DNA extraction and PCR}

We sampled from within the groups identified through the allozyme analysis, and sequenced 178 samples variously identified as G. punctata and G. pilbara for the mtDNA NADH-hydrogenase subunit 2 gene (ND2). In addition, we supplemented these samples with $83 \mathrm{mtDNA}$ data from other studies (Sistrom et al. 2009; Pepper et al. 2013; J. Huey and P. Doughty, unpublished data).

DNA was obtained from the allozyme homogenates for new samples in this study using the EDNA HiSpEx tissue kit (Chaga) following the manufacturers protocol. The ND2 region was amplified and sequenced in three overlapping fragments, using the forward primer L4437 (5'-AAGCTTTCGGGGCCCATACC-3'; Macey et al. 1998) and the reverse primer tRNA ${ }^{A s n}$ (5' - C TA A A A T R T T RCGGGA TCGAGGCC-3'; Read et al. 2001). A modified version of $\mathrm{L} 4882$ (5'-CAACCTGACAAAAAHTHGCMC-3'; Macey et al. 2000) was used as an internal sequencing primer.

PCR amplification was performed in a $25 \mu$ reaction mix consisting of $12.5 \mu \mathrm{l}$ GoTaq (Promega), $10.5 \mu \mathrm{l}$ double distilled water, $1.0 \mu \mathrm{l}$ of both forward and reverse primers (10 pmol) and $1.0 \mu \mathrm{l}$ of template DNA. Amplification of the fragment was conducted using a Corbett PC-960C cooled thermal cycler with an activation step at $94^{\circ} \mathrm{C}$ for $3 \mathrm{~min}$, followed by 37 cycles of denaturation at $94^{\circ} \mathrm{C}$ for $30 \mathrm{~s}$, annealing at $60^{\circ} \mathrm{C}$ for $30 \mathrm{~s}$, and extension at $72^{\circ} \mathrm{C}$ for $60 \mathrm{~s}$ followed by a final extension step at $72^{\circ} \mathrm{C}$ for 10 min. Approximate concentration and size of amplification products was determined by electrophoresis in a $2 \%$ agarose gel stained with 5.0 ul SYBR Safe (Invitrogen) and visualised under ultra-violet light. Target products were purified using $0.4 \mu \mathrm{l}$ Exonuclease I, and $1.6 \mu \mathrm{l}$ shrimp alkaline phosphatase (exo/SAP).
Cycle-sequencing reactions were performed in reaction volumes of $20 \mu \mathrm{l}$, consisting of $1.0 \mu \mathrm{l}$ BigDye (Applied Bio-systems), $4.5 \mu \mathrm{l}$ of $5 \mathrm{X}$ sequencing buffer, $0.32 \mu \mathrm{l}$ Primer $(10 \mathrm{pmol}), 12.5 \mu \mathrm{l}$ double distilled water and $1.0 \mu \mathrm{l}$ purified PCR product. To precipitate sequence products and to remove all unincorporated nucleotides, $40 \mu \mathrm{l}$ of cold $100 \%$ ethanol and $3 \mu \mathrm{l}$ of $\mathrm{NaOAc}$ was added to each sample and left for $15 \mathrm{~min}$ at room temperature. Precipitated DNA was pelleted by centrifuging for 30 mins and washed three times in $150 \mu \mathrm{l}$ of $70 \%$ ethanol with a 10 min centrifuge step. Pellets were dried before being dissolved in $20 \mu \mathrm{l}$ of HiDi formamide and run on an ABI 3100 auto-sequencer. All genes were sequenced from both 3' and 5' ends separately. Sequences were edited and assembled using Sequencher 3.0 (Genes Codes Corporation). Alignment of sequences was first performed automatically using the software MUSCLE (Edgar 2004), then refined by eye in Se-Al (Rambaut 1996). Protein-coding regions were translated into amino acid sequences using the vertebrate mitochondrial genetic code or universal nuclear genetic code and were checked for internal stop codons and frame-shift mutations.

\section{Phylogenetic analyses}

Each edited alignment comprised 1,044 characters for 261 individuals. We used PartitionFinder (Lanfear et al. 2012) to determine the best partitioning strategy for the mtDNA locus, whereby codon positions one and two were considered together, and codon three was partitioned separately. Maximum likelihood (ML) estimation of the phylogeny of the dataset was performed in RAxML, v.7.0.4 (Stamatakis 2006). The data were analysed under the Generalized Time Reversible model of sequence evolution (variable base frequencies, and a symmetrical substitution matrix) (Rodríguez et al. 1990), and with an across site rate variation modelled to a Gamma distribution $(\mathrm{GTR}+\Gamma)$. The best ML tree was determined using 20 distinct randomised Maximum Parsimony (MP) starting trees. Support values were estimated from 1,000 bootstrap replicates, with bootstrap values above 80 considered as strong support. In our summary phylogram (Figure 1) we present a reduced subset of specimens for legibility. Appendix 1 provides details of all specimens sequenced that we used to generate distribution maps and to identify individuals for morphological analyses.

\section{MORPHOLOGY}

Individuals for which we had allozyme profiles were initially chosen as the core group of samples with which to establish morphological boundaries among taxa and to choose further samples for mtDNA analysis. Specimens examined are in the type lists under species accounts and Appendix 1.

Morphological characters (Table 1) were measured with digital calipers to the nearest $0.1 \mathrm{~mm}$, except SVL and TailL that were measured with a rule to the nearest 0.5 and $1.0 \mathrm{~mm}$, respectively. Scale counts (e.g. labial scales, subdigital lamellae) were also scored and we 


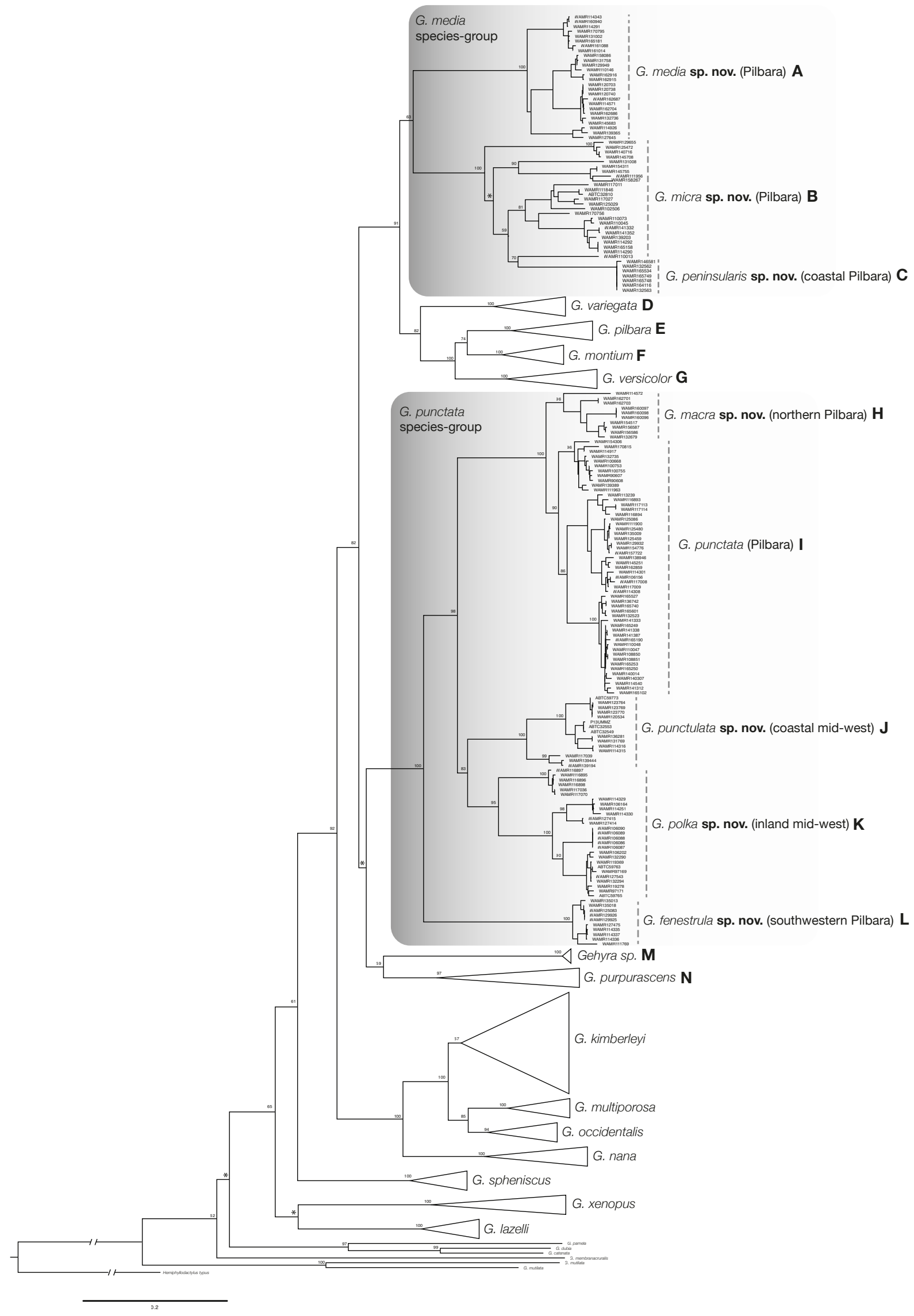

FIGURE 1 Phylogram of the Gehyra variegata group and related species focussed on the G. punctata species complex based on the mitochondrial gene ND2. Numbers above or on the left of nodes on the tree refer to ML bootstrap support values from the RAxML analysis; "*" indicates values $<50$. 
followed the terminology for scales around the tip of the snout in Sistrom et al. (2009; fig. 6, p. 24), except for modification of Hutchinson et al. (2014) to refer to the 'postmentals' as inner chin shields, and to the 'sublabials' as parinfralabials as suggested by King (1982b). Notes on reproduction for males and females were also made, but few females were gravid. Live or moribund photographs of vouchered specimens (or unvouchered based on geography) were used for the description of colour and patterns.

\section{SPECIES CONCEPT EMPLOYED}

Australian Gehyra pose a taxonomic challenge in that intraspecific morphological variation is often high and interspecific differences subtle. The availability of large samples across the Pilbara and adjacent regions has allowed us to identify putative phylogenetic signal from widely overlapping phenotypic differences. However, recognition of species-level taxonomic units was also guided by the unpublished allozyme data set and mtDNA phylograms. In addition, we drew from an extensive phylogenomic analysis of Australian Gehyra (Ashman et al. 2018), which recovered with high support all the lineages described as new species here. Thus we have employed an integrative taxonomic approach (Padial et al. 2010), whereby we base taxonomic decisions on multiple lines of evidence.

We here employ a general lineage-based species concept (Frost and Hillis 1990; Frost et al. 1992; Mayden 1997; de Queiroz 1998, 2007) and treat as species those entities that clearly represent independent historical lineages based on two or more lines of evidence. In practical terms, we have focussed on the operational criteria that permit us to infer independently-evolving lineages (Wiens and Penkrot 2002; Sites and Marshall 2003, 2004; Bauer et al. 2006; Camargo and Sites 2013). Such criteria may be either tree-based or character-based and we employ both approaches in this paper, basing our taxonomic decisions on the conjunction of data from mtDNA phylograms, the phylogenomic analysis of Ashman et al. (2018), the unpublished pilot allozyme analysis and diagnostic morphological traits. Although distribution patterns alone should not be used in erecting initial hypotheses of species boundaries, geographic concordance with other evidence of lineage independence may be corroborative of taxonomic decisions based on tree- and character-based delimitations (Bergmann and Russell 2007). When there was conflict among datasets, we weighed up the total evidence to arrive at a taxonomic conclusion. Owing to the difficult nature of working with the G. punctata species complex, we have taken a conservative approach in naming species, electing to recognise species for which there was strong support from multiple lines of evidence, despite some conflict between datasets. The most difficult choice was the recognition of $G$. peninsularis sp. nov. (lineage $\mathrm{C}$ on Figure 1), as this was recovered inside $G$. micra sp. nov. (lineage B) in the mtDNA data, yet in the nDNA analysis of Ashman et al. (2018) it was recovered as the sister of G. media sp. nov. (lineage A) + G. micra sp. nov. However, owing to consistent morphological differences and geographic isolation, the balance of evidence indicated this was a species.

This revision greatly stabilises the taxonomy of this species complex by applying names to lineages recovered from the robust genetic and morphological analyses. Future work will be able to further analyse diversity within some of our species units such as G. micra sp. nov., as this taxon possesses complex phylogenetic structure but for which there are few morphological characters to distinguish them from other species at present.

TABLE 1 Morphological characters measured on Gehyra punctata species complex specimens.

\begin{tabular}{ll} 
Abbreviation & Definition \\
\hline SVL & Snout-vent length: from tip of snout to anterior edge of cloaca. \\
TailL & Tail length: from cloaca to tail tip; original or regenerated tails noted. \\
HeadL & Head length: from tip of snout to edge of retroarticular process of upper jaw; caliper held at oblique angle. \\
HeadW & Head width: widest part of head, measured behind eyes. \\
HeadD & Head depth: deepest part of head behind eyes, with caliper on lower jaw bones. \\
LegL & Leg length: length of lower leg measured from heel to knee with leg at right angle. \\
SupLab & Number of supralabial scales, defined as being larger than surrounding scales on head. \\
InfLab & Number of infralabial scales, defined as being larger than surrounding scales on head. \\
SupNas & Suprnasal scales: scored whether in contact or separated by internasal scales. \\
Notched infralabial & $\begin{array}{l}\text { Scored which InfLab (2nd or 3rd) if posterior edge of InfLab was notched when contacted by } \\
\text { parinfralabial scale. }\end{array}$ \\
4TLam & Fourth toe lamellae: number of expanded lamellae, excluding triangular-shaped wedge at tip. \\
PCP & Pre-cloacal pores: counted if pore perforated, usually yellowish (dimpled scales not counted). \\
\hline
\end{tabular}




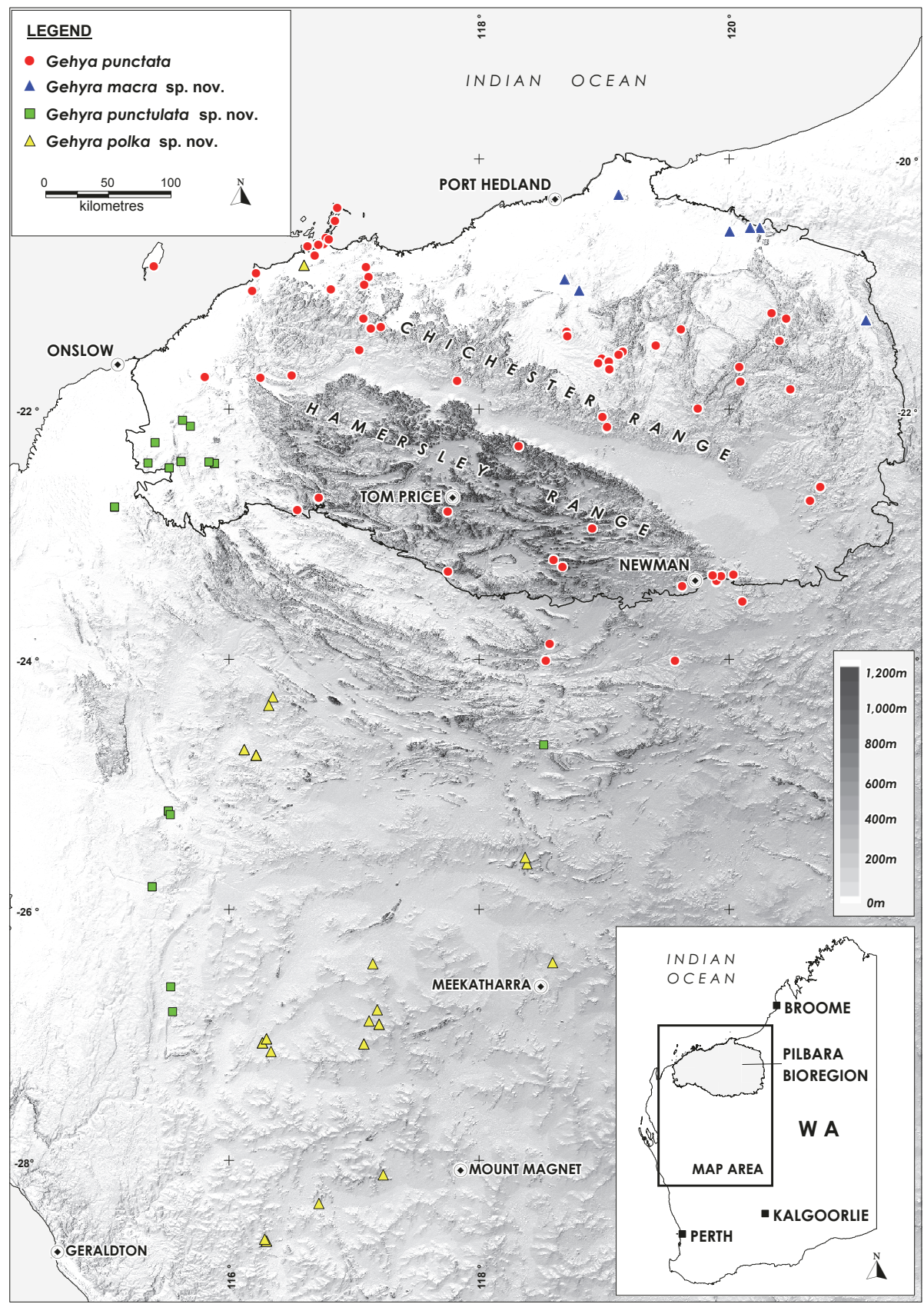

FIGURE 2 Distribution of the large-bodied members of the Gehyra punctata species-group in the Pilbara and regions to the south in Western Australia based on individuals with mtDNA genotyping or allozymes: G. punctata, G. macra sp. nov., G. punctulata sp. nov. and G. polka sp. nov.

\section{RESULTS}

\section{MITOCHONDRIAL DNA}

Our analysis of mtDNA recovered many groups that corresponded to the allozyme groups from the initial pilot study, as well as many other described taxa, including those in other recent Gehyra studies (Figure 1; Ashman et al. 2018; Kealley et al. 2018; Moritz et al. 2018). A conspicuous feature of the phylogram was the recovery of two major clades that roughly consisted of small and large-bodied forms of $G$. punctata s.l. and other closely allied taxa, confirming that G. punctata as presently conceived is paraphyletic with several cryptic lineages within each clade.

The larger-bodied G. punctata clade, henceforth the 'G. punctata species-group' had three major clades within it: a Pilbara craton clade (lineages $\mathrm{H}+\mathrm{I}$ ), a clade south of the Pilbara (lineages $\mathrm{J}+\mathrm{K}$ ) and another with a small body size and restricted distribution in the southeast Pilbara near Newman (lineage L) (Figures 2-3). The Pilbara craton clade had specimens that corresponded to the type of Fry's G. punctata, 


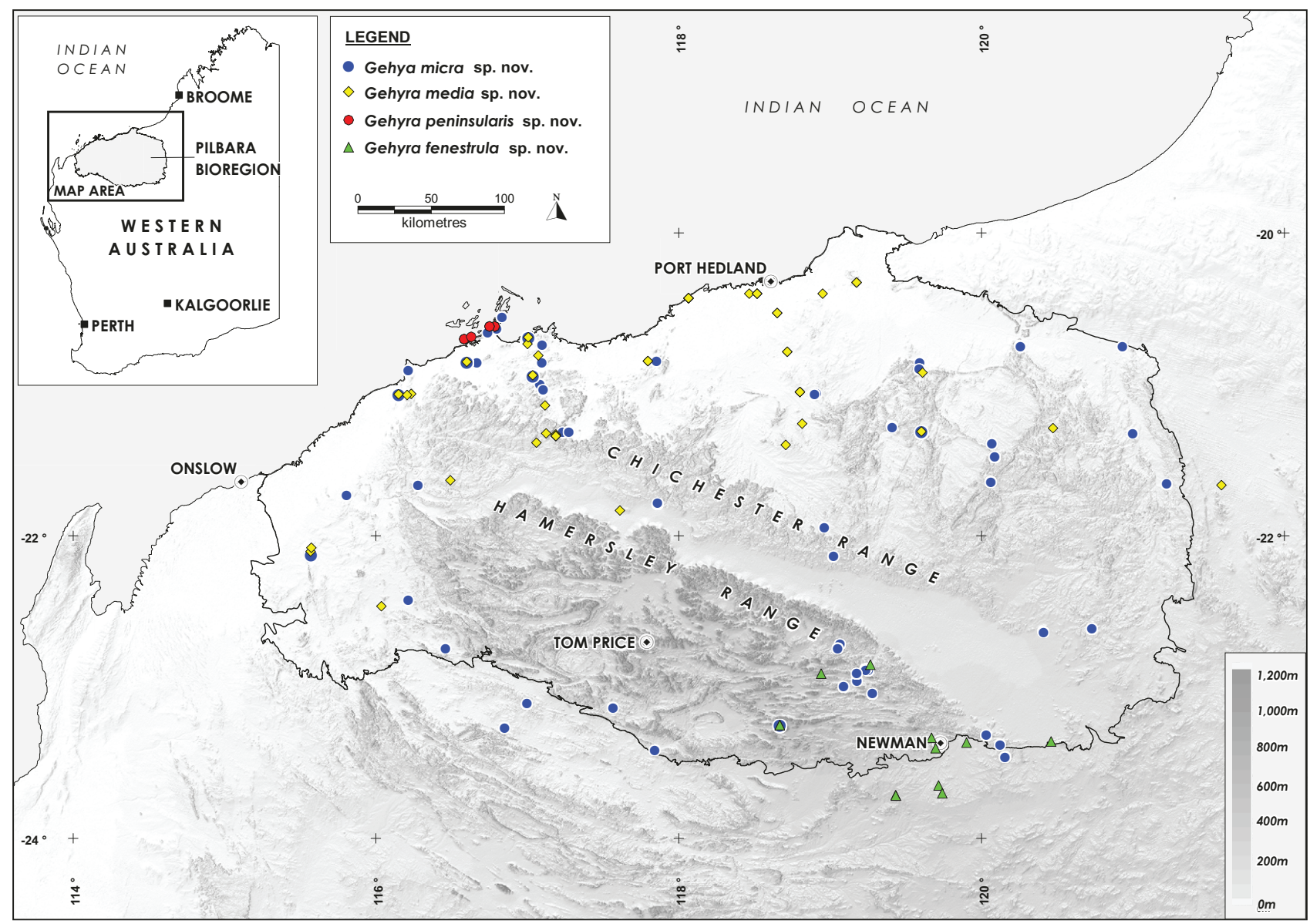

FIGURE 3 Distribution of the small-bodied members of the Gehyra punctata species complex in the Pilbara in Western Australia based on individuals with mtDNA genotyping or allozymes: G. media sp. nov., G. micra sp. nov., G. peninsularis sp. nov. (the G. media species-group) and G. fenestrula sp. nov. (part of the G. punctata species-group).

i.e. lineage I, to which we refer that species name. In addition, there was an even larger-bodied form within this clade that was restricted to the northern Pilbara (lineage H). This large-bodied form was the sister lineage to G. punctata. The southernmost clade (lineages $\mathrm{J}+\mathrm{K}$ ) ranged as far south as Yalgoo at $\sim 28^{\circ} \mathrm{S}$ latitude and approximately $200 \mathrm{~km}$ inland from Geraldton on the west coast, and this clade showed significant genetic structuring among some populations. However, two major monophyletic groupings within the southern clade corresponded with geography and dorsal patterning (see below). The Newman lineage (lineage L) is sister to all other large-bodied lineages, with individuals from this clade reaching only small to moderate sizes.

A weakly divergent small-bodied clade, henceforth the 'G. media species-group', comprises two major groups and is sister to a different group of small-bodied species in the arid clade of the $G$. variegata group that included $G$. variegata, G. pilbara, G. montium and $G$. versicolor (Figure 1; Kealley et al. 2018). The two major groups within this lineage showed different levels of genetic structure within them, with one ( $G$. media sp. nov., lineage A) being fairly uniform (corresponding to a lineage with moderate-sized individuals) and one (G. micra sp. nov., lineage B + G. peninsularis sp. nov., lineage C) with significant structure (with mostly small body sizes), including a geographically restricted form from the Burrup Peninsula on the northern Pilbara coast (Figure 3).

Both the G. punctata and G. media species-groups, plus the G. variegata species-group (Hutchinson et al. 2014; Kealley et al. 2018) were sister to the nana clade, i.e. saxicoline species from the Australian monsoonal tropics (Moritz et al. 2018).

\section{MORPHOLOGICAL ANALYSES}

Examination of specimens assigned to the various groups based on the mtDNA data presented here, along with the unpublished allozyme and the recently published tree based on large numbers of nDNA exon captures (Ashman et al. 2018), resulted in the recognition of several morphological characters such as the configuration of scales on the underside of the chin and various pattern elements that could be used to diagnose taxa (Table 2 and species accounts in the Taxonomy section, below). As the two available names 


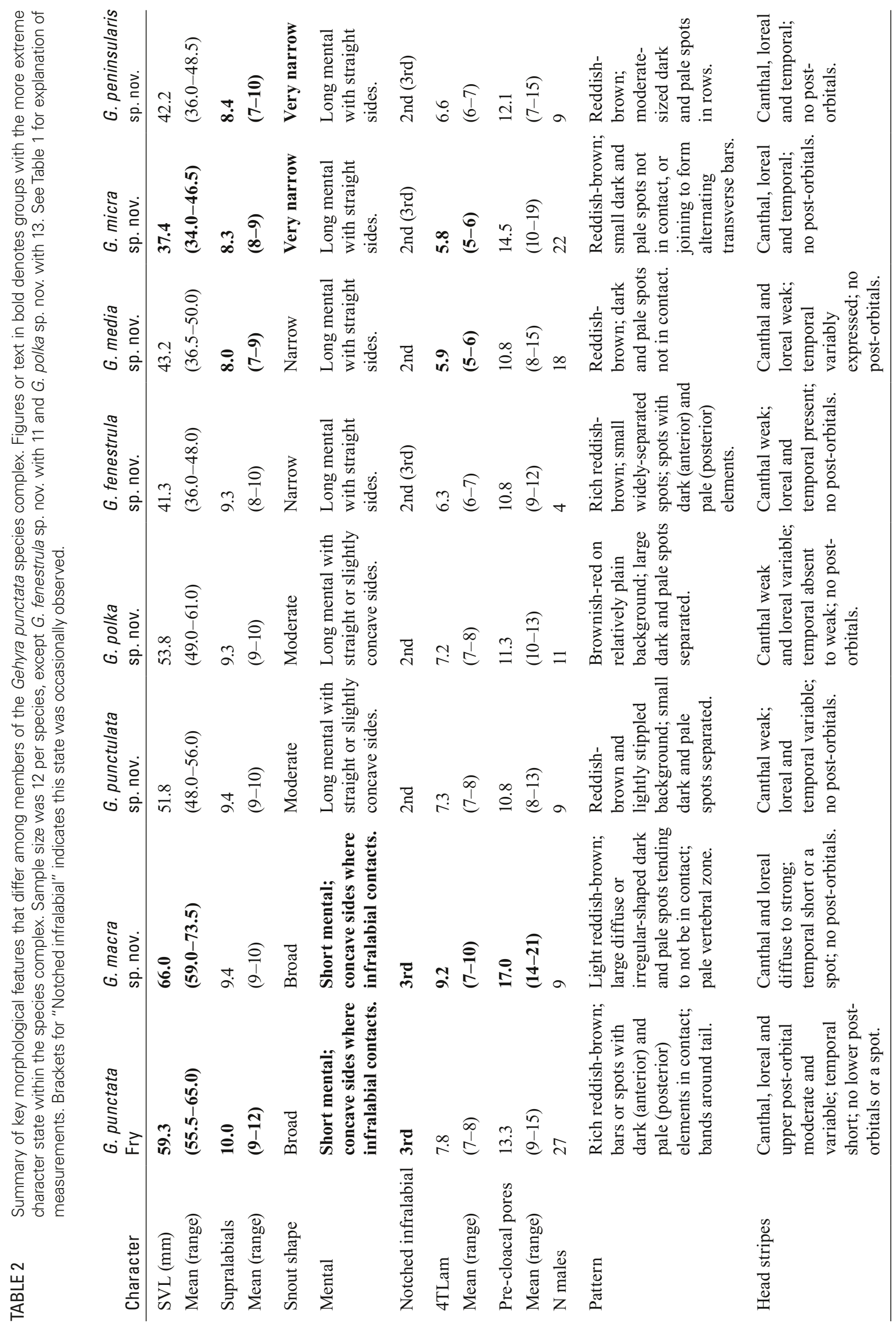




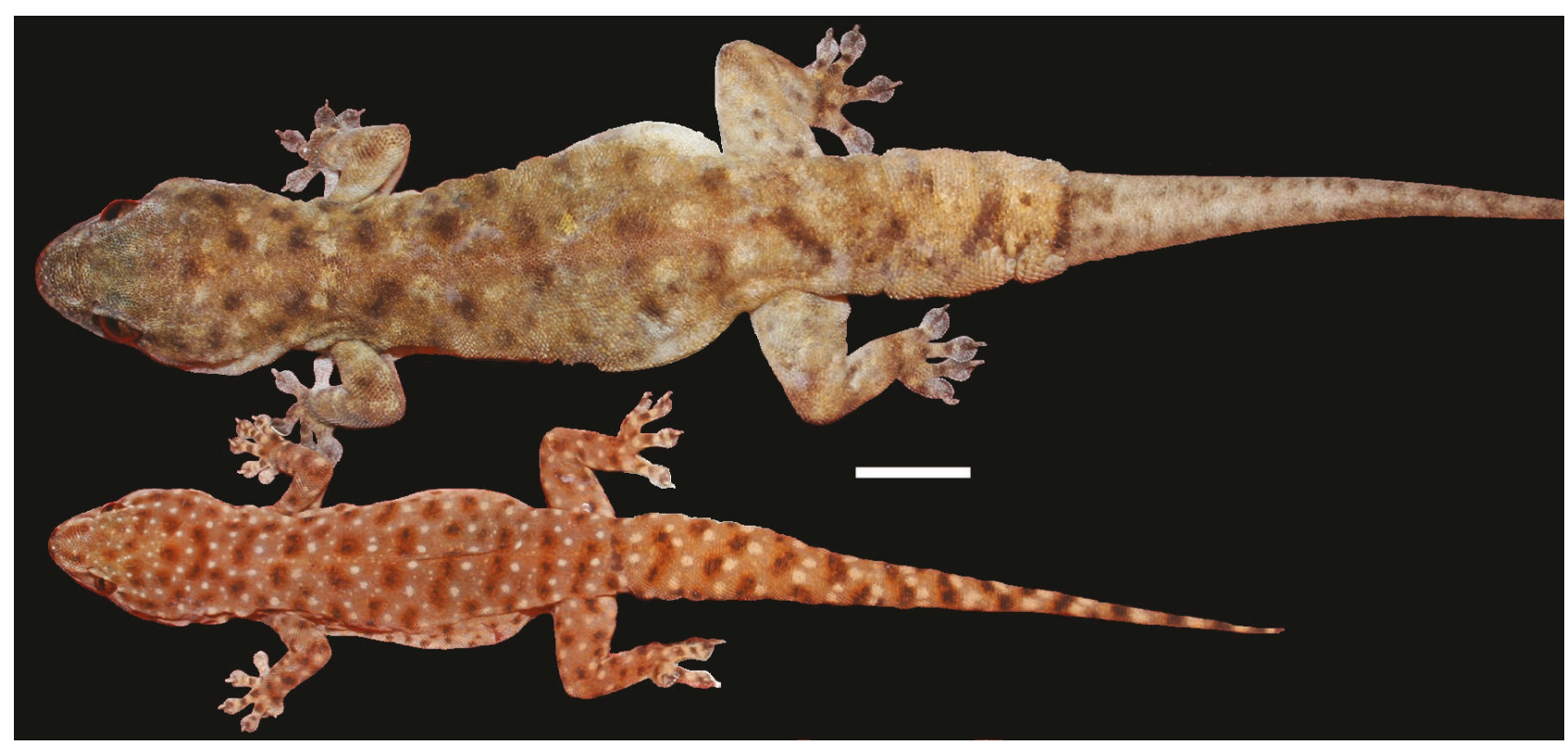

FIGURE 4 Image of Gehyra macra sp. nov. (WAM R162688) (upper) and G. media sp. nov. (holotype, WAM R162687) (lower), collected from the same outcrop in the northern Pilbara (Photo: P. Doughty).

(i.e. punctata and fenestra) refer to the same taxon, here we review the morphological characters that differ among G. punctata s.l. taxa described here.

Based on the rediscovery of Fry's syntype of Peropus variegatus punctatus and its resemblance to the largebodied common form in the Pilbara (see Ellis et al. 2018 for a detailed treatment), we interpret this name to apply to the widespread large-bodied form on the Pilbara craton, i.e. lineage I of Figure 2. Mitchell (1965) proposed the name G. fenestra for this species and provided a detailed diagnosis and description in his revision. This form is morphologically distinctive owing to its large body size, pattern elements made up of a solid dark bar or spot (anterior) joined to a solid or broken pale bar or spot (posterior) scattered on the dorsum and its crevice-dwelling habits, usually being found around boulders and on vertical rock faces.

Within the G. punctata species-group, there were four other lineages. The northern lineage (G. macra sp. nov., lineage $\mathrm{H}$ ) had very large body size (up to $73.5 \mathrm{~mm}$ SVL - the largest of any species within the arid clade of the $G$. variegata group) and more numerous subdigital lamellae (up to 10) than all other taxa. This lineage was confined to the northern Chichester subregion of the Pilbara and was parapatric with respect to G. punctata and syntopic with the smaller-sized species from the $G$. media species-group (Figures 2-3), even occurring on the same rock outcrops (Figure 4). Although evidence from mtDNA show this large-bodied form has only recently diverged from $G$. punctata, the differences in allozymes (unpublished data) and morphology, coupled with the observations of parapatry or sympatry, indicate it is an independently evolving lineage. The study of Ashman et al. (2018) also identified this lineage as a distinct species.
The two southern lineages of the G. punctata speciesgroup were similar to $G$. punctata but differed in their dorsal patterns by having clearly separated dark and pale spots vs. a pattern with the dark (anterior) and pale (posterior) bars or spots in contact. The two southern species were further separable on the relative size of the spots, with the eastern inland lineage (lineage K) having large spots, whereas the lineage to the west and north (lineage J) had smaller spots. These two species tended to be smaller than G. punctata and possessed differences in scalation as well (Table 2, Appendix 2). We describe these forms as G. punctulata sp. nov. for the fine-spotted form and G. polka sp. nov. for the form with larger spots.

In the mtDNA phylogram of the G. punctata speciesgroup was a distinct basal lineage (lineage L) with small body size with most specimens from the Hamersley Range near the town of Newman in the southwest Pilbara (Figure 3). This form was morphologically similar to several other species in the G. punctata species complex but differed subtly in pattern and was clearly genetically distinctive based on the mtDNA presented here, the allozyme pilot study data (where it constituted a unique group) and the study of Ashman et al. (2018). We also describe this lineage as a new species, G. fenestrula sp. nov.

The mtDNA analyses also found two lineages of the $G$. media species-group that were more closely related to common and widely distributed members of the arid zone $G$. variegata group such as $G$. variegata, $G$. pilbara and G. montium, which also occur in the Pilbara. Similar to the $G$. punctata species-group, individuals of the two mtDNA lineages possessed a reddish-brown background colour overlain with dark and pale spots or bars but tended to have smaller body sizes and narrower snouts. In addition, these forms were usually collected 
among small rocks or scree and were rarely found on boulders or vertical rock faces, supporting Mitchell's (1965) observations of the small-bodied form (his $G$. punctata) on the ground among small rocks and the large-bodied form (his G. fenestra) preferring vertical crevices among boulders and outcrops.

Within the G. media species-group, the lineage (lineage A) with moderate body size was relatively uniform genetically in the mtDNA data (Figure 1) and had a dorsal pattern of discrete dark and pale spots that tended to not be in contact, and regularly spaced. We describe this form largely from the northern Pilbara as G. media sp. nov. The other group was even smaller in size with the background pattern featuring more bars in alternating rows and contact among dark and pale elements. There was considerable structure within this group in the mtDNA data and nDNA data of Ashman et al. (2018). One lineage (lineage C) within this clade was restricted to the Burrup Peninsula area near Karratha and possessed a more elongate body than other lineages. In addition, Ashman et al. (2018) recovered the Burrup Peninsula lineage as basal to all other G. media speciesgroup lineages, supporting its distinctiveness. Therefore, we describe this lineage as G. peninsularis sp. nov., with the remaining lineages described as G. micra sp. nov. (lineage B).

\section{TAXONOMY}

\section{Genus Gehyra Gray, 1834}

\section{TYPE SPECIES}

Gehyra pacifica Gray, 1834 (= Gehyra oceanicus [Lesson, 1830]), by monotypy.

\section{Gehyra punctata (Fry, 1914)}

\section{Spotted Pilbara Rock Gehyra}

Figures 5, 7

Peropus variegatus punctatus Fry, 1914: 178.

\section{MATERIAL EXAMINED}

\section{Lectotype}

Australia: Western Australia: WAM R176100 (formerly 9879; subadult female), 'Strelley River, Pilbara' WA $\left.20^{\circ} 33^{\prime} \mathrm{S}, 119^{\circ} 00^{\prime} \mathrm{E}\right]$, J.B. Cleland, collection date unknown, presumably 1907, here designated. As noted in the introduction of this paper and in Ellis et al. (2018), there has been confusion regarding the identity of Gehyra punctata virtually since its description. A century of subsequent research has led to the recognition that spotted Gehyra from the Pilbara and other rocky regions from the Australian arid zone represent many different species that share a superficially similar phenotype, especially with respect to colouration and the presence of dark and pale spots on the dorsum. This has been exacerbated by the inability of several recent workers to locate the Strelley River specimen cited by Fry (1914), and by oversight of the fact that a specimen illustrated in Lucas and Frost (1896, p. 124, pl. IX, figure 3) also constitutes part of the type series. The latter specimen, collected on the Horn Expedition, appears to represent the taxon presently recognised as G. moritzi Hutchinson, Sistrom, Donnellan and Hutchinson, 2014, and may correspond to NMV D268, although the illustration appears to be a somewhat idealised representation if it, is indeed based on this specimen (see Ellis et al. 2018). In order to stabilise the application of the name $G$. punctata and permit its comparison with the many other spotted congeners from the Pilbara, including many named as new in this paper, we hereby select WAM R176100 as the lectotype of G. punctata. This results in the application of the name to the specimen actually examined by Fry. Ellis et al. (2018) provide a detailed explanation of the history of the specimens that have been associated with this taxon, and include photographs of the lectotype, now in a poor state of preservation.

\section{Paralectotype}

Australia: Northern Territory: Specimen illustrated in figure 3 on pl. IX, p. 124, Lucas and Frost (1896); possibly corresponding to NMV D268 in the herpetological collection of Museum Victoria. Collected from the Central Ranges on the Horn Scientific Expedition. See explanation above for lectotype designation.

\section{Synonymy, Storr (1982):}

Gehyra fenestra Mitchell, 1965

\section{Holotype}

Australia: Western Australia: WAM R20199, 'adult male, rock crevice near summit of Mt. Herbert' (p. 307) (estimate: $\sim 21.33^{\circ} \mathrm{S}, 117.22^{\circ} \mathrm{E}$ ), by F.J. Mitchell and W.H. Butler on 25 July 1958.

\section{Paratypes}

Australia: Western Australia: WAM R20198, 'roof of cave near Tambrey Homestead'; WAM R20200, 'under rock, Big Hill Pool'; WAM R20201, 'rocks on table-land behind Tambrey Homestead'; WAM R20202, 'under rocks on the side of Mt. Herbert'; SAMA R496, 'under rocks on the side of Mt. Herbert'; SAMA R4597, R4601-2, '3 specimens from table-land behind Tambrey Homestead'; SAMA R4600, 'summit of Mt. Herbert'.

\section{DIAGNOSIS}

Differs from non-Australian Gehyra by lack of extensive webbing between toes III and IV, a cutaneous fold along the posterior margin of the hindlimb and the 

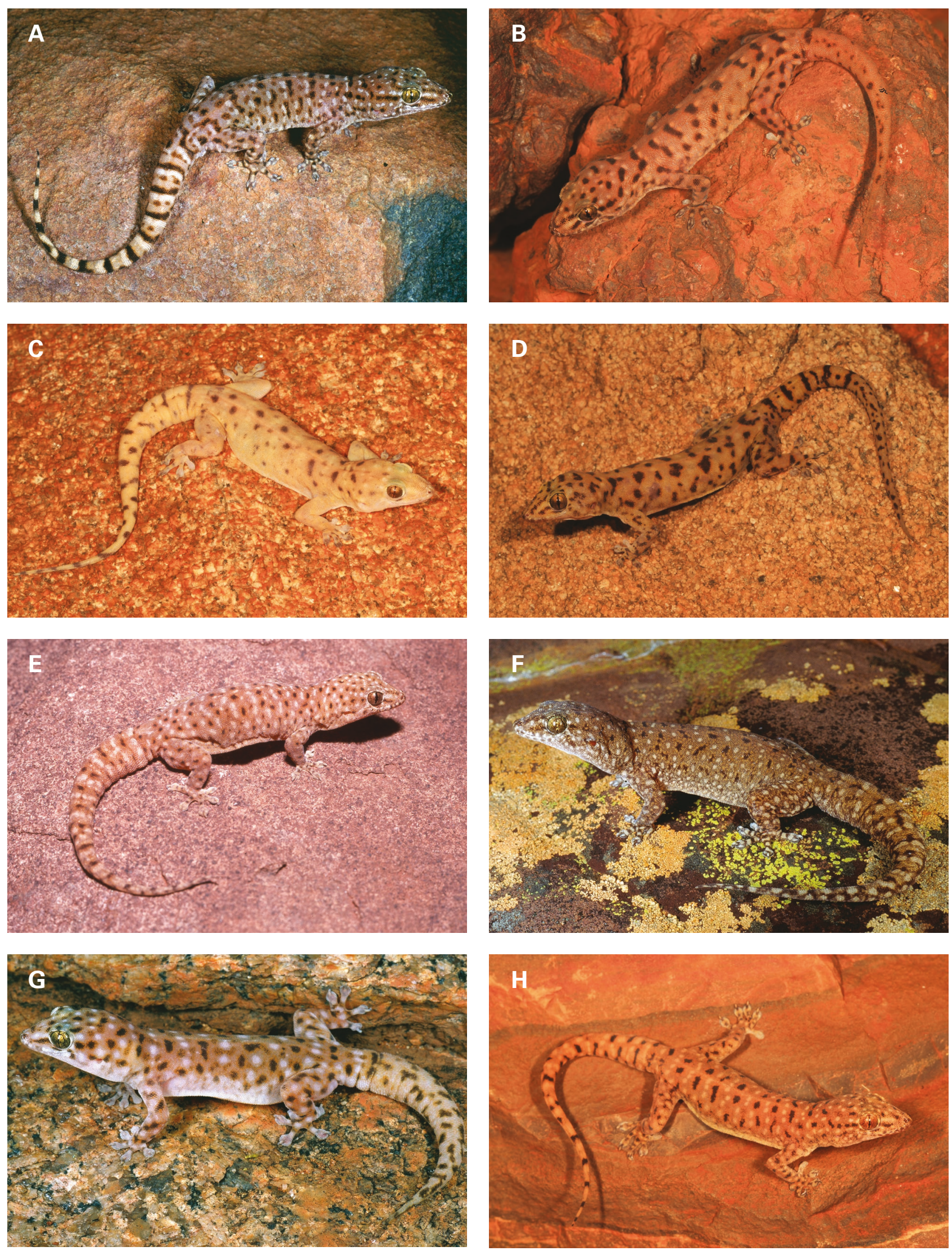

FIGURE 5 Images in life of the large-bodied members of the Gehyra punctata species-group: A) G. punctata - Burrup Peninsula, Western Australia (Photo: B. Maryan); B) G. punctata - Red Hill Station, Western Australia (Photo: R.J. Ellis); C-D) G. macra sp. nov. - Indee Station, Western Australia (Photo: R.J. Ellis); E) G. punctulata sp. nov. - Callytharra Springs, Western Australia (Photo: G.M Shea); F) G. punctulata sp. nov. - Butcher's Track, Muggon Station, Western Australia (Photo: B. Maryan); G) G. polka sp. nov. - Walga Rock, Western Australia (Photo: B. Maryan); H) G. polka sp. nov. - Mt Augustus, Western Australia (Photo: R.J. Ellis). 
presence of transversely widened subcaudal scales. Distinguished from other Australian Gehyra by possession of moderate body size (up to $65 \mathrm{~mm} \mathrm{SVL}$ ), gabled rostral, upper postnasal $1 / 3$ the size of lower, 9-12 supralabials, first supralabial narrower and taller than second, mental length short often with concave sides where in contact with first infralabial, two pairs of chin shields, inner chin shield in contact with second infralabial, first parinfralabial encroaching on posterior edge of third infralabial; subdigital lamellae on fourth toe 7-8, lamellae divided and without basal wedge of granules; background colour reddish-brown with markings consisting of dark (anterior) and pale (posterior) bars or spots usually in contact (or narrowly separated), occasionally forming transverse bars; canthal, loreal, temporal and upper post-orbital stripes usually present, post-orbital stripe variably expressed, often reduced to a spot, pale patch between canthal and loreal stripes near eye; original tails ringed by dark (anterior) and pale (posterior) bands; typically 11-15 pre-cloacal pores in males.

Further distinguished from other reddish-brown Gehyra from the region as follows. From G. fenestrula sp. nov., G. media sp. nov., G. micra sp. nov. and $G$. peninsularis sp. nov. by larger body size, broader snout, more pronounced jaw adductor muscles and first parinfralabial in contact with third (not second) infralabial; from G. macra sp. nov. by smaller body size, fewer subdigital lamellae and pre-cloacal pores, more reddish dorsum, and clearly demarcated markings comprised of dark (anterior) and pale (posterior) elements; from G. punctulata sp. nov. and G. polka sp. nov. by larger body size, first parinfralabial usually encroaching on posterior edge of third (not second) infralabial, and pale and dark elements of markings on dorsum in contact; from G. pilbara by larger body size, longer and broader snout, and larger markings on dorsum; and from G. montium by larger body size, absence of reticulations on dorsum and larger, more pronounced dark and pale markings.

\section{DESCRIPTION}

From series of recently collected specimens listed in Appendix 1. Body size medium (mean $59.3 \mathrm{~mm}$ SVL), habitus slightly robust, depressed dorsally, flat ventrally with defined ventro-lateral fold. Head depressed $($ HeadD $=38 \%$ HeadL), in profile snout long and eye over half the length of the snout, snout (interorbital/frontal region) almost straight (a slight convexity), canthus rounded and slightly raised forming shallow concavity in between canthal ridges, nostril region swollen; jaw adductor musculature robust and protruding laterally; in dorsal view, head widest behind eyes narrowing anteriorly to triangular snout with rounded tip; neck constricted to approximately $4 / 5$ maximum head width. Scales on top and sides of snout $>3$ times larger than crown and rest of body; scales in contact with nostril - rostral, supranasal, 2 postnasals (upper one third the size of lower) and first supralabial; supralabials 9-12; infralabials 8-10; rostral strongly gabled dorsally, deeply furrowed medially, rostral crease $50-70 \%$ of height of rostral; internasals $0-1$; nostrils circular and directed dorsally and slightly posteriorly. Mental triangular, penetrating $1 / 3$ between inner chin shields, sides of mental in contact with first infralabial usually concave; inner chin shields in contact with second infralabial; outer chin shield $\sim 60 \%$ of height of inner chin shield with straight to rounded outer edge, in contact with second (occasionally third) infralabial, first parinfralabial and granules below parinfralabials; eye moderate, pupil oval with crenulated edges ( 3 scallops on each side); above and anterior to eye a projecting ridge and posterior-dorsal edge slightly covered by layer of skin; ear opening oval and oriented vertically.

Dorsal scales small and homogeneous, juxtaposed, moderately rounded with apex slightly posterior; ventral scales 2-3 times larger than dorsal scales, flat and slightly imbricate. In males, pre-cloacal pores usually $11-15$, arranged in a chevron with the apex pointing anteriorly; cloacal spurs 2-4 slightly enlarged, rounded and projecting scales on both sides of cloacal opening.

Limbs short, moderately developed; projecting narrow claws present on all digits except digit I, claw projects above and beyond expanded toe pads, dorsal edge of toe pad with elongate row of scales forming a fringe; below digit a single row of 6-8 enlarged round to oval tubercles increasing in size towards toe pads, distal 2-3 divided; no conspicuous webbing between digits; subdigital lamellae divided, no wedge of granules at base, number on fourth finger 6 or 7 , fourth toe 7 or 8 .

Tail long and thin, ovoid at body, tapering to a fine point; scales on dorsal surface of original tail $\sim 2 \mathrm{x}$ size of scales on body, flattened and arranged in regular rows; ventral scales of original tails enlarged and oriented transversely, scales on regenerated portion as for original but forming less regular rows on dorsal surface.

Colouration. In life, rich reddish-brown background colour on dorsum; approximately eight rows of markings (from neck to hindlimbs), markings consisting of a dark (anterior) spot or short bar in contact with a pale spot or bar, occasionally markings connect forming transverse rows (Figure 7). Head as for body but dark spots smaller, canthal, loreal and temporal stripes moderately marked but variable in expression, usually a dark upper post-orbital stripe but lower absent or reduced to a spot; labials, rostral and lower sides of snout dark brown, hiatus of pigment on labial sutures; dorsal surface of limbs with smaller or more diffuse markings; tail ringed by dark (anterior) 

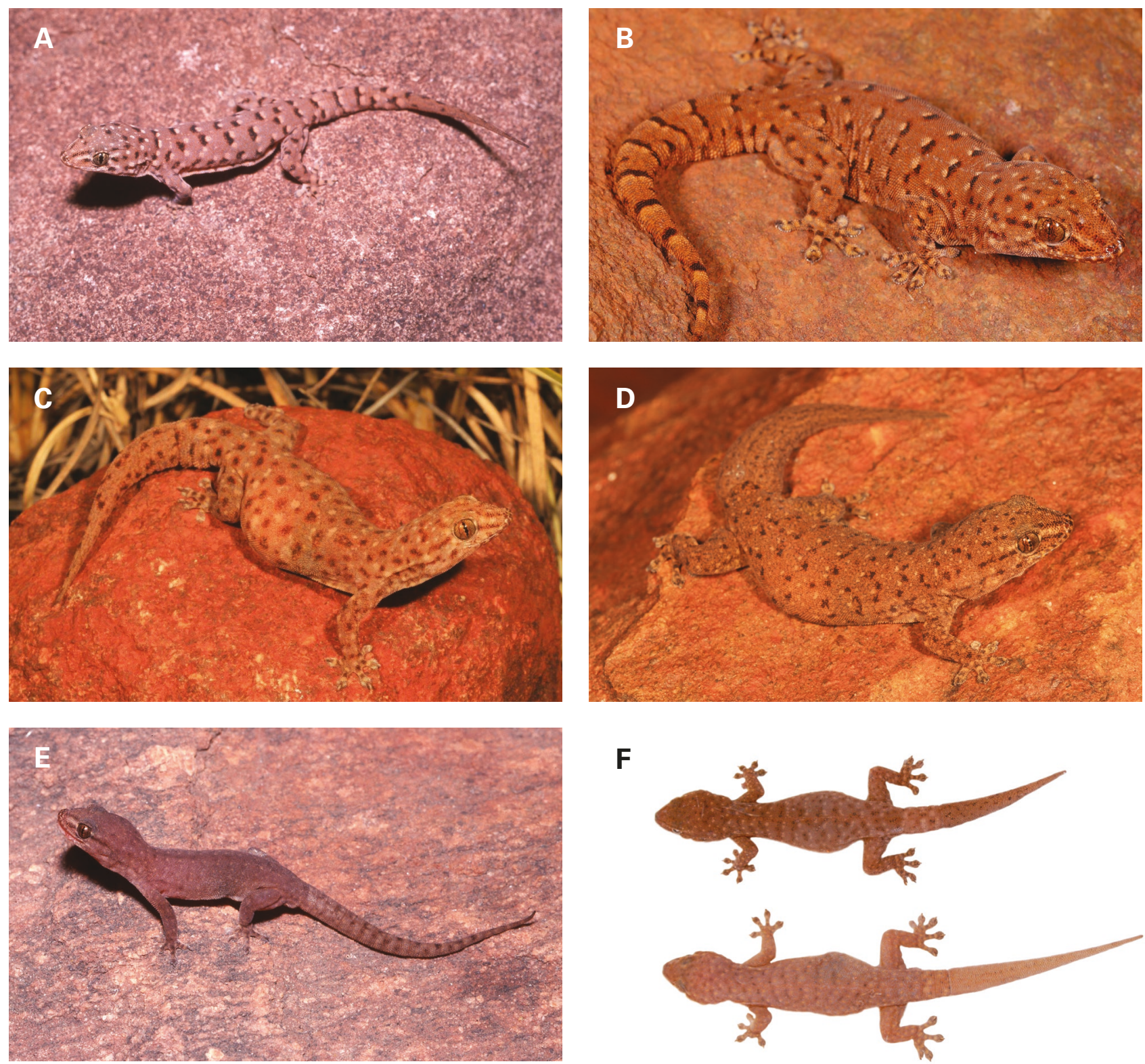

$\mathbf{F}$
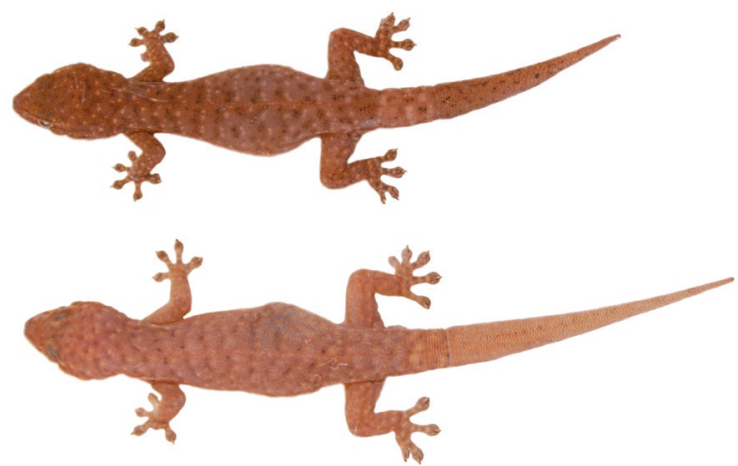

G
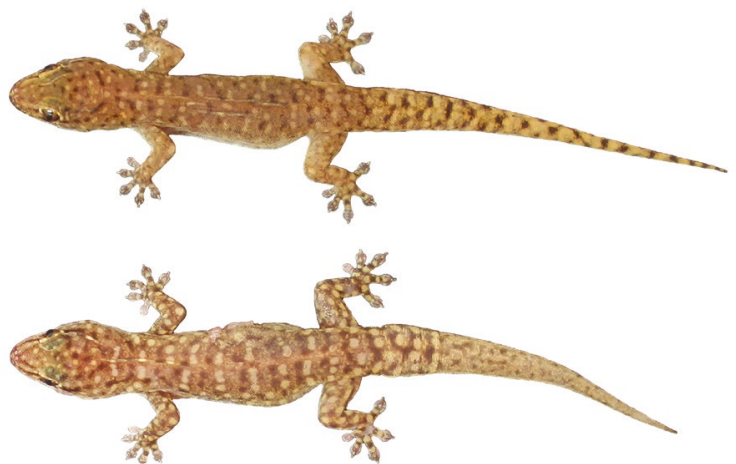

FIGURE $6 \quad$ Images in life of small-bodied species of the Gehyra punctata species complex-G. fenestrula sp. nov. from the G. punctata species-group, and the three members of the G. media species-group: A) G. fenestrula sp. nov. - 31.3 km east of Prarie Downs, Western Australia (Photo: G.M. Shea); B) G. fenestrula sp. nov. - 28 km east of Newman, Western Australia (Photo: B. Maryan); C) G. media sp. nov. - 67 km south of Port Hedland, Western Australia (Photo: R.J. Ellis); D) G. media sp. nov. - Nanutarra Roadhouse, Western Australia (Photo: R.J. Ellis); E) G. micra sp. nov. - Ashburton Downs, Western Australia (Photo: G.M. Shea); F) G. micra sp. nov. - Wheelarra Hill, Western Australia (top - WAM R111845, bottom - WAM R11846) (Photos: P. Doughty); G) G. peninsularis sp. nov. - Burrup Peninsula, Western Australia (top - WAM R165748, bottom - WAM R165749) (Photos: P. Doughty). 
and pale (posterior) bands; venter pale with diffuse pigmentation; infralabials, palmar and plantar surfaces and ventral surface of tail slightly darker; eye orange with dark pupil. In preservative, the reddish hues tend to be lost, and the markings less distinct.

\section{VARIATION}

Table 2 and Appendix 2 present variation in size and meristic characters, and Figure 7 shows a range of variation in dorsal patterns. The smallest male with fully expressed pre-cloacal pores was $52.0 \mathrm{~mm} \mathrm{SVL}$ with 11 pores, with a likely subadult at $47.0 \mathrm{~mm}$ SVL with only 7 pores. Of 27 males, the lowest count was one individual with 9, otherwise the lowest was 11 (several males). Females with conspicuous eggs or enlarged follicles ranged from $48.0 \mathrm{~mm}$ to $58.5 \mathrm{~mm} \mathrm{SVL}$. Females lack pre-cloacal pores and enlarged cloacal spurs, but otherwise resemble males.

Colouration varied from a rich reddish-brown to a more subdued brown, the spots on the dorsum occasionally connected to form transverse bars, and the dark and pale elements were sometimes not in contact - usually narrow but occasionally evenly spaced. Juveniles and subadults possessed darker and more contrasting markings to background colour. Coastal Pilbara and Barrow Island individuals had prominent bars as well as small spots. Canthal, loreal and temporal head stripes were somewhat variably expressed, with wider and darker parts and thinner and lighter parts within the same stripe. Postorbital stripes were more variable: the lower post-orbital stripe was occasionally present, and connected to ear opening in some specimens; upper post-orbital stripe was occasionally absent, although spots sometimes joined above eye to form an irregular stripe.

\section{HABITAT AND ECOLOGY}

Gehyra punctata is commonly encountered on the vertical faces of large boulders on rocky outcrops in the Pilbara region. Figure 8 shows a typical rock face on which $G$. punctata commonly occurs. Collectors' notes on the WAM database mention vertical rock faces, rock platforms, ironstone and granite outcrops, gorges, scree slopes, crevices and 'under rock on rock'. Occasional entries mention creek banks and rarely on trees or shrubs. PBS site descriptions mention the following attributes: boulder slope to range, massive outcrop, scree slope under scarp, stone valley floor and skeletal clay and stones over massive duricrust on top of mesa.

In the PBS, a large number of pitfall traps were deployed across the region to capture terrestrial vertebrates (McKenzie et al. 2009), and opportunistic searching at night for herpetofauna was also undertaken. It is interesting to note that very few $G$. punctata were captured in pitfall traps, whereas small-bodied members

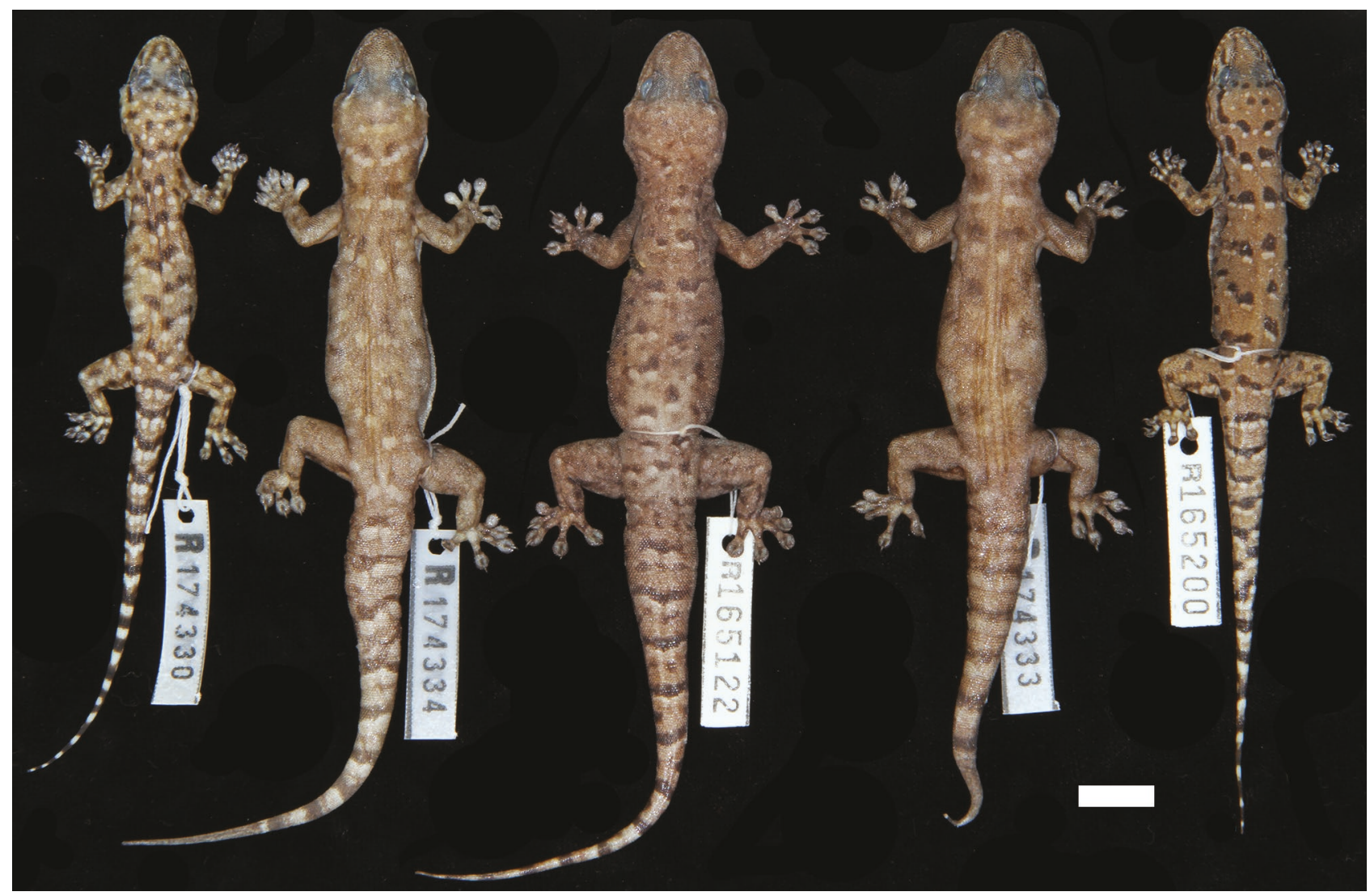




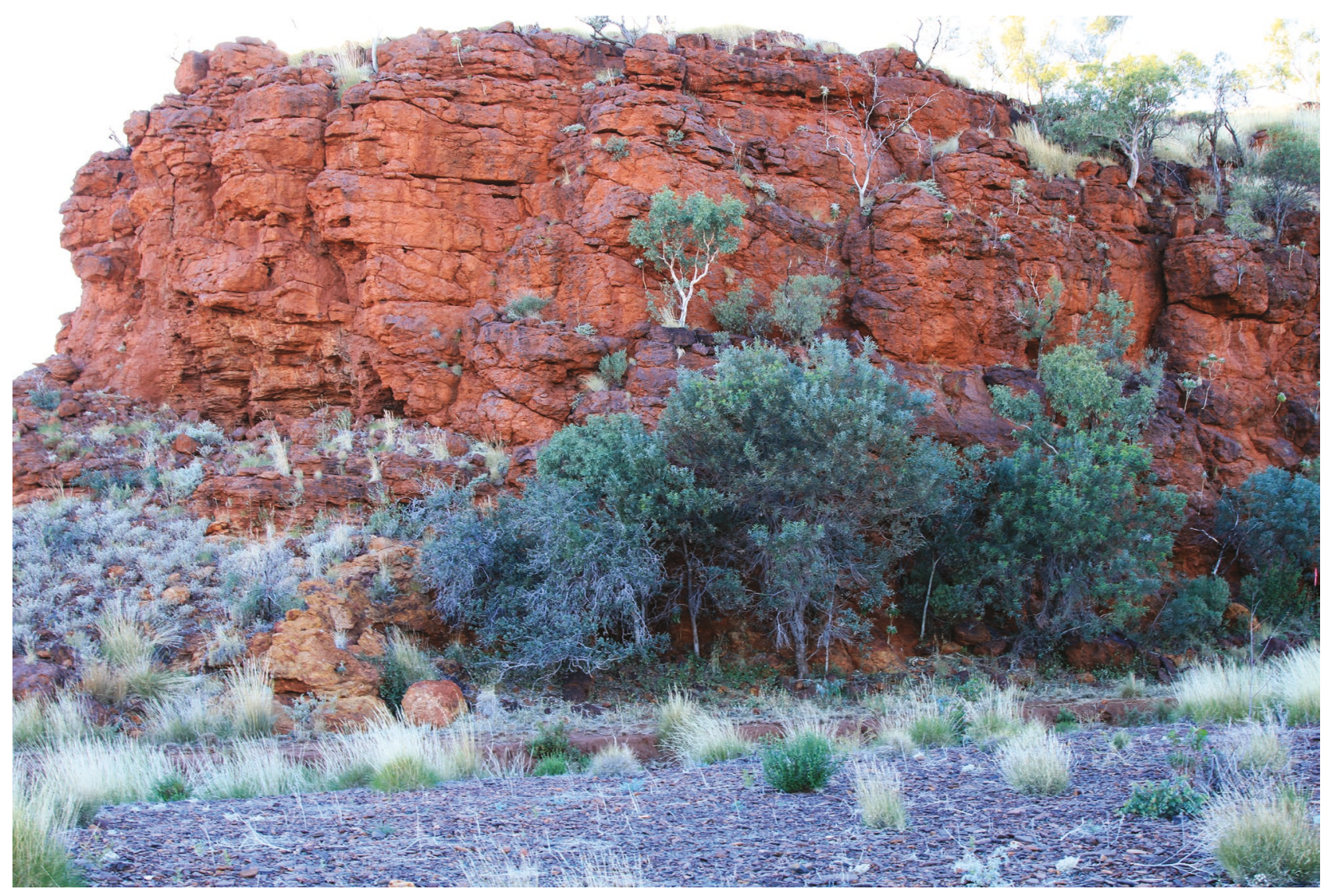

FIGURE 8

Typical habitat of G. punctata in the Pilbara: vertical rock face with deep crevices near Pannawonica (Photo: R.J. Ellis).

of the complex were trapped at much higher frequency in pitfall traps (Doughty et al. 2011). In contrast, searching for lizards with head torches at night on rocky ridges almost invariably resulted in large numbers of $G$. punctata seen and collected, with very few of the smallbodied G. punctata species complex members seen. This recent result mirrors the observations reported by Mitchell (1965) and reflect the preference of G. punctata to shelter in deep crevices on vertical rocks on cliff faces and boulder fields.

\section{DISTRIBUTION}

Generally confined to the Pilbara craton, except the northern portion of the Pilbara where it is replaced by $G$. macra sp. nov., with isolated populations in the western edge of the Little Sandy Desert. Also on Barrow Island (Figure 2).

\section{REMARKS}

In hindsight, Storr's decision to synonymise $G$. fenestra (Mitchell's large-bodied taxon) with $G$. punctata (believed by Mitchell to be the small-bodied form described by Fry) seems to be a case where wide variation in morphology resulted in a conservative application of a single name. However, previous workers could not have suspected the high numbers of Gehyra that occur in the Pilbara region at the time. Indeed, at the initiation of this project, we did not envisage so many species present in such a relatively small area, including the occurrence of G. montium as well as the species resembling $G$. vareigata described in Kealley et al. (2018). A problem in recognising the great diversity is the similar appearance of many of the species to each other, relative to G. variegata-like species - that is, reddish, spotted Gehyra associated with rocks. Gehyra can also be very variable in appearance within species (e.g. Sistrom et al. 2012; Hutchinson et al. 2014; Doughty et al. 2018). The presence of so many similar-looking species in one area resulted in Storr taking a conservative stance, viewing $G$. 'punctata' as a variable species, ultimately deciding to collapse them in to a single taxon. In addition, further collections from the Pilbara have uncovered more specimens of the newer species, although almost all were represented in collections that Storr examined.

As G. punctata is widespread throughout the Pilbara craton, including several national parks and nature reserves, and is abundant where it occurs, we regard it as being of least conservation concern.

\section{ETYMOLOGY}

Punctata means 'small spots'. Fry would have been using this name in reference to the spotted pattern in $G$. punctata as opposed to the network of irregular lines in G. variegata and other arboreal species. 


\section{Gehyra macra sp. nov.}

\author{
Large Pilbara Rock Gehyra
}

Figures 4, 5, 9

urn:Isid:zoobank.org:act:01D323B0-89A4-4008-ACOF-
D4E702D3A6CA

\section{MATERIAL EXAMINED}

\section{Holotype}

Australia: Western Australia: WAM R162703, an adult male collected from Baldy Rock $\left(21.05^{\circ} \mathrm{S}\right.$, $118.80^{\circ}$ E), by P. Doughty, C.A. Stevenson, and P.G. Kendrick on 17 May 2006.

\section{Paratypes}

Australia: Western Australia: WAM R154517 (male), Yarrie Mining Camp $\left(20.533^{\circ} \mathrm{S}, 120.233^{\circ} \mathrm{E}\right)$; WAM R156587 (male), $\left(20.5488^{\circ} \mathrm{S}, 120.1681^{\circ} \mathrm{E}\right) ; \mathrm{R} 160096-7$ (males), WAM R160098 (female), $13 \mathrm{~km}$ southeast of Braeside $\left(21.280^{\circ} \mathrm{S} ; 121.096^{\circ} \mathrm{E}\right)$; WAM R162688 (female), WARM R162701 (female), WAM R162702 (male), as for holotype; WAM R173363 (males), Roy Hill Rail chainage 76, $65 \mathrm{~km}$ south of Port Hedland $\left(20.9658^{\circ} \mathrm{S}, 118.6844^{\circ} \mathrm{E}\right)$; WAM R173364 (female) and WAM R173366 (male), Roy Hill Rail chainage 75, 67 km south of Port Hedland $\left(20.9618^{\circ} \mathrm{S}, 118.6846^{\circ} \mathrm{E}\right)$.

\section{DIAGNOSIS}

Differs from non-Australian Gehyra by lack of extensive webbing between toes III and IV and a cutaneous fold along the posterior margin of the hindlimb, and the presence of transversely widened subcaudal scales. Distinguished from Australian $G$. variegata group members by very large body size (to $73.5 \mathrm{~mm}$ SVL), depressed body and head, relatively slender tail, moderately long and broad snout with swollen nostril region, robust jaw adductor musculature, strongly gabled rostral, upper postnasal half the size of lower, 0-1 internasals, first supralabial slightly taller and narrower than second, 9-10 supralabials, inner chin shields in contact with second infralabial, first parinfralabial encroaching on third infralabial, fourth finger lamellae 8-9, fourth toe lamellae 8-10, lamellae divided and lacking wedge of granules at base of toe, pre-cloacal pores in adult males 14-21; reddish to greyish-brown background colour, dorsal pattern variable, with scattered pale and dark spots, short transverse bars or blotches usually not in contact, slightly paler vertebral zone, canthal and loreal head stripes present but variable expressed, temporal head stripe short or reduced to a spot, post-orbital stripes absent.

\section{DESCRIPTION OF HOLOTYPE}

Body size moderately large $(69.0 \mathrm{~mm}$ SVL) with robust habitus, depressed dorsally, flat ventrally with defined ventro-lateral fold. Head depressed (HeadD
$=35 \%$ HeadL), in profile snout moderately long and almost half as long as eye, snout (interorbital/frontal region) straight, canthus broadly rounded and slightly raised forming shallow depression in between canthal ridges, nostril region swollen; in dorsal view, head widest behind eyes narrowing anteriorly to broadly rounded snout; robust laterally protruding jaw adductor musculature, neck only slightly constricted. Scales on top and sides of snout $>3$ times larger than crown and rest of body; scales in contact with nostril - rostral, supranasal, 2 postnasals (upper half the size of lower) and first supralabial; first supralabial slightly taller and narrower than second; supralabials 10, infralabials 8; rostral height $1.9 \mathrm{~mm}$, width $2.7 \mathrm{~mm}$, strongly gabled dorsally, deeply furrowed medially, rostral crease $\sim 45 \%$ of height of rostral; internasal 1; nostrils circular and directed dorsolaterally. Mental length $2.9 \mathrm{~mm}$, width $2.8 \mathrm{~mm}$, triangular with straight sides except concave where in contact with first infralabial, penetrating $1 / 3$ in to inner chin shields; inner chin shields in short contact with second infralabial; chin shields $\sim 60 \%$ of height of inner chin shield with rounded outer edge in contact with granules, first parinfralabial encroaching on posterior edge of third infralabial, an elongate granule between chin shield and third infralabial and in contact with posterior edge of second infralabial; eye relatively small, pupil oval with crenelated edges; above eye a projecting anterior ridge; ear opening moderately large, oval, and oriented at a $30^{\circ}$ angle (anterior edge lower).

Dorsal scales small and homogeneous, juxtaposed, moderately rounded with apex slightly posterior; ventral scales 2-3 times larger than dorsal scales, flat and slightly imbricate; scales on limbs as for body. Precloacal pores 17, arranged in a chevron with the apex pointing anteriorly; cloacal spurs 1 (right side) or 5 (left), slightly enlarged, rounded and projecting scales to either side of cloaca.

Limbs short, moderately developed; projecting narrow claws present on all digits except digit I, claw projects above and beyond expanded toe pads, dorsal edge of toe pad with elongate row of scales forming a fringe; below digit a row of 4-6 enlarged round to oval tubercles increasing in size towards toe pads, last 2-3 divided; no conspicuous webbing between digits; subdigital lamellae divided, number on fourth finger 9, fourth toe 10 .

Tail ovoid at body, original portion swollen, regenerated portion gradually narrowing to a fine point; proximal original tail $25 \mathrm{~mm}$ from cloaca, distal regenerated portion $58 \mathrm{~mm}$; scales on dorsal surface of original tail $\sim 2 \times$ size of scales on body, slightly imbricate and rounded with posterior apex, arranged in regular rows; ventral scales of original tails enlarged (3.9 x $1.6 \mathrm{~mm}$ at base) and oriented transversely, scales on regenerated portion as for original but forming less ordered rows.

Colouration (in preservative). Light brown pinkishgrey background colour on dorsum; scattered small to large dark brown and pale spots not in contact; head as for body but snout dark brown, canthal, loreal, temporal 


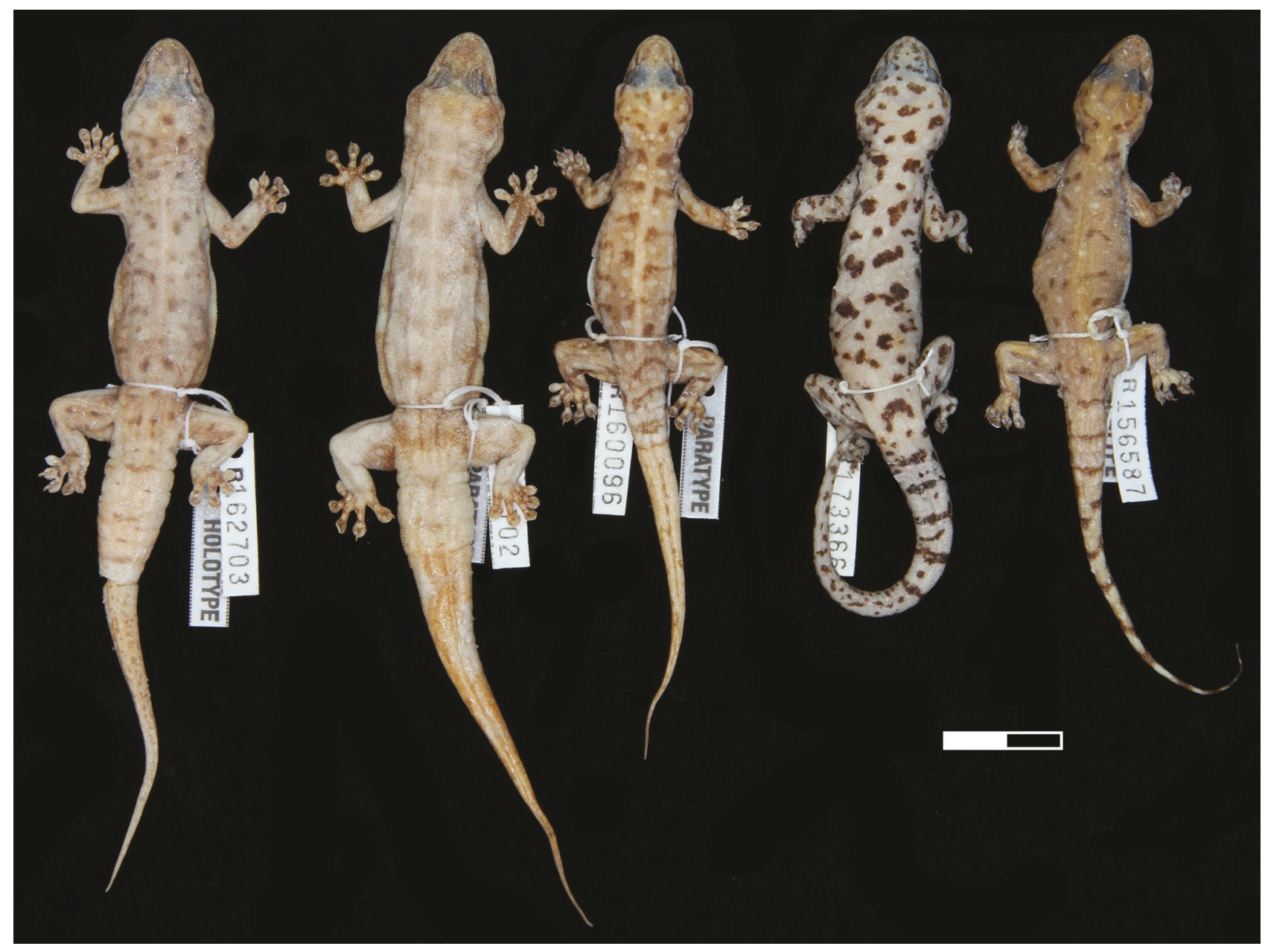

FIGURE 9 Variation among Gehyra macra sp. nov. specimens. Holotype specimen is on the left. Scale bar $=20 \mathrm{~mm}$ (white and dark both $10 \mathrm{~mm}$ each).

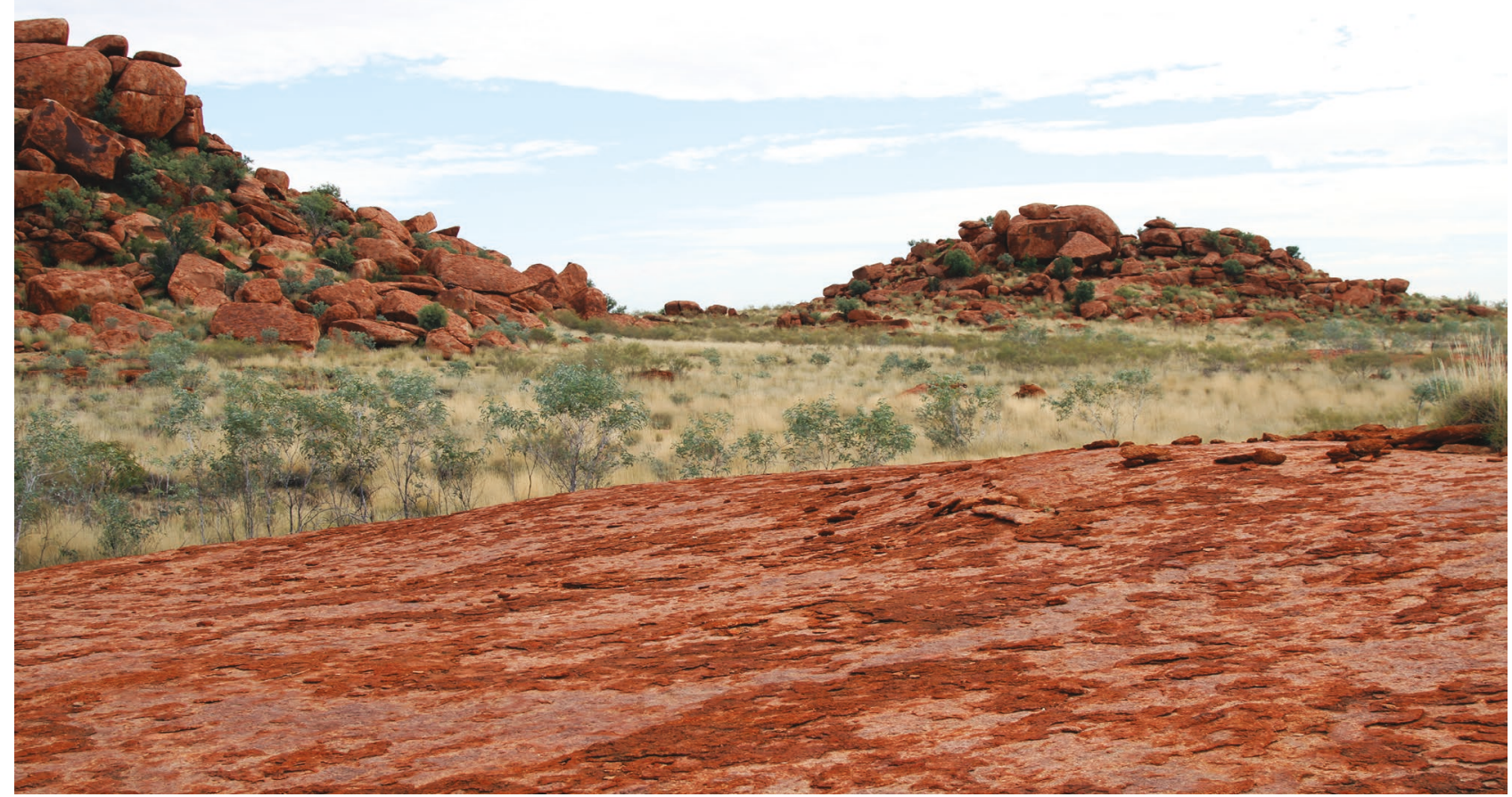

FIGURE 10 Habitat of G. macra sp. nov. and G. media sp. nov. in the northern Pilbara (Indee Station): granitic outcrops with domes and boulder piles (Photo: R.J. Ellis). 
stripes present, a poorly-defined upper post-orbital stripe, no lower post-orbital stripe; vertebral zone noticeably lighter in shade compared to surrounding areas on dorsum; dorsal surface of limbs with diffuse markings; venter pale with diffuse pigmentation (especially near ventrolateral edge), infralabials, and ventral surface of tail darker near edges, digits, palmar and plantar surfaces dark grey.

\section{VARIATION}

Table 2 and Appendix 2 show variation in meristic characters. Females lacked pores and the enlarged cloacal spurs of males. Pre-cloacal pores of males varied from 14-21, and there was no association with body size and number of pores (the largest male had the fewest pores).

Colouration varied from a light greyish-brown background to a dark reddish-brown. Dark and pale spots were scattered and usually not in contact. One specimen (WAM R160096, Figure 10) had dark bars with longitudinal extensions towards the midline, whereas another specimen (WAM R173366, Figures 5 and 9) had highly irregular-shaped dark blotches. A juvenile (WAM R132679) also showed a similar pattern, and the markings are more vibrant than in larger individuals. Figure 9 shows variation across several specimens.

\section{HABITAT AND ECOLOGY}

From collector's notes and personal observations, individuals have been collected from beneath exfoliating rocks on granite rock outcrops (Figure 10), with observations of individuals running across the tops of domes towards shelter (P. Doughty, M. Pepper, R.J. Ellis, pers. obs.).

\section{DISTRIBUTION}

Confined to the northern edge of the Pilbara, including south and east of Port Hedland, Shay Gap, Cundaline Gap and near Braeside on the eastern edge of the Pilbara (Figure 2).

\section{REMARKS}

Although only weakly divergent from G. punctata in the mtDNA phylogram shown in Figure 1, G. macra sp. nov. differed in the nDNA data set of Ashman et al. (2018) and differed strikingly in morphology across several characters as well. The more subdued greyishbrown colouration with more poorly-defined spots compared to $G$. punctata may be an adaptation to the relatively low and browner granite outcrops of the northern Pilbara where this species occurs (Pepper et al. 2013).

In addition to the large body size, this species is extremely robust, with a large deep head and welldeveloped jaw adductor musculature. This is the largest species of the entire arid zone radiation of the $G$. variegata group, and with only $G$. occidentalis from the northern Kimberley in the $G$. nana clade reaching similar sizes ( $75 \mathrm{~mm}$ maximum SVL).

Owing to its remote location, relatively large distribution and occurrence on less lucrative granitic geology (vs ironstones to the south), we regard this species as of least conservation concern. However, more information on its ecology and habitat preferences are warranted, including the extent of its true distribution in the Pilbara.

\section{ETYMOLOGY}

Macra is derived from the Greek makros meaning large or long. It is used as an adjective here.

\section{Gehyra punctulata sp. nov.}

Small-spotted Mid-west Rock Gehyra

Figures 5, 11

urn:Isid:zoobank.org:act:9D5BF909-B245-4235-96804F7828D3DED2

\section{MATERIAL EXAMINED}

\section{Holotype}

Australia: Western Australia: WAM R139194, an adult male collected at Mount Minnie $\left(22.2650^{\circ} \mathrm{S}\right.$, $115.4072^{\circ}$ E) by P.G. Kendrick on 26 June 2000.

\section{Paratypes}

Australia: Western Australia: WAM R113599 and WAM R113633 (males), $30 \mathrm{~km}$ east-north-east of Nanutarra $\left(22.4166^{\circ} \mathrm{S}, 115.6167^{\circ} \mathrm{E}\right)$; WAM R117038 (female) and WAM R117040 (male), $18 \mathrm{~km}$ west of Mt Stuart Homestead $\left(22.4333^{\circ} \mathrm{S}, 115.8833^{\circ} \mathrm{E}\right)$; WAM R131769 (female), Muggon Station $\left(26.6166^{\circ} \mathrm{S}\right.$, $115.5333^{\circ} \mathrm{E}$ ); WAM R163106 (female), $19.5 \mathrm{~km}$ southsouth-west of Mt Amy $\left(22.4193^{\circ} \mathrm{S}, 115.8380^{\circ} \mathrm{E}\right)$.

\section{DIAGNOSIS}

Differs from non-Australian Gehyra by lack of extensive webbing between toes III and IV and a cutaneous fold along the posterior margin of the hindlimb and transversely widened subcaudal scales. Distinguished from other Australian Gehyra by possession of moderate body size (up to $56 \mathrm{~mm} \mathrm{SVL}$ ) and broad snout, dorsal edge of rostral flat to gabled and moderately furrowed, upper postnasal $1 / 3$ the size of lower, 9-10 supralabials, first supralabial slightly taller and narrower than second, inner chin shields in contact with second infralabial, first parinfralabial in contact with posterior edge of second infralabial, mental scale penetrates along half the length of the inner chin shields with straight sides or slight concavity in contact with first infralabial, subdigital lamellae on fourth finger $6-7$, fourth toe $7-8$, lamellae divided and without basal wedge of granules; background colour light reddish to 
greyish-brown with small dark and pale spots not in contact and evenly spaced, canthal stripe weak, loreal and temporal stripe variable, post-orbital stripes absent, tail with alternating dark and pale rows of spots, dark spots forming bands distally.

Further distinguished from other reddish-brown Gehyra in the mid-west and Pilbara regions as follows. It resembles G. polka sp. nov. most closely but differs by possessing a darker and more stippled background with smaller spots. From G. media sp. nov., G. micra sp. nov. and $G$. peninsularis sp. nov. by larger body size, longer and more depressed snout and more numerous supralabials and subdigital lamellae; from G. punctata by slightly smaller body size, first parinfralabial encroaching on posterior edge of second (not third) infralabial and dark and pale spots on dorsum not in contact; from G. macra sp. nov. by smaller body size, fewer subdigital lamellae and pre-cloacal pores, more reddish dorsum, clearly demarcated spots and lack of a pale, narrow vertebral stripe; from $G$. pilbara and $G$. montium by larger body size, longer snout, and distinct markings on dorsum without background reticulations.

\section{DESCRIPTION OF HOLOTYPE}

Body size medium (54.0 $\mathrm{mm}$ SVL), depressed dorsally, flat ventrally with defined ventro-lateral fold (Figure 11). Head moderately depressed (HeadD $=38 \%$ HeadL), in profile snout moderately long and less than twice the length of the eye, snout (interorbital/frontal region) straight, canthus broadly rounded and slightly raised forming shallow depression in between canthal ridges, nostril region slightly swollen; moderately developed jaw adductor musculature protruding laterally posterior to mouth; in dorsal view head widest behind eyes narrowing anteriorly to triangular snout with rounded tip; neck constricted to approximately $4 / 5$ maximum head width. Scales on top and sides of snout $>3$ times larger than crown and rest of body; scales in contact with nostril - rostral, supranasal, 2 postnasals (upper $40 \%$ the size of lower) and first supralabial; supralabials 9, infralabials 9; rostral height $1.3 \mathrm{~mm}$, width $2.2 \mathrm{~mm}$, rostral flat dorsally, furrowed medially, rostral crease $40 \%$ of height of rostral, then angling to right for another $20 \%$ of rostral length; internasals 1; nostrils circular and directed dorsolaterally. Mental triangular, length $2.6 \mathrm{~mm}$, width $2.0 \mathrm{~mm}$, penetrating $55 \%$ in to inner chin shields, sides slightly concave where in contact with first infralabial; inner chin shields in broad contact with second infralabial; outer chin shield $2 / 3$ the height of inner chin shield with rounded outer edge in contact with second infralabial, first parinfralabial and enlarged granule below parinfralabial row; pupil oval with crenulated edges ( 3 scallops on each side); above and anterior to eye a projecting ridge and posterior-dorsal edge slightly covered by layer of skin; ear openings oval and oriented horizontally with anterior end more dorsal than posterior.
Dorsal scales small and homogeneous, juxtaposed, moderately rounded with apex slightly posterior; ventral scales $\sim 2$ times larger than dorsal scales, flat and slightly imbricate; scales on limbs as for body. Pre-cloacal pores 10 , arranged in a chevron with the apex pointing anteriorly; cloacal spurs in a single row with 3 (right) and 2 (left) enlarged and projecting scales on both sides of cloacal opening.

Limbs short and moderately developed; projecting narrow claws present on all digits except digit I, claw projects above and beyond expanded toe pads, dorsal edge of toe pad with elongate row of scales forming a fringe; below digit a single row of 6-8 enlarged round to oval tubercles increasing in size towards toe pads, distal tubercle divided; no conspicuous webbing between digits; subdigital lamellae divided, no wedge of granules at base, number on fourth finger 7 , fourth toe 8 .

Tail long and thin, somewhat depressed basally, becoming cylindrical distally, tapering to a fine point; original portion $6 \mathrm{~mm}$, regenerated portion $43 \mathrm{~mm}$ with irregular longitudinal folds along dorsal surface (an artefact of preservation) and irregular rows of scales dorsally and transversely elongated subcaudals.

Colouration. In preservative, light brown background colour on dorsum; small dark brown and pale spots from snout to end of original portion of tail; pale spots rounded with thin dark brown border, dark markings rounded with some more irregularly shaped; dark and pale markings not in contact and evenly spaced on dorsum. Head as for body but dark spots smaller; canthal and loreal stripes weak, weak temporal stripe posterior to eye on right side, pale patch between canthal and loreal stripes, left temporal and post-orbital stripes absent reduced to a spot; supralabials, rostral and lower sides of snout moderately stippled with dark brown; dorsal surface of limbs with diffuse alternating light and dark spots; venter pale yellowy-cream.

\section{VARIATION}

Table 2 and Appendix 2 presents variation in size and meristic characters, and Figure 11 illustrates the range of variation found in dorsal patterns. Females lack precloacal pores and cloacal spurs, but otherwise resemble males. A male with a SVL of $43 \mathrm{~mm}$ had 10 pores that were only weakly expressed, indicating an approximate size at maturity. There were no gravid females or any with noticeable follicular development in the sample.

On original tails scales on the dorsal surface were arranged in regular transverse rows, with transversely widened subcaudal scales, with the proximal 1-5 scales potentially divided.

Background colouration varies from a light reddishbrown to dark greyish-brown. The spots on the dorsum were usually small, with a few individuals having somewhat larger spots. Most spots circular, but some irregular and tending to elongate transversely. In the 


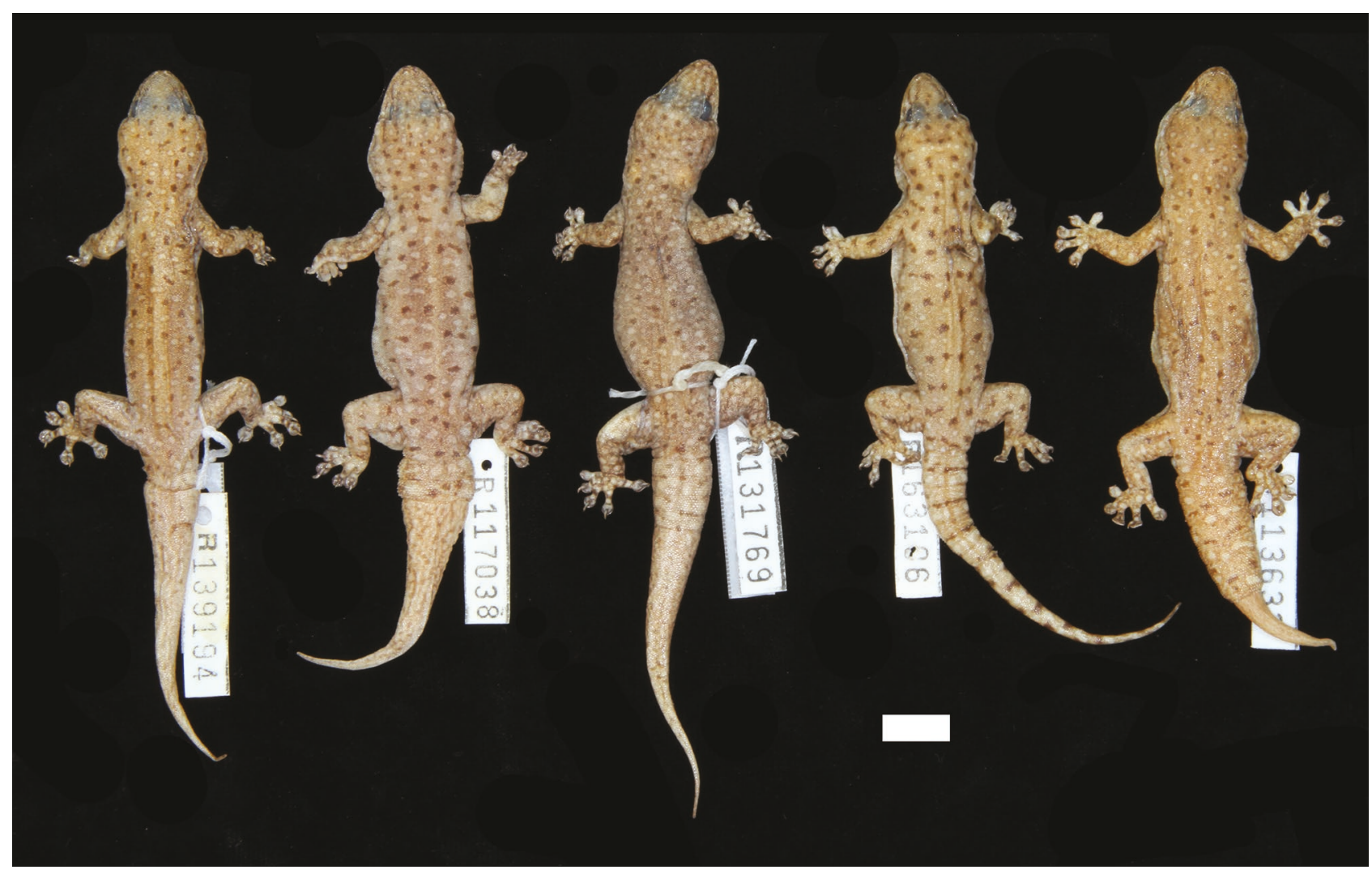

FIGURE 11 Variation among Gehyra punctulata sp. nov. specimens. Holotype specimen is on the left. Scale bar $=10 \mathrm{~mm}$. (Photo: R.J. Ellis).

majority of individuals spots were scattered evenly, with others having the spots form alternating rows of dark and pale spots. Original tails had alternating rows of dark and pale spots, with the dark spots tending to coalesce to form solid bands, especially distally.

\section{HABITAT AND ECOLOGY}

Very little is known of this species. Collector's notes mention granite outcrops and ridges, a dry stream bed and undulating stony ground. Specimens collected from rock crevices, under exfoliating granite slabs, rocks or under rubbish.

\section{DISTRIBUTION}

Occurs inland of the mid-west coast of Western Australia. In the south, from Toolonga Nature Reserve near Murchison, north to Callythara Springs, $40 \mathrm{~km}$ east of Gascoyne Junction. A separate population from genotyped individuals occurs in the western Pilbara area, from approximately $100 \mathrm{~km}$ south-east of Onslow in the Cane River area (Figure 2).

We include one subadult specimen with atypically large spots for this species (WAM R114320) from near Collier Range National Park based on an allozyme profile that placed it within G. punctulata sp. nov. This indicates that this species could also occur to the east in the Ashburton region south of the Pilbara and $G$. punctata and north of $G$. polka sp. nov.
Further collecting from this area could better resolve species boundaries and evaluate the possibility of introgression.

\section{REMARKS}

As for G. polka sp. nov., this species was recovered from the Ashman et al. (2018) exon capture analysis as an independent evolving lineage, and we also found support for its distinctiveness from the mtDNA data (Figure 1). Within this lineage, the two geographically separated populations of genotyped individuals are also distinct in the mtDNA phylogram. It is likely there are intervening populations in between these two known ones, and there were no obvious phenotypic differences between them. The elongate north-south distribution inland along the coast appears to follow granitic outcrops, with G. polka sp. nov. replacing this species to the east. Resolving where precisely the two species come together is an area for future research, as they are similar in body size and appearance. Owing to this species' broad distribution and abundance where it occurs, we regard it as being of least conservation concern.

\section{ETYMOLOGY}

Punctulata is the diminutive of punctata, referring to this species' smaller spots relative to those of $G$. punctata and G. polka sp. nov. 


\section{Gehyra polka sp. nov.}

Large-spotted Mid-west Rock Gehyra

Figures 5, 12

urn:Isid:zoobank.org:act:E74FB1B1-B463-4762-B5379DA0A79C7F4F

\section{HOLOTYPE}

Australia: Western Australia: WAM R132290, an adult male collected $6 \mathrm{~km}$ north-west of Noondie Outstation $\left(27.0744^{\circ} \mathrm{S}, 117.0789^{\circ} \mathrm{E}\right)$ by B. Maryan on 11 April 1998.

\section{PARATYPES}

Australia: Western Australia: WAM R119368-9 (males), $50 \mathrm{~km}$ south-west of Yalgoo $\left(28.65^{\circ} \mathrm{S}, 116.30^{\circ} \mathrm{E}\right)$; WAM R127414-5 (males), $10.3 \mathrm{~km}$ south of Yinnietharra Homestead $\left(24.7202^{\circ} \mathrm{S}, 116.1197^{\circ} \mathrm{E}\right)$; WAM R127543 (female), Barnong Homestead $\left(28.6333^{\circ} \mathrm{S}, 116.2833^{\circ} \mathrm{E}\right)$; WAM R132291 (male), as for holotype; WAM R132294 (male), Marlandy Hill (28.1216 $\left.{ }^{\circ} \mathrm{S}, 117.2331^{\circ} \mathrm{E}\right)$.

\section{DIAGNOSIS}

Differs from non-Australian Gehyra by lack of extensive webbing between toes III and IV and a cutaneous fold along the posterior margin of the hindlimb, and the presence of transversely widened subcaudal scales. Distinguished from other Australian Gehyra by possession of moderate body size (up to $61 \mathrm{~mm}$ SVL) and widened snout, well-developed jaw adductor musculature, moderately gabled rostral, upper postnasal 1/3 the size of lower, 9-10 supralabials, first supralabial slightly taller and narrower than second, inner chin shields in contact with second infralabial, first parinfralabial in contact with posterior edge of second infralabial, mental scale long, penetrating along half the length of the inner chin shields with straight sides or slight concavity when in contact with first infralabial, subdigital lamellae on fourth finger $6-7$, fourth toe 7-8, lamellae divided and without basal wedge of granules; background colour reddish-brown with large dark and pale spots not in contact, canthal stripe weak, loreal and temporal stripes variably expressed, no post-orbital stripes, tail with alternating dark and pale bands.

Further distinguished from other reddish-brown Gehyra in the mid-west and Pilbara regions as follows. It resembles G. punctulata sp. nov. most closely, but differs by possessing a more plain and reddish background with larger spots. From G. media sp. nov., G. micra sp. nov. and $G$. peninsularis sp. nov. by larger body size, longer and more depressed snout and more numerous supralabials and subdigital lamellae; from G. punctata by slightly smaller body size, first parinfralabial encroaching on posterior edge of second (vs third) infralabial and dark and pale spots on dorsum not in contact; from G. macra sp. nov. by smaller body size, fewer subdigital lamellae and pre-cloacal pores, more reddish dorsum, clearly demarcated spots and lack of a pale, narrow vertebral stripe; from $G$. pilbara and $G$. montium by larger body size, longer snout, and distinct markings on dorsum without background reticulations.

\section{DESCRIPTION OF HOLOTYPE}

Body size medium (56.0 mm SVL), depressed dorsally, flat ventrally with defined ventro-lateral fold (Figure 12). Head moderately depressed (HeadD = $40 \%$ HeadL), in profile snout moderately long and less than twice the length of the eye, snout (interorbital/ frontal region) straight, canthus broadly rounded and slightly raised forming shallow depression in between canthal ridges, nostril region swollen; in dorsal view snout moderately wide, jaw adductor musculature well-developed and laterally protruding behind jaw, head widest behind eyes narrowing anteriorly to triangular snout with rounded tip; neck constricted to approximately 3/4 maximum head width. Scales on top and sides of snout $>3$ times larger than crown and rest of body; scales in contact with nostril - rostral, supranasal, 2 postnasals (upper one third the size of lower), and first supralabial; supralabials 9, infralabials 7; rostral height $1.5 \mathrm{~mm}$, width $2.2 \mathrm{~mm}$, rostral gabled dorsally, deeply furrowed medially, rostral crease $40 \%$ of height of rostral; internasals 1; nostrils circular and directed dorsolaterally. Mental triangular, length $2.8 \mathrm{~mm}$, width $1.9 \mathrm{~mm}$, penetrating $2 / 3$ in to inner chin shields, sides slightly concave where in contact with first infralabial; inner chin shields in broad contact with second infralabial; outer chin shield half the height of inner chin shield with straight to rounded outer edge in contact with second infralabial, first parinfralabial, and granules below parinfralabials; pupil oval with crenulated edges (3 scallops on each side); above and anterior to eye a projecting ridge and posterior-dorsal edge slightly covered by layer of skin; ear opening round (right) or slightly oval and oriented horizontally (left).

Dorsal scales small and homogeneous, juxtaposed, moderately rounded with apex slightly posterior; scales on flanks slightly smaller and arranged more irregularly; ventral scales $\sim 2$ times larger than dorsal scales, flat and slightly imbricate; scales on limbs as for body. Pre-cloacal pores 12, arranged in a chevron with the apex pointing anteriorly; cloacal spurs 3 enlarged and projecting scales on both sides of cloacal opening.

Limbs short and moderately developed; projecting narrow claws present on all digits except digit I, claw projects above and beyond expanded toe pads, dorsal edge of toe pad with elongate row of scales forming a fringe; below digit a single row of 6-8 enlarged round to oval tubercles increasing in size towards toe pads, distal tubercle divided; no conspicuous webbing between digits; subdigital lamellae divided, no wedge of granules at base, number on fourth finger 6 , fourth toe 7 .

Tail original, long and thin, somewhat depressed basally, becoming cylindrical distally, tapering to a 
fine point; scales on dorsal surface of original tail $\sim 2 \mathrm{x}$ size of scales on body, flattened and arranged in regular rows; ventral scales of original tails enlarged ( $2.5 \times 1.4$ $\mathrm{mm}$ at base) and oriented transversely.

Colouration. In preservative, light brown background colour on dorsum; alternating rows of predominantly transversely-oriented dark brown and pale markings from snout to end of original portion of tail; whitish markings rounded to oval spots, dark markings more variable in shape, some asymmetrical and/or fused to form larger blotches; dark and pale markings not touching on dorsum. Head as for body but dark spots smaller; canthal stripes weak, loreal stripe present and continuing as weak temporal stripe posterior to eye, pale patch between canthal and loreal stripes, a short dark post-orbital stripe on right side, less distinct on left; supralabials, rostral and lower sides of snout lightly stippled with dark brown; inner chin shields pale white; dorsal surface of limbs with diffuse alternating light and dark markings; venter pale cream; ventral surface of tail slightly darker, with dorsal pattern extending onto lateral subcaudal surfaces.

\section{VARIATION}

Table 2 and Appendix 2 presents variation in size and meristic characters, and Figure 12 illustrates the range of variation found in dorsal patterns. Females lack precloacal pores and enlarged cloacal spurs, but otherwise resemble males. Background colouration varies from a rich to light reddish-brown. The spots on the dorsum exhibit a range of size variation from fine to quite large, with most pale white spots being large and circular but with some individuals having more irregular spots (Figure 12); dark spots tending to be more irregularly shaped. Rows of spots generally evenly spaced, with 6-9 rows of dark markings between nape and sacrum; pale spots often with diffuse edges, especially on flanks, and poorly defined anterior to orbits. Dark markings on tail sometimes forming complete narrow transverse bands proximally; dark and light markings may contact one another on tail. In life, anteriormost granular throat scales and medial portion of tail venter with an orangeybrown suffusion; dark dorsal and hindlimb markings surrounded by 2-3 rows of taupe to orange-tinged granules; iris coppery. As for the other species, juveniles tend to have darker and more contrasting markings.

\section{HABITAT AND ECOLOGY}

Rocky outcrops, including sandstone, granite and metamorphosed rocks. Notes from collectors indicate specimens were often encountered under slabs of rocks at the top of outcrops, and active individuals are seen on vertical rock faces as well as horizontal surfaces. Figure 13 shows a typical boulder pile where G. polka sp. nov. occur in the Weld Range.

\section{DISTRIBUTION}

Occurs in the mid-west of Western Australia, as far south and west approximately $150 \mathrm{~km}$ east of Geraldton near Yalgoo, then inland north through Mt Magnet, Meekatharra and Kumarina, and as far north and west as Mt Augustus (Figure 2). Outlying records were found near Karratha at Mardie Pool. This may have resulted from an error handling the tissue sample in the field or in the lab. Alternatively, this is a popular camping area for the Pilbara region (P. Kendrick, pers. comm.) and the specimens may have been inadvertently transported here.

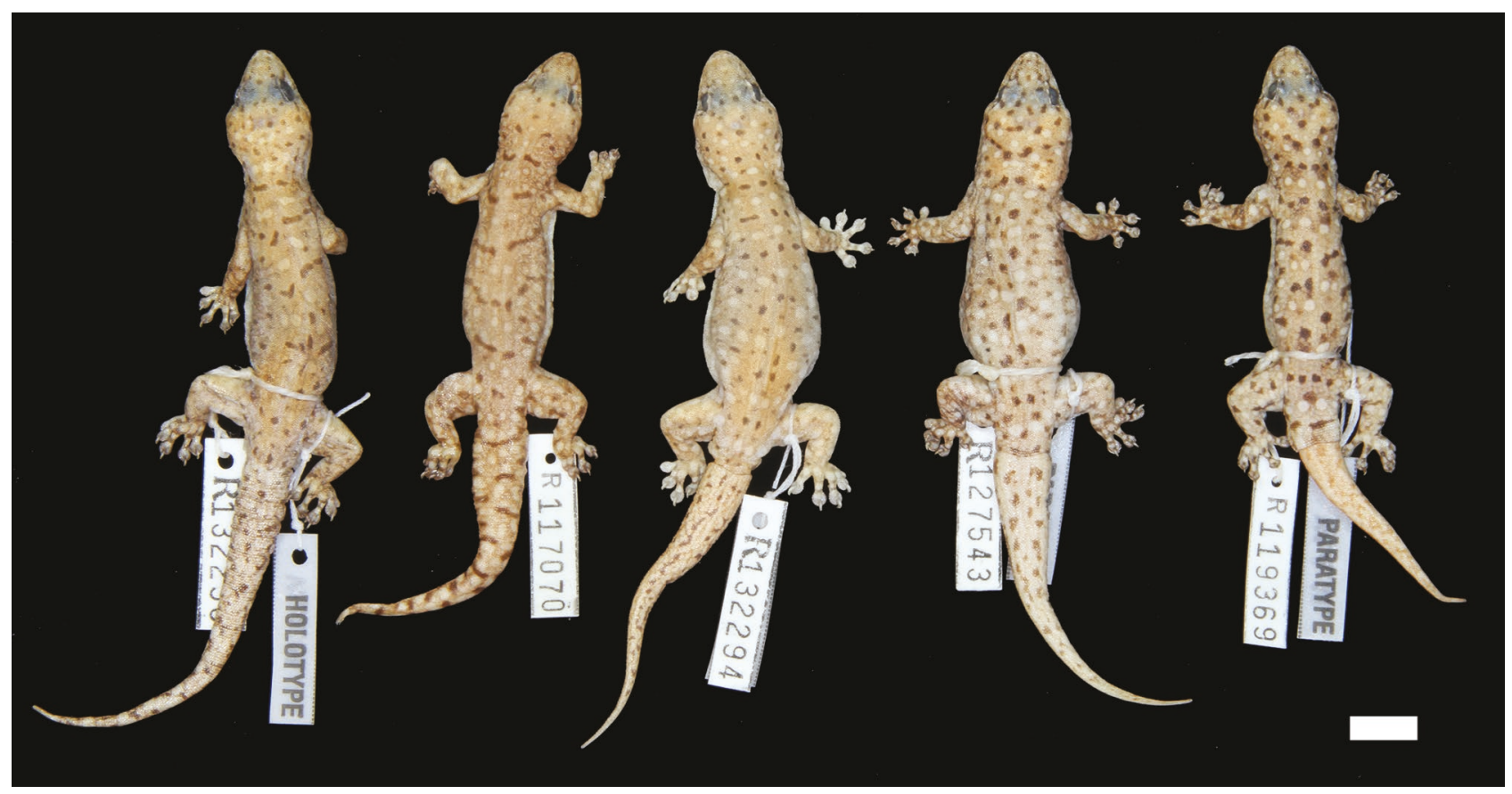

FIGURE 12 Variation among Gehyra polka sp. nov. specimens. Holotype specimen is on the left. Scale bar $=10 \mathrm{~mm}$. 


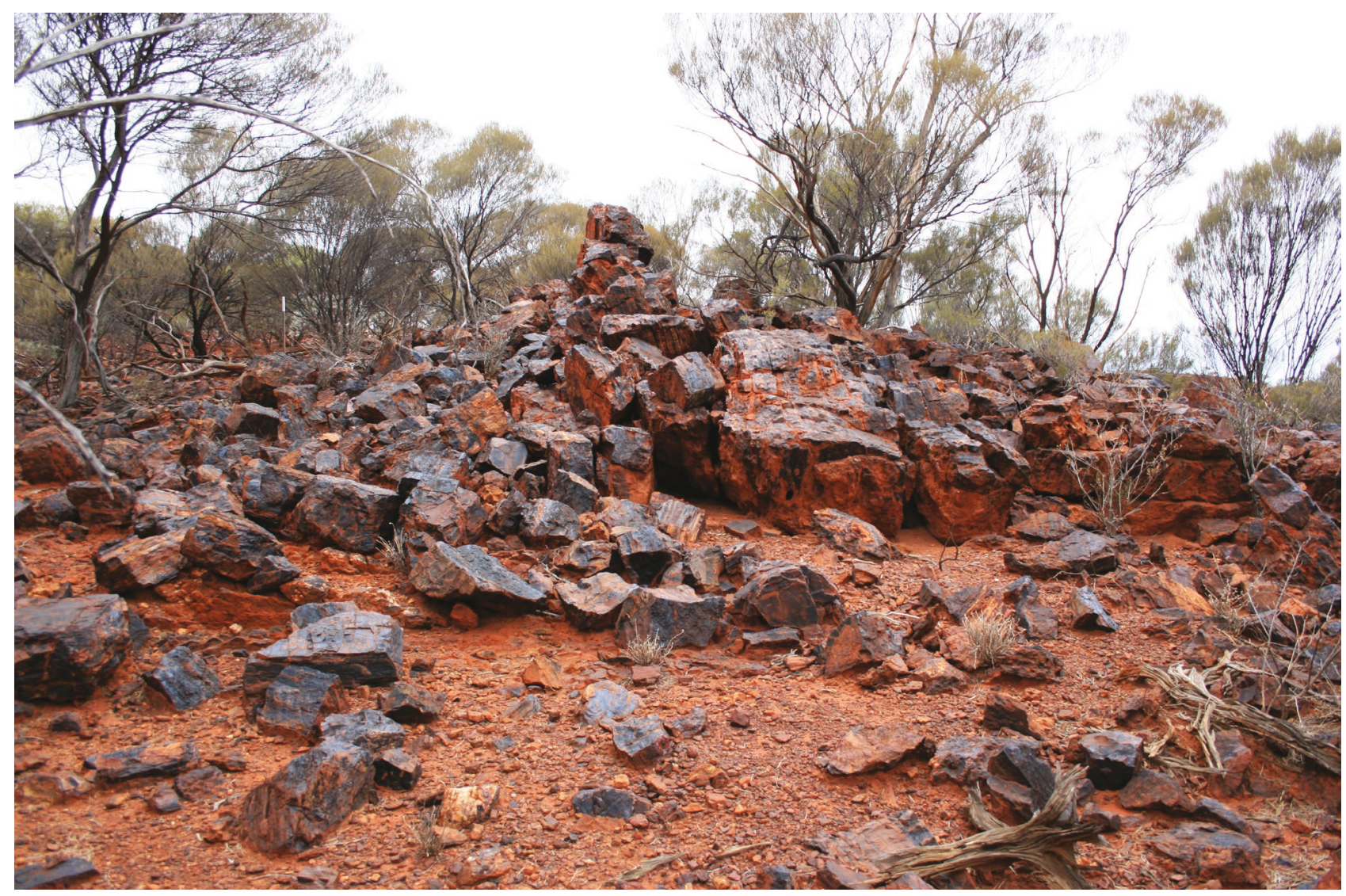

FIGURE 13 Habitat of G. polka sp. nov.: dark granitic jumbled rock in Weld Range (Photo: R.J. Ellis).

\section{REMARKS}

It is interesting to note the clear genetic separation of G. punctulata sp. nov. and G. polka sp. nov. in Ashman et al. (2018), although the sample sizes were small (4 and 2, respectively). Our mtDNA analysis also recovered these taxa as monophyletic lineages, but with some geographic structure evident. The similarity between the two species indicates a moderate-large body size in the regions south of the Pilbara may be adaptive in the absence of both larger-bodied rock-dwelling Gehyra species ( $G$. punctata and G. macra sp. nov.) and the smaller saxicoline species ( $G$. fenestrula sp. nov., $G$. media sp. nov., G. micra sp. nov. and G. peninsularis sp. nov.).

Owing to its southern occurrence, many photographs of 'G. punctata' are of this species (e.g. Storr et al. 1990, plate 10, Figure 1; Bush et al. 2007). This species is widespread and locally abundant in rocky areas that are unsuitable for agriculture, although they may be locally affected by mining activity. It occurs in protected areas at Mt Augustus National Park and other reserves from ex-pastoral leases (e.g., Waldburg and Mt Phillip). We therefore regard it as of least conservation concern.

\section{ETYMOLOGY}

Polka is an allusion to the polka dot patterns on the dorsum of this species. The Bohemian 'polka dance' was fashionable in the mid-19th century, and polka was appended to the names of many goods and objects, but only 'polka dot' is in use today. The word may have been a modification of the Czech pulka, meaning 'half', in reference to the quick steps employed in the dance. Used as a noun in apposition.

\section{Gehyra fenestrula sp. nov.}

Hamersley Range Spotted Gehyra

Figures 6,14

urn:Isid:zoobank.org:act:6E92943F-8CB1-4DA2-B10D381FBB7850C9

\section{MATERIAL EXAMINED}

\section{Holotype}

Australia: Western Australia: WAM R111769, male collected from Wheelarra Hill (PBS site BDRS03; $23.3586^{\circ} \mathrm{S}, 120.4590^{\circ} \mathrm{E}$ ) by Pearson, D., Morris, K. and Pepper, M. on 2 October 2005.

\section{Paratypes}

Australia: Western Australia: WAM R71633 (male), $21 \mathrm{~km}$ west-south-west Marillana homestead $\left(22.67^{\circ} \mathrm{S}\right.$, $119.22^{\circ} \mathrm{E}$ ); WAM R114337 (male), $35 \mathrm{~km}$ southeast of Prarie Downs $\left(23.7166^{\circ} \mathrm{S}, 119.4333^{\circ} \mathrm{E}\right)$; WAM R125083 
(female), $15 \mathrm{~km}$ east of Newman $\left(23.37^{\circ} \mathrm{S}, 119.90^{\circ} \mathrm{E}\right)$; WAM R127475 (female), $32 \mathrm{~km}$ south of Newman $\left(23.65^{\circ} \mathrm{S}, 119.72^{\circ} \mathrm{E}\right)$; WAM R129925 (female), West Angelas, $100 \mathrm{~km}$ west-north-west from Newman $\left(23.25^{\circ} \mathrm{S}, 118.67^{\circ} \mathrm{E}\right)$; WAM R135018 (female), Mt Whaleback $\left(23.3347^{\circ} \mathrm{S} ; 119.6694^{\circ} \mathrm{E}\right)$.

\section{DIAGNOSIS}

Differs from non-Australian Gehyra by lack of extensive webbing between toes III and IV and a cutaneous fold along the posterior margin of the hindlimb, and the presence of transversely widened subcaudal scales. Distinguished from other Australian Gehyra by moderately small body size (to $48.0 \mathrm{~mm}$ SVL), depressed body and head, moderately long and narrow snout with swollen nostril region, gabled rostral, upper postnasal slightly smaller than lower, 0-2 internasals, 8-10 supralabials, first supralabial narrower and taller than second, inner chin shields usually in contact with second infralabial, or if not, narrowly excluded, first parinfralabial encroaching on second or rarely third infralabial, fourth finger lamellae 5-6, fourth toe lamellae 6-7, lamellae divided and lacking wedge of granules at base of toe, pre-cloacal pores in adult males 9-12; in preservative, light to dark brown background colour, dorsal pattern with small widely scattered spots, spots formed by dark (anterior) and pale (posterior) elements in contact, spots sometimes forming irregular transverse rows; loreal and temporal head stripes moderately developed, canthal stripe weak, postorbital stripes absent or reduced to a spot; white patch above and below loreal and occasionally temporal stripe.

Further distinguished from other Gehyra from the region with reddish-brown colouration as follows: from G. punctata, G. macra sp. nov., G. punctulata sp. nov. and $G$. polka sp. nov. by smaller body size and fewer subdigital lamellae; further distinguished from G. macra sp. nov. by adult males possessing fewer pre-cloacal pores (9-12 vs. 14-21); from G. media sp. nov., G. micra sp. nov. and $G$. peninsularis sp. nov. by more numerous supralabials; from $G$. pilbara by longer and more depressed head, longer inner chin shields in contact with second infralabial and spots on dorsum more clearly demarcated from background colour; and from $G$. montium by fewer subdigital lamellae and lacking short bars (vs spots) or network of irregular dark lines.

\section{DESCRIPTION OF HOLOTYPE}

Body size moderately small (44.5 mm SVL), depressed dorsally, flat ventrally with defined ventrolateral edge. Head depressed (HeadD $=39 \%$ HeadL), in profile snout moderately long, snout (interorbital/ frontal region) straight with angle just anterior to eyes, canthus broadly rounded and slightly raised forming shallow depression in between canthal ridges, nostril region swollen; in dorsal view head widest behind eyes narrowing anteriorly to rounded snout; neck only slightly constricted. Scales on top and sides of snout $\sim 3$ times larger than crown and rest of body; scales in contact with nostril - rostral, supranasal, 2 postnasals (upper slightly smaller than lower) and first supralabial; first supralabial slightly taller than second; supralabials 9, infralabials 7; rostral height $1.1 \mathrm{~mm}$, width $1.8 \mathrm{~mm}$, deeply furrowed medially, rostral crease $\sim 55 \%$ of height of rostral; internasal 1; nostrils circular and directed dorsolaterally. Mental length $2.0 \mathrm{~mm}$, width $1.6 \mathrm{~mm}$, triangular, straight sides shared with first infralabial, penetrating $50 \%$ along inner chin shields; inner chin shields in moderate contact with second infralabial; chin shields $\sim 55 \%$ of height of inner chin shield with rounded outer edge in contact with $1^{\text {st }}$ parinfralabial and surrounding granules, first parinfralabial encroaching on posterior edge of second infralabial; pupil oval with crenelated edges (spectacle opaque); above and anterior to eye a projecting ridge; ear opening moderately large, oval, and oriented at a $30^{\circ}$ angle (anterior edge lower).

Dorsal scales small and homogeneous, juxtaposed, moderately rounded with apex slightly posterior; ventral scales 2-3 times larger than dorsal scales, flat and slightly imbricate; scales on limbs as for body. Precloacal pores 9, arranged in a shallow chevron with the apex pointing anteriorly; cloacal spurs 3 on each side, slightly enlarged, rounded and projecting scales to either side of cloaca.

Limbs short and moderately developed; projecting narrow claws present on all digits except digit I, claw projects above and beyond expanded toe pads, dorsal edge of toe pad with elongate row of scales forming a fringe; below digit a row of 6-9 enlarged round to oval tubercles increasing in size towards toe pads, last 2-3 divided; no conspicuous webbing between digits; subdigital lamellae divided, number on fourth finger 5, fourth toe 6 .

Tail ovoid at body, original portion swollen, regenerated portion gradually narrowing to a fine point, but with a $5 \mathrm{~mm}$ regenerated portion coming off the tip of the tail at nearly a right angle; proximal original tail $15 \mathrm{~mm}$ from cloaca, distal regenerated portion 19 $\mathrm{mm}$; scales on dorsal surface of original tail $\sim 2 \mathrm{x}$ size of scales on body, slightly imbricate and rounded with posterior apex, arranged in regular rows; ventral scales of original tails enlarged (2.1 x $0.9 \mathrm{~mm}$ at base) and oriented transversely (proximal 3-4 scales divided), scales on regenerated portion as for original but forming less ordered rows on dorsal surfaces, ventral surfaces with enlarged transverse scales as for original portion.

Colouration (in preservative). Light brown background colour on dorsum; widely scattered small dark brown and pale spots in contact or slightly separated, with dark anterior element and pale posterior element; dark elements above shoulders forming short bars; head as for body, canthal, loreal, temporal stripes present, weak lower post-orbital stripe; dorsal surface of limbs with fine dark and pale spots; venter pale with diffuse pigmentation (especially near ventrolateral edge), infralabials, and ventral surface of tail darker near edges, digits, palmar and plantar surfaces grey. 


\section{VARIATION}

Table 2 and Appendix 2 present variation in quantitative characters, Figure 6 shows two individuals in life and Figure 14 shows variation in dorsal patterning in preserved specimens. Body size of measured specimens varied between $36.0-48.0 \mathrm{~mm}$ SVL, with the smallest male possessing pre-cloacal pores at $43.5 \mathrm{~mm}$ SVL. Despite a female-biased sample, only one large female (48.0 mm SVL) was conspicuously gravid. Other specimens were generally $<30 \mathrm{~mm}$ SVL. There were only four adult males, and pre-cloacal pore counts were 9, 11, 11 and 12 .

Other specimens had similar colouration and patterning to the holotype, a light sandy brown to dark reddish-brown background colour. Spotting showed more variation, with a typical pattern of dark (anterior) and pale (posterior) elements in contact, spots overall quite small and widely spaced. A variation in several specimens was the pale element of the spot being circular and somewhat large, resulting in the dark anterior element having a 'U'-shape. In one individual (WAM R125083) the spots formed transverse rows, especially posteriorly.

\section{HABITAT AND ECOLOGY}

Very little known, as the description is based on relatively few specimens. Collectors' notes mention occurrence on banded ironstone outcrops, under granite caprock, edge of river gorge and shrubland and spinifex steppe on Mt Whaleback. PBS sites where specimens were pit-trapped occurred on rocky outcrops with large boulders and scree.

\section{DISTRIBUTION}

Restricted to a relatively small area in the southeast Pilbara region of Western Australia, including Packsaddle Range, Mt Whaleback and other locations near the mining town of Newman (Figure 3).

\section{REMARKS}

Gehyra fenestrula sp. nov. is an unusual species, as it has a body size typical of many other species of the arid clade of the G. variegata group (mean $\sim 41 \mathrm{~mm} \mathrm{SVL}$ ), yet appears to be a basal lineage of the large-bodied $G$. punctata complex members (Figure 1). Coupled with its restricted range in the south-eastern Pilbara and unique dorsal pattern of small widely-spaced spots with dark and pale elements together, G. fenestrula sp. nov. seems to be more of a relictual species that persists in the Hamersley Range despite the evolution and expansion of more recent and widespread species such as G. punctata and G. micra sp. nov.

Despite its relatively restricted distribution compared to other species treated here, G. fenestrula sp. nov. occurs over a wide enough area in the Pilbara such that its conservation status would seem to be secure, i.e. least

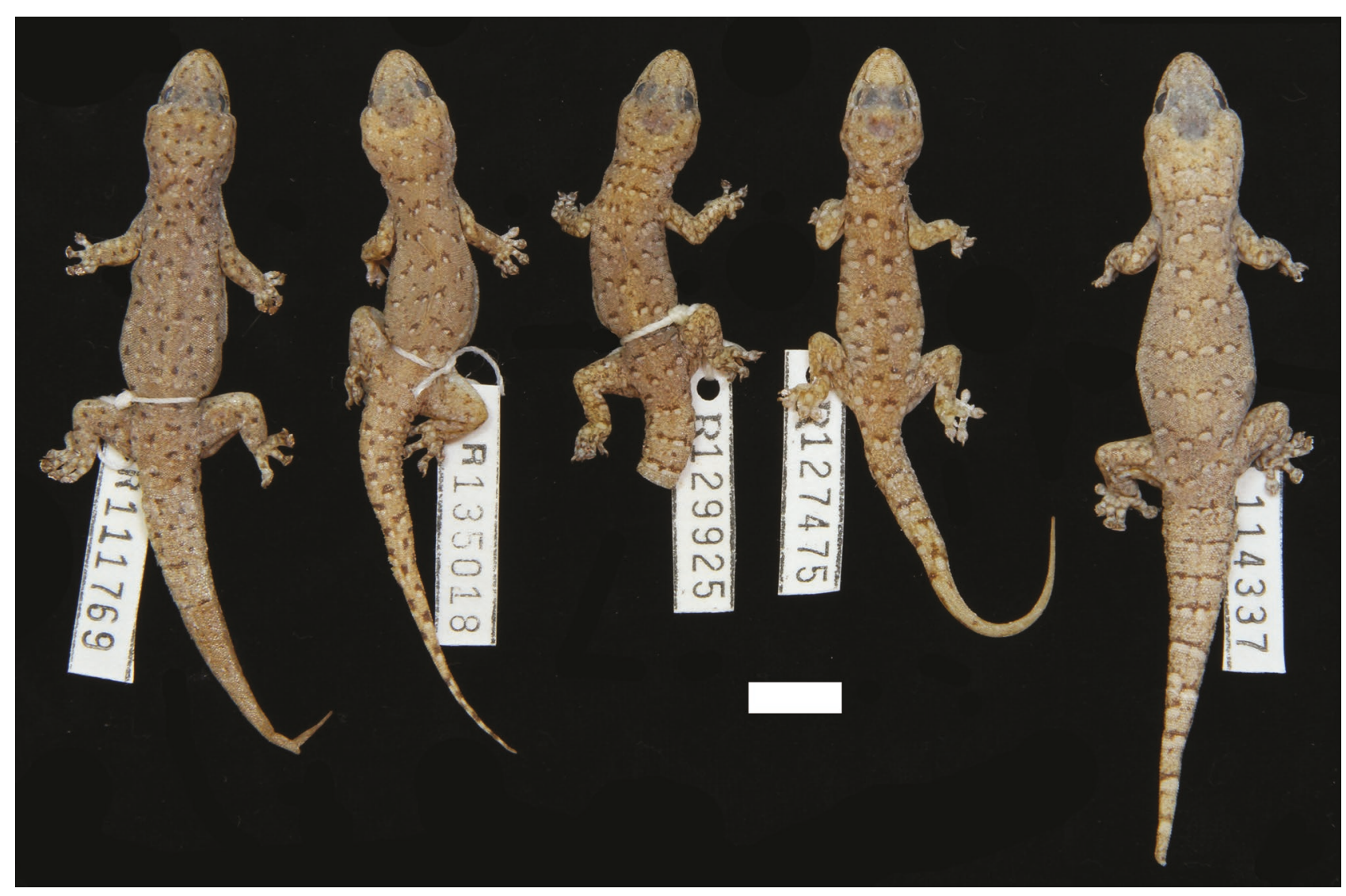

FIGURE 14 Variation among Gehyra fenestrula sp. nov. specimens. Holotype specimen is on the left. Scale bar $=10 \mathrm{~mm}$. 
concern. Nevertheless, further studies on its behaviour and habitats would be of interest, especially how it interacts ecologically with other similar and related rock-dwelling forms where it occurs.

\section{ETYMOLOGY}

Fenestrula is the diminutive of fenestra and refers to the fact that this species is the smallest member of the large-bodied G. punctata complex lineage, to which the junior synonym $G$. fenestra Mitchell belongs. The name thereby acknowledges Mitchell's contributions to Pilbara Gehyra systematics despite having his name of fenestra being a junior synonym of punctata owing to the inability of WAM staff to locate Fry's punctata type in the 1960s.

\section{Gehyra media sp. nov.}

Medium Pilbara Spotted Rock Gehyra

Figures 4, 6, 15

urn:Isid:zoobank.org:act:665D3755-5CD0-44F0-B03FA568C0FC4686

\section{MATERIAL EXAMINED}

\section{Holotype}

Australia: Western Australia: WAM R162687, adult male, collected from Baldy Rock, Pilbara region $\left(21.05^{\circ} \mathrm{S}, 118.80^{\circ} \mathrm{E}\right)$, by P. Doughty, C.A. Stevenson and P.G. Kendrick on 15 May 2006.

\section{Paratypes}

Australia: Western Australia: WAM R160940, male, $9 \mathrm{~km}$ northwest of Lake Poongkaliyarra $\left(20.9399^{\circ} \mathrm{S}\right.$, $118.0640^{\circ} \mathrm{E}$ ); WAM R161014, female, $3.5 \mathrm{~km}$ south of Marda Pool $\left(21.065^{\circ} \mathrm{S}, 116.150^{\circ} \mathrm{E}\right)$; WAM R162686, male, as for holotype; WAM R162704, female, as for holotype; WAM R174289, female, Nanutarra Roadhouse $\left(22.46434^{\circ} \mathrm{S}, 116.03714^{\circ} \mathrm{E}\right)$

\section{DIAGNOSIS}

Differs from non-Australian Gehyra by lack of extensive webbing between toes III and IV, a cutaneous fold along the posterior margin of the hindlimb, and the presence of transversely widened subcaudal scales. Differs from other Australian Gehyra by possessing small body size, moderately narrow snout, weakly gabled rostral, upper postnasal half to $1 / 3$ the size of lower, 7-9 supralabials, first supralabial taller and usually narrower than second, mental long with straight sides, inner chin shields in contact or narrowly excluded with second infralabial, second infralabial notched by encroachment of first parinfralabial, 5 or 6 divided lamellae on the fourth toe (without basal wedge of granules), in adult males 8-15 pre-cloacal pores arranged in a chevron. Dorsal pattern with dark brown and pale spots on light reddish-brown background, spots usually not in contact; canthal and loreal stripes weak, temporal stripe variable expressed, post-orbital stripes reduced to at most a spot, pale zone between canthal and loreal stripes.

Further distinguished from other Gehyra from the region with reddish-brown colouration as follows: from G. punctata, G. macra sp. nov., G. punctulata sp. nov. and $G$. polka sp. nov. by smaller body size, shorter and more convex snout and fewer subdigital lamellae; further distinguished from G. macra sp. nov. by adult males possessing fewer pre-cloacal pores ( $8-15$ vs $14-$ 21); from $G$. fenestrula sp. nov. by dark and pale spots separated (vs joined); from G. micra sp. nov. by slightly larger body size, broader snout and dorsal pattern consisting of scattered spots (vs rows of short bars) and pale spots with dark border; from $G$. peninsularis sp. nov. by fewer subdigital lamellae (5-6 vs 6-7) and pattern consisting of small spots not in contact (vs large spots tending to form transverse rows); from $G$. pilbara by longer and more depressed head, longer inner chin shields in contact with first infralabial and spots on dorsum more clearly demarcated from background colour; and from G. montium by fewer subdigital lamellae and lacking short bars (vs spots) or network of irregular dark lines.

\section{DESCRIPTION OF HOLOTYPE}

Body size small (48.0 mm SVL), depressed dorsally, flat ventrally with defined ventro-lateral edge. Head depressed (HeadD $=33 \%$ HeadL), snout short and narrow with orbit length over half the length of the snout; snout shape (interorbital/frontal region) convex, a fold of skin on snout (an artefact of preservation), canthus broadly rounded and poorly defined, nostril region only slightly swollen at tip; in dorsal view head widest behind eyes narrowing anteriorly to triangular snout with rounded tip; neck constricted to $3 / 4$ maximum head width. Scales on top and sides of snout $>3$ times larger than crown and rest of body; scales in contact with nostril - rostral, supranasal, 2 postnasals (lower twice the size of upper) and first supralabial; supralabials 8 , first taller and narrower than second, infralabials 7; rostral width $2.1 \mathrm{~mm}$, height $1.2 \mathrm{~mm}$, weakly gabled dorsally, furrowed medially, rostral crease $\sim 50 \%$ of height of rostral; internasal 1; nostrils circular and directed laterodorsally. Mental $1.7 \mathrm{~mm}$ long, $1.5 \mathrm{~mm}$ wide, triangular with straight sides, penetrating $1 / 3$ in to inner chin shields; elongate inner chin shields in contact with second infralabial; outer chin shields $2 / 3$ the height of inner chin shield, in contact with second infralabial and first parinfralabial; third chin shield $1 / 3$ height of outer. Eye large, pupil oval with crenulated edges ( 3 scallops on each side); above and anterior to eye a projecting ridge with posterior-dorsal edge slightly covered by superficial layer of skin; ear opening small and circular. 


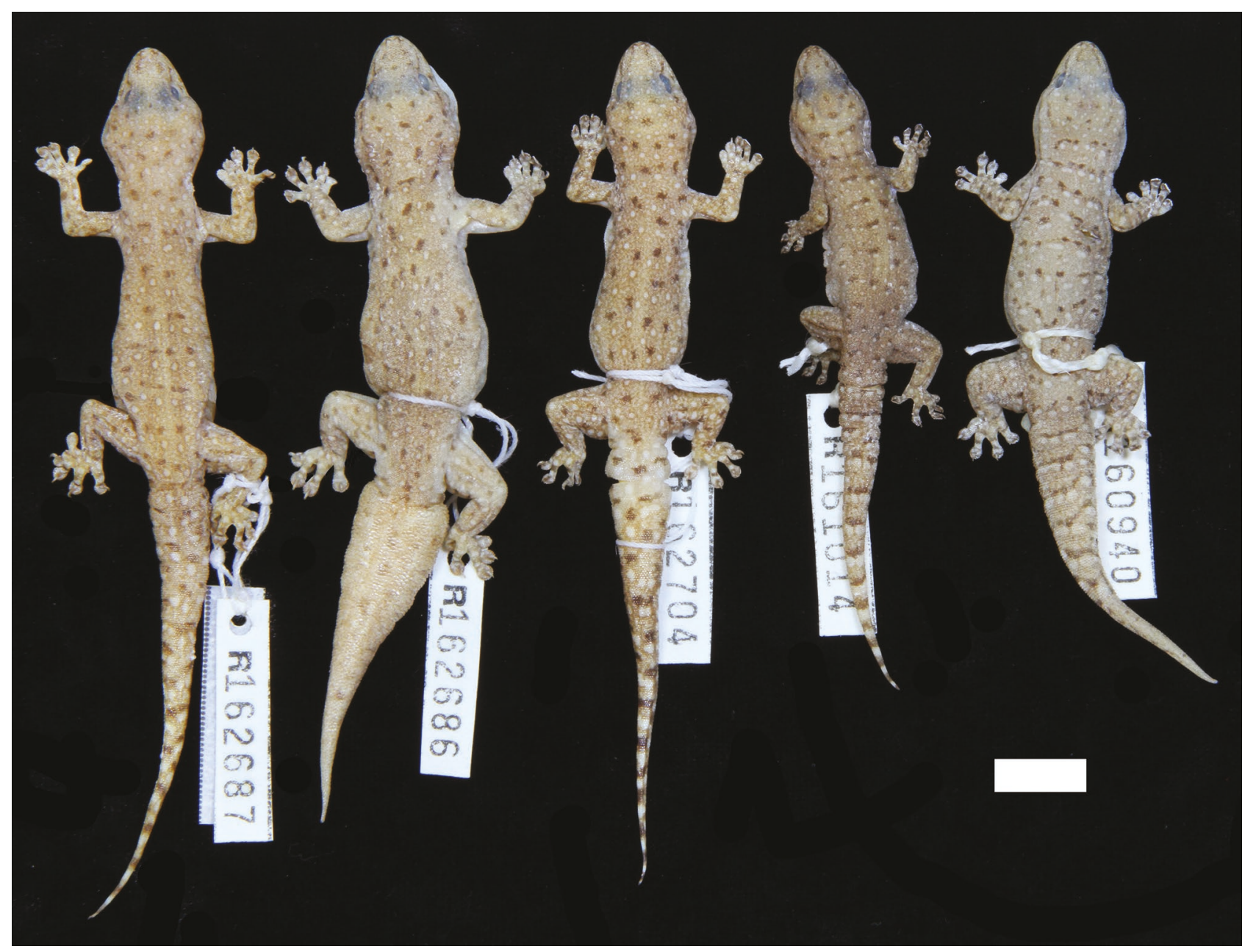

FIGURE 15 Variation among Gehyra media sp. nov. specimens. Holotype specimen is on the left. Scale bar $=10 \mathrm{~mm}$.

Dorsal scales small and homogeneous, juxtaposed, moderately rounded with apex slightly posterior; ventral scales 2-3 times larger than dorsal scales, flat and slightly imbricate; scales on limbs as for body. Precloacal pores 9, arranged in a short chevron with the apex pointing anteriorly; cloacal spurs - 3 slightly enlarged, rounded and projecting scales on each side of cloaca.

Limbs short and moderately developed; projecting narrow claws present on all digits except digit I, claws project above and beyond expanded toe pads, dorsal edge of toe pad with elongate row of scales forming a fringe; below digit a row of enlarged round to oval tubercles increasing in size towards toe pads, distal 2-3 tubercles divided; no conspicuous webbing between digits; subdigital lamellae divided, no wedge of granules at base, number of subdigital lamellae on fourth finger and toe 6.

Tail long and thin, slightly ovoid at body, tapering to a fine point; original tail $55 \mathrm{~mm}$; scales on dorsal surface of original tail $\sim 2 \times$ size of scales on body, squarish, flattened and arranged in regular rows; ventral scales of tail enlarged (up to $1.6 \times 1.1 \mathrm{~mm}$ near base) and oriented transversely or divided and squarish with rounded posterior edges.
Colouration. In life, a light brown background colour with loosely formed rows of rich reddish-brown blotches and small pale spots; reddish-brown blotches occasionally joining to form short transverse bars; canthal, loreal and temporal stripes present, with pale area between canthal and loreal stripes, post-orbital stripes reduced to a spot at most; pale spots finer on top of head and snout and larger on tail; tail without welldefined bands except near tip; eye reddish-orange with dark pupil. In preservative, as for life except as follows: light brown background colour on dorsum; pale spots with dark brown border; supralabials, rostral and lower sides of snout dark brown; dorsal surface of limbs as for head; venter pale, infralabials slightly darker.

\section{VARIATION}

Table 2 and Appendix 2 present variation in quantitative characters, and Figures 6 and 15 show a range of dorsal patterns. Body size ranged up to 50.0 $\mathrm{mm}$ SVL. To increase sample sizes, we scored 13 additional males not measured for Table 2 and Appendix 2 for the presence and number of pre-cloacal pores, and the average of 18 males was 10.8 , range of $8-15$. The smallest male with pores was $32.5 \mathrm{~mm}$ SVL. Females lack pre-cloacal pores and enlarged cloacal 
spurs, instead having slightly raised analogous scales bordering the cloaca. Several females possessed eggs or large follicles (always only one), with the smallest reproductively active female being $38.0 \mathrm{~mm} \mathrm{SVL}$. This indicates a large range in adult body sizes for both males and females of this species.

For patterning, the spots in juveniles often had the dark and pale markings in contact, but with an increase in size the spots tended to spread apart more conspicuously representing a possible age shift in this character. The well-defined border of the small pale spots is usually visible in preserved specimens, but in some individuals it is not apparent. Some individuals (e.g. WAM R159912) had very fine spots covering the dorsum. Regenerated tails had some spotting with highly variable and irregular patterns.

\section{HABITAT AND ECOLOGY}

Collection notes mention under small rocks near roadsides, Triodia plain on stony sandy soil, granite rocks, rocky drainage lines, sandplain and dune slope. Human habitats include under sheets of tin and 'old airstrip'. Of the PBS sites where specimens were pittrapped, notes on habitat included low stony hills, bedrock debris, rock fragments, scree and gravel on the lower slopes of hills, thin layer of rock pebbles and clay over massive stone, broken rocks and stones on outcrop surface and a low ridge on slope of basalt outcrop. These site descriptions are of low-lying rocks rather than large boulders on outcrops that the G. punctata species-group members typically inhabit.

\section{DISTRIBUTION}

Pilbara region of Western Australia (Figure 3). Gehyra media sp. nov. occurs throughout the Pilbara, except in the Hamersley Range.

\section{REMARKS}

Within the Pilbara region, G. media sp. nov. occurs in the northern portion and also extends to the western area south-west of Pannawonica. Although G. micra sp. nov. also has a small body size, G. media sp. nov. is slightly larger, suggesting some habitat partitioning between the two species. Interestingly, it is absent from the Hamersley Range, although the small-bodied species G. fenestrula sp. nov. and G. micra sp. nov. occur in the eastern portion.

Owing to its widespread distribution in the Pilbara and apparent abundance, we regard this species as of least conservation concern.

\section{ETYMOLOGY}

Media is derived from the neuter of medius, meaning middle, in reference to this species' intermediate size between G. micra sp. nov. and G. macra sp. nov.

\section{Gehyra micra sp. nov.}

Small Pilbara Spotted Rock Gehyra

Figures 6, 16

urn:Isid:zoobank.org:act:535AB2F7-FDF7-4388-8035ODFE5A8595F6

\section{MATERIAL EXAMINED}

\section{Holotype}

Australia: Western Australia: WAM R165158, adult male, collected from $3.5 \mathrm{~km}$ north of Karratha Station (PBS site DRW05) $\left(20.8539^{\circ} \mathrm{S}, 116.669^{\circ} \mathrm{E}\right)$, by P. Doughty and L. Gibson on 17 May 2005.

\section{Paratypes}

Australia: Western Australia: WAM R110011 (female), $6 \mathrm{~km}$ north-west of Roebourne $\left(20.7364^{\circ} \mathrm{S}\right.$, $117.099^{\circ} \mathrm{E}$ ); WAM R110013 (male), $5 \mathrm{~km}$ south of Lake Poongkaliyarra $\left(21.0364^{\circ} \mathrm{S}, 117.106^{\circ} \mathrm{E}\right)$; WAM R110045 (female) and WAM R110073 (female), $13.5 \mathrm{~km}$ west of Wickam (PBS site DRC11) $\left(20.6884^{\circ} \mathrm{S}, 117.007^{\circ} \mathrm{E}\right)$; WAM R125029 (male), Yandicoogina $\left(22.7125^{\circ} \mathrm{S}\right.$, $\left.119.0672^{\circ} \mathrm{E}\right) ; \mathrm{R} 160879$ (female), $3.5 \mathrm{~km}$ south of Marda Pool (PBS site DRW11) $\left(21.0655^{\circ} \mathrm{S} ; 116.15^{\circ} \mathrm{E}\right)$.

\section{DIAGNOSIS}

Differs from non-Australian Gehyra by lack of extensive webbing between toes III and IV and a cutaneous fold along the posterior margin of the hindlimb, and the presence of transversely widened subcaudal scales. Distinguished from other Australian Gehyra by small body size (mean $37.4 \mathrm{~mm}$, maximum $46.5 \mathrm{~mm}$ SVL), depressed body and head, snout short and narrow with slightly swollen nostril region, top of rostral weakly curved, upper postnasal smaller than lower postnasal; postnasals $\sim$ half the size of supranasals; 0-1 small internasals; nostril surrounded by rostral, supranasal, 2 postnasals and first supralabial; 8 or 9 supralabials, first supralabial slightly taller and narrower than second; mental elongate with straight sides and penetrating to half the length of the inner chin shield, inner chin shields in contact with second infralabial, first parinfralabial encroaching on second (usually) or third (occasionally) infralabial, fourth finger and toe lamellae 5-6, lamellae divided and lacking wedge of granules at base of toe, pre-cloacal pores in adult males 10-19; reddish-brown background colour, dorsal pattern with short transverse pale and dark bars or spots not in contact; canthal, loreal and temporal stripes present, white patch between canthal and loreal stripes and pale bar above temporal stripe usually present.

Further distinguished from other reddish-brown Gehyra in the Pilbara as follows. From G. peninsularis sp. nov. by less elongate body shape, spots on dorsum smaller with pale spots tending to form transverse bars, canthal stripe darker, and scales on chin more pigmented; from G. media sp. nov. by smaller body 


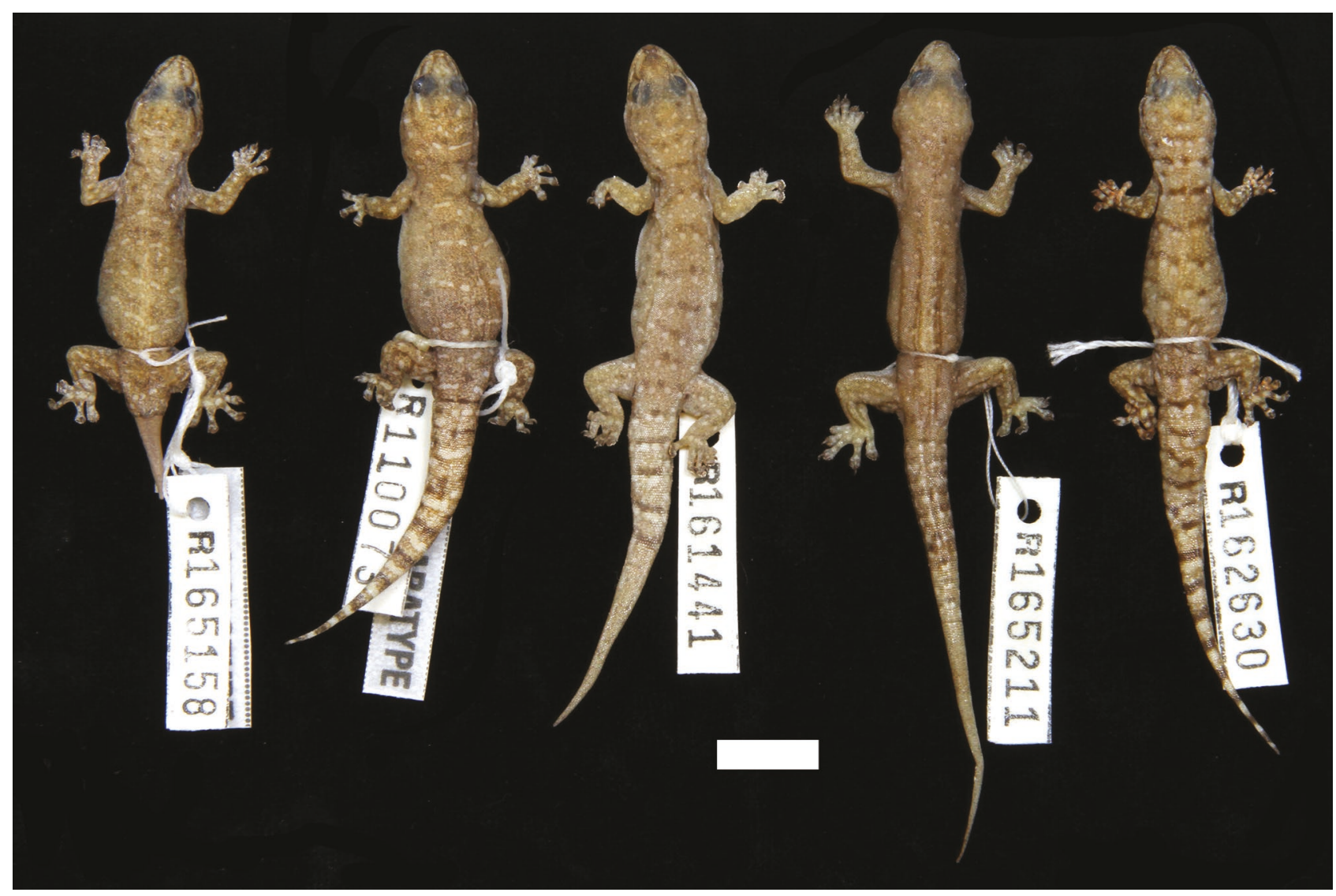

FIGURE 16 Variation among Gehyra micra sp. nov. specimens. Holotype specimen is on the left. Scale bar $=10 \mathrm{~mm}$.

size, narrower snout and spots tending to be ordered in rows with pale spots lacking dark edging and often forming transverse bars; from G. fenestrula sp. nov. by smaller body size, narrower snout, fewer supralabials and subdigital lamellae, and pale spots tending to form transverse bars with dark and pale elements not in contact; from $G$. punctata by smaller body size, deeper head, fewer supralabials and subdigital lamellae and pale dark and pale elements of markings not in contact; from $G$. macra sp. nov. by much smaller body size, fewer supralabials and subdigital lamellae, more reddish dorsum and clearly demarcated spots; from G. pilbara by longer and narrower snout, chin shields not very reduced in length and lacking a diffuse reticulum as a dorsal background pattern; from G. montium by smaller body size, narrower snout, fewer subdigital lamellae, more numerous pre-cloacal pores and lacking dark reticulum on dorsum.

\section{DESCRIPTION OF HOLOTYPE}

Body size small (35.0 mm SVL), depressed dorsally, flat ventrally with defined ventro-lateral fold. Head moderately depressed $($ HeadD $=39 \%$ HeadL), in profile snout moderately long and longer than eye, snout (interorbital/frontal region) straight, canthus broadly rounded and slightly raised forming shallow depression in between canthal ridges, nostril region only slightly swollen; in dorsal view head widest behind eyes narrowing anteriorly to relatively narrow snout; neck constricted to $2 / 3$ of the widest part of the head. Scales on top and sides of snout $>3$ times larger than crown and rest of body; scales in contact with nostril - rostral, supranasal, 2 postnasals (upper half the size of lower), and first supralabial; first supralabial slightly taller and narrower than second; supralabials 8 , infralabials 7 ; rostral height $0.9 \mathrm{~mm}$, width $1.4 \mathrm{~mm}$, slightly rounded dorsally, weakly furrowed medially, rostral crease $\sim 55 \%$ of height of rostral; internasals 0 ; nostrils circular and directed dorsolaterally and slightly anteriorly. Mental length $1.6 \mathrm{~mm}$, width $1.4 \mathrm{~mm}$, triangular, penetrating just over half the length of the inner chin shields; inner chin shields in short contact with second infralabial; outer chin shields $2 / 3$ the height of inner chin shield with rounded outer edge (right) or more acute edge (left) in contact with granules, first parinfralabial encroaching on posterior edge of second infralabial, followed by 2 (right) or 3 (left) parinfralabials; eye relatively small, pupil oval with crenelated edges; above and anterior to eye a projecting ridge; ear opening moderate size, oval, and lower edge angled forward $\sim 10^{\circ}$.

Dorsal scales small and homogeneous, juxtaposed, moderately rounded with apex slightly posterior; ventral scales 2-3 times larger than dorsal scales, flat and slightly imbricate; scales on limbs as for body. Precloacal pores 17 , arranged in a chevron with the apex pointing anteriorly; cloacal spurs 1 (right side) or 5 (left), slightly enlarged, rounded and projecting scales to either side of cloaca. 
Limbs short, arms slender, legs more robust; projecting narrow claws present on all digits except digit I, claw projects above and beyond expanded toe pads, dorsal edge of toe pad with elongate row of scales forming a fringe; below digit a row of 3-6 enlarged round to oval tubercles increasing in size towards toe pads, last 2-3 divided; no conspicuous webbing between digits; subdigital lamellae divided, number on fourth finger 5, fourth toe 6 . Tail ovoid at body, but broken near body; regenerated portion $48 \mathrm{~mm}$, narrowing to a point.

Colouration (in preservative). Light greyish-brown background colour on dorsum and upper surfaces; rows of alternating pale or brown transverse bars (or spots on nape and crown) not in contact; canthal, loreal and temporal stripes present, pale patch between canthal and loreal stripes, pale bar posterior to eye above temporal stripe; labial scales stippled with hiatus near sutures; dorsal surface of limbs with scattered pale spots; venter dull cream; infralabials, upper limbs, posterior edge of thigh, digits, and palmar and plantar surfaces dark grey.

\section{VARIATION}

Table 2 and Appendix 2 presents variation in quantitative characters, and Figure 16 shows a range of dorsal patterns. The smallest male with fully expressed pre-cloacal pores was $33.5 \mathrm{~mm} \mathrm{SVL}$, with another male that was $30.0 \mathrm{~mm} \mathrm{SVL}$ having 13 pores that were only weakly perforated. The smallest female with an enlarged follicle or egg was $34.5 \mathrm{~mm}$ SVL. Most adult body sizes were in the $35-40 \mathrm{~mm}$ SVL range, but with an exceptionally large individual reaching a maximum of $46.5 \mathrm{~mm}$ SVL.

Pattern was somewhat variable, with usually short dark and pale bars across the dorsum, often forming transverse rows but many individuals had isolated spots. The head stripes were variably expressed as well, but the loreal and temporal stripe were prominent, canthal stripe usually present but variably expressed and post-orbital stripes absent or reduced to a spot at best.

\section{HABITAT AND ECOLOGY}

Encountered among low rocks on horizontal surfaces, only rarely observed on vertical rocks or trees. Typical habitats are like the scree at the base of the vertical rock face to the left in Figure 8. Collectors' notes indicate its occurrence on Triodia plains on stony sandy soil, rocky hills and gorges, schist and granite outcrops, under rocks, with one specimen on a rock face and one $1.5 \mathrm{~m}$ on a small tree in a creek line.

During the PBS survey, as for G. media sp. nov., this species was captured in high numbers in pitfall traps (Doughty et al. 2011). PBS sites where G. micra sp. nov. was captured include rocky hillsides, scree and gibber below massive outcrops and breakaway, sides of basalt hills with rock fragments, Triodia hilltop with bedrock debris, valley floor plain with pebbles, duricrust on top of mesa and rock-sheets below outcrops (McKenzie et al. 2009).

\section{DISTRIBUTION}

Occurs widely across the Pilbara craton, but absent from the central and western portions of the Hamersley Range and also the Burrup Peninsula near Karratha where it is replaced by $G$. peninsularis sp. nov. (Figure 3).

\section{REMARKS}

This species is one of the smallest within the arid clade of the Gehyra variegata group at typically less than $40 \mathrm{~mm}$ SVL. This small body size with narrower snout and preference for low rocks indicates a decided shift away from the climbing habits of other species from the G. punctata species-group. However, it is similar in body size and habits to G. media sp. nov., and the two species overlap over most of the Pilbara, suggesting they may differ subtly in habitat preferences and feeding ecology that are yet to be discerned. However, these two species do slightly displace each other geographically with G. micra sp. nov. absent from the northern edge of the Pilbara, and G. media sp. nov. absent from the Hamersley Range and areas to the east where records of G. micra sp. nov. occur (Figure 3).

Owing to this species' abundance and widespread distribution in the Pilbara, we regard its conservation status as of least concern.

\section{ETYMOLOGY}

Micra is derived from the Greek mikros meaning small. Used as an adjective.

\section{Gehyra peninsularis sp. nov.}

\author{
Burrup Peninsula Rock Gehyra
}

Figures 6, 17

urn:Isid:zoobank.org:act:486CBDC3-E9F3-42BA-BBB76B5FC1E3CF89

\section{MATERIAL EXAMINED}

Holotype

Australia: Western Australia: WAM R165749, an adult male collected from Dampier Port, Burrup Peninsula $\left(20.6166^{\circ} \mathrm{S}, 116.7500^{\circ} \mathrm{E}\right)$ by G. Harold and L. Beesley on 26 April 2006.

\section{Paratypes}

Australia: Western Australia: WAM R132562 (female), WAM R146581 (male), Burrup Peninsula (20.6161 $\left.{ }^{\circ} \mathrm{S}, 116.7850^{\circ} \mathrm{E}\right)$; WAM R165748 (female), as for holotype; WAM R165239 (female), $2.4 \mathrm{~km}$ west of Hearson Cove, Burrup Peninsula $\left(20.617^{\circ} \mathrm{S}, 116.772^{\circ} \mathrm{E}\right)$; WAM R165240 (male), $3.4 \mathrm{~km}$ north-east of Dampier, Burrup Peninsula $\left(20.658^{\circ} \mathrm{S}, 116.741^{\circ} \mathrm{E}\right)$. 


\section{DIAGNOSIS}

Differs from non-Australian Gehyra by lack of extensive webbing between toes III and IV and a cutaneous fold along the posterior margin of the hindlimb, and the presence of transversely widened subcaudal scales. Distinguished from other Australian Gehyra by small body size (mean $42.2 \mathrm{~mm}$, maximum $48.5 \mathrm{~mm}$ SVL), depressed body and head, snout short and narrow with slightly swollen nostril region, top of rostral weakly curved, furrowed medially, upper postnasal half the size of lower; 0-1 small internasals (supranasals usually in contact); nostril surrounded by rostral, supranasal, 2 postnasals and first supralabial; 7-10 supralabials, first supralabial slightly taller and narrower than second, mental elongate with straight sides and penetrating to approximately half the length of the inner chin shield, inner chin shields in contact with second infralabial, first parinfralabial encroaching on second (usually) or third (occasionally) infralabial; fourth finger and toe lamellae 5-6, lamellae divided and lacking wedge of granules at base of toe, precloacal pores in adult males 7-15; light reddish-brown background colour, dorsal pattern comprised of rows of alternating moderately large pale and dark spots, often forming transverse bars; canthal, loreal and temporal stripes present, pale white patch between canthal and loreal stripes and pale bar above temporal stripe usually present.

Further distinguished from other reddish-brown Gehyra in the Pilbara as follows. From G. media sp. nov. by larger spots tending to be in contact and forming transverse bars, and pale spots lacking dark edging; from G. micra sp. nov. by more elongate body shape and spots on dorsum larger, forming thicker transverse bars; from $G$. fenestrula sp. nov. by deeper head, fewer supralabials, and pale spots tending to form transverse bars with dark and pale elements not in contact; from $G$. punctata by smaller body size, deeper head, fewer supralabials and subdigital lamellae and pale dark and pale elements of markings not usually in contact; from G. macra sp. nov. by much smaller body size, fewer supralabials and subdigital lamellae, more reddish dorsum and clearly demarcated spots; from $G$. pilbara by longer and narrower snout, chin shields not very reduced in length and lacking a diffuse reticulum as a dorsal background pattern; from G. montium by narrower snout, inner chin shield in contact with second infralabial and different dorsal pattern: lacking short dark and pale bars and/or dark reticulum on dorsum.

\section{DESCRIPTION OF HOLOTYPE}

Body size small (41.0 mm SVL), depressed dorsally, flat ventrally with defined ventro-lateral fold. Head moderately depressed (HeadD $=37 \%$ HeadL), in profile snout moderately long and longer than eye, snout (interorbital/frontal region) straight, canthus broadly rounded and slightly raised forming shallow depression in between canthal ridges, nostril region only slightly swollen; in dorsal view head widest behind eyes narrowing anteriorly to triangular snout with rounded tip; neck constricted to approximately $3 / 4$ maximum head width; scales on top and sides of snout $>3$ times larger than crown and rest of body; scales in contact with nostril - rostral, supranasal, 2 postnasals (upper half the size of lower), and first supralabial; first supralabial slightly taller and narrower than second; supralabials 8 , infralabials 7; rostral height $0.9 \mathrm{~mm}$, width $1.8 \mathrm{~mm}$, flat dorsally, furrowed medially, rostral crease $\sim 50 \%$ of height of rostral; no internasals; nostrils circular and directed dorsolaterally and slightly anteriorly. Mental length $1.8 \mathrm{~mm}$, width $1.9 \mathrm{~mm}$, narrow and triangular, penetrating half the length of the inner chin shields; inner chin shields in narrow contact with first infralabial; outer chin shields $2 / 3$ the height of inner chin shield, first parinfralabial encroaching on posterior edge of second infralabial; pupil oval with crenelated edges; above and anterior to eye a projecting ridge; ear opening moderate size, oval, and lower edge angled forward $\sim 30^{\circ}$.

Dorsal scales small and homogeneous, juxtaposed, moderately rounded with apex slightly posterior; ventral scales 2-3 times larger than dorsal scales, flat and slightly imbricate; scales on limbs as for body; pre-cloacal pores 14, arranged in a chevron with the apex pointing anteriorly; cloacal spurs 3 on each side, slightly enlarged, rounded and projecting scales to either side of cloaca.

Limbs short, arms slender, legs more robust; projecting narrow claws present on all digits except digit I, claw projects above and beyond expanded toe pads, dorsal edge of toe pad with elongate row of scales forming a fringe; below digit a row of 3-5 enlarged round to oval tubercles increasing in size towards toe pads, last 1-3 divided; no conspicuous webbing between digits; subdigital lamellae divided, number on fourth finger 5 , fourth toe 6 . Tail ovoid at body, original portion $10 \mathrm{~mm}$ and swollen, regenerated portion $\sim 34$ $\mathrm{mm}$ and gradually narrowing to a fine point; scales on dorsal surface of original tail $\sim 2 \mathrm{x}$ size of scales on body, slightly imbricate and rounded with posterior apex, arranged in regular rows; ventral scales of original tails enlarged and oriented transversely, scales on regenerated portion as for original but forming less ordered rows.

Colouration. In preservative, light brown background colour on dorsum; alternating regular rows of moderately large pale or dark spots on dorsum. Head as for body but dark spots smaller; canthal stripe weak, loreal and temporal stripes present, post-orbital stripes absent, white patch between canthal and loreal stripes; labial scales near tip of snout lightly pigmented, hiatus of pigment near sutures; dorsal surface of limbs with pale scattered spots; venter pale cream. 


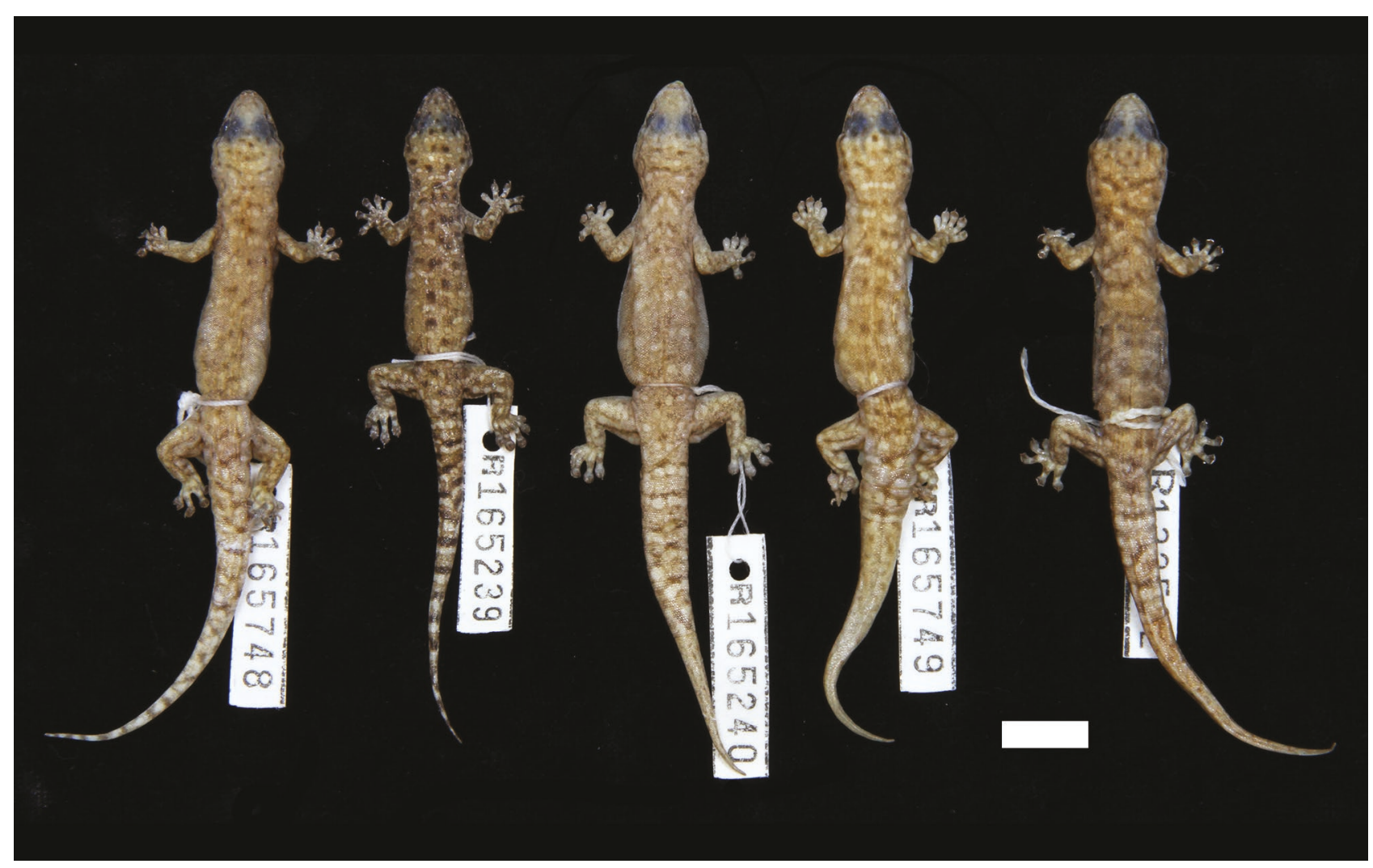

FIGURE 17 Variation among Gehyra peninsularis sp. nov. specimens. Holotype specimen is second from the right. Scale bar $=10 \mathrm{~mm}$.

\section{VARIATION}

Table 2 and Appendix 2 present variation in quantitative characters, and Figure 17 shows a range of dorsal patterns. The smallest male with fully expressed pre-cloacal pores was $35.5 \mathrm{~mm}$ SVL. Most adult body sizes were in the $35-45 \mathrm{~mm}$ SVL range, but with a maximum of $48.5 \mathrm{~mm} \mathrm{SVL}$.

In life, the background colour is a rich reddish-brown (Figure 6), with yellowish-white pale spots and dark brown markings; in preservative, background colour varied from a light to medium-dark brown. The spots on the dorsum sometimes were so close as to form almost continuous rows (cf. WAM R132562), ranging to more widely separated (WAM R165748).

\section{ECOLOGY AND HABITAT}

There are almost no habitat notes for this species, other than a single mention of 'creek line' on the WAM database for one specimen (WAM R164116). Given the habitats where it occurs and the reddish, spotted pattern it is likely to be a terrestrial species living among rocks and stones (i.e. not vertical crevices in boulders as for the G. punctata species-group members).

\section{DISTRIBUTION}

Confined to the Burrup Peninsula and offshore islands in the northern Pilbara near Karratha, including the Dampier port and West Intercourse Island (Figure 3).

\section{REMARKS}

This species is closely related to G. micra sp. nov., with $G$. peninsularis appearing as a lineage within this species in the mtDNA data (Figure 1) but positioned as a basal lineage within the Ashman et al. (2018) exon capture data set and distinctive with respect to allozymes as well (M. Adams and P. Doughty, unpublished data). Coupled with the slightly elongate body shape, large rows of spots on the dorsum and geographical isolation on the Burrup Peninsula, the combined evidence indicates this is a distinctive independently evolving lineage. Populations of Crenadactylus pilbarensis Doughty, Ellis and Oliver, 2016 from the Burrup Peninsula were also slightly genetically distinctive (Oliver et al. 2010) as well as G. punctata with differences in allozymes (M. Adams and P. Doughty, unpublished data). The history of the Burrup Peninsula as a potential refugium may be of interest biogeographically, especially coupled with studies of the effects of changes in sea levels connecting current offshore islands, including Barrow Island, and the mainland.

Owing to this species' restricted distribution, we regard its conservation status as 'data deficient'.

\section{ETYMOLOGY}

The specific name of peninsularis refers to this species' occurrence on the Burrup Peninsula on the northern Pilbara coast. 


\section{DISCUSSION}

Storr's (1982) taxonomic conservatism with respect to the reddish-brown spotted Gehyra of the Pilbara was understandable, given the paucity of collections then available and the lack of genetic analyses with which to evaluate phylogenetic structure and species boundaries. However, both general surveys and directed fieldwork in the Pilbara have generated large collections of Gehyra in recent decades, yielding geographically representative genetic samples and series of specimens large enough to meaningfully evaluate intra- vs. interspecific variation. This has permitted us to make progress in the face of what King (1979) rightly considered a 'taxonomist's nightmare'. Our method followed the approach of integrative taxonomy (Padial et al. 2010) in which molecular data and morphology provide independent lines of evidence to support the recognition of species level lineages that are both monophyletic and morphologically diagnosable and are broadly consistent with the general lineage species concept (de Querioz 1998).

We relied on three main lines of evidence in this study, including morphology, a mtDNA data set that screened hundreds of individuals across the region, and a recently published phylogeny that sequenced hundreds of nDNA genes but with very few individuals per lineage sampled. Each data source excels in some areas but has weaknesses in others. For morphology, phenotypic expression of colouration can be highly variable and convergent, with patterns fading in preservation leading to the loss of characters. Moreover, the body plan of Gehyra is highly conserved across this old and widespread group, with only subtle changes in shape across widely divergent lineages (Heinicke et al. 2011; Ashman et al. 2018; Doughty et al. 2018; Kealley et al. 2018). However, the benefit of working with morphology is that many potentially informative characters can be inexpensively assessed. For the mtDNA evidence, incomplete lineage sorting and introgression after divergence can obscure patterns of evolutionary history (Maddison and Knowles 2006). On the other hand, sufficient numbers of specimens can be incorporated into such analyses to evaluate putative morphologically-derived clusters of specimens and to estimate true geographic distribution, an important outcome when working with cryptic species (Kealley et al. 2018). Obtaining and analysing nDNA sequences is far more laborious in terms of time and cost, resulting in very few individuals being sequenced. However, the insight gained from such analyses can provide robust tests of whether putative taxa behave as independentlyevolving lineages, a crucial step in evaluating whether to refer to such lineages as species (Fujita et al. 2012; Sukumaran and Knowles 2017).

In practice, the key to assigning names to lineages in this study first required the stabilisation of the name $G$. punctata, the application of which had been uncertain since its first use more than a century ago. After this was accomplished, we needed to evaluate the validity of $G$. fenestra, itself an unstable and uncertain entity since its proposal by Mitchell (1965). Having identified the genetic lineage to which both of these names correctly apply, all other lineages recognised through genetic means could be characterised and diagnosed morphologically and formally described. This integrative approach taken here and elsewhere recently (e.g. Sistrom et al. 2009; Doughty et al. 2012, 2018; Hutchinson et al. 2014; Oliver et al. 2016; Kealley et al. 2018) has proved highly effective at resolving cryptic diversity in conservative Gehyra lineages.

The resolution of the Gehyra punctata species complex here reveals an intriguing large-scale biogeographic pattern that can provide insights into the evolution of the Australian arid zone fauna. The most apparent pattern of Pilbara region Gehyra is the high species diversity for saxicoline species compared to arboreal and generalist species such as $G$. variegata and $G$. purpurascens in the arid zone (see also Pepper et al. 2014; Heineke et al. 2017; Ashman et al. 2018). The arboreal-generalist species tend to have massive distributions across the arid zone, whereas the saxicoline species have much smaller distributions, possibly reflecting patterns of diversity related to the rocky regions such as the Pilbara and Central Ranges that serve as ancient refugia that are able to promote speciation through time (Doughty et al. 2011; Pepper et al. 2013; Ashman et al. 2018). The lower diversity of arboreal-generalist species may be correlated with their habitat preferences for trees and shrubs because arboreal habitats are continuous through the arid zone compared to the clumped nature of rocky refugia. Interestingly, within the arboreal lineages the evolution of saxicoline forms has occurred multiple times, e.g. G. minuta, G. einasleighensis and other occasions in the G. variegata species-group (Ashman et al. 2018; Kealley et al. 2018).

Within the saxicoline species of the Pilbara region there were interesting patterns of body size and distribution. For instance, the G. punctata species-group and $G$. media species-group members with generally large differences in body size and habitat preferences had wide overlap within the Pilbara craton. For the large-bodied species of the G. punctata species-group, they appeared to be parapatric with G. macra sp. nov. occurring exclusively in the northern Pilbara and $G$. punctata to the south. The nature of the rock outcrops within these distributions also differs with ironstones to the south and more granitoids in the north, and the species may be adapted to these different substrates (Pepper et al. 2013), bearing in mind the complex matrix of habitat types in close proximity in the Pilbara (Doughty et al. 2011). The Hamersley endemic species $G$. fenestrula sp. nov. is a basal member of the G. punctata species-group and has a moderate body size more typical of other arid clade members of the G. variegata group (see also Ashman et al. 2018). It overlaps broadly with $G$. punctata and G. micra sp. nov., possibly indicating a different habitat preference from those more recently evolved species. For the 
two southern $G$. punctata species-group members, $G$. punctulata sp. nov. and G. polka sp. nov., these species did not overlap with either the larger-bodied members of their species-group to the north and no G. media species-group members occur south of the Pilbara. These southern species possessed body sizes that were intermediate, possibly reflecting evolution of a more generalised saxicoline body size in the absence of other competition. Within the G. media species-group, $G$. media sp. nov. and G. micra sp. nov. differed slightly in body size and had areas of wide overlap throughout the Pilbara, but with the northern (G. media sp. nov. only) and Hamersley Range (G. micra sp. nov. only) areas where there was only a single species. Gehyra peninsularis sp. nov. appears to be an allopatric replacement of other G. micra sp. nov. lineages on the Burrup Peninsula. These speculations and more sophisticated biogeographic scenarios could be further tested, but the description of the species here and in Kealley et al. (2018) and other works on Gehyra provide a fertile field of further enquiry.

In addition to being ideal groups for studying a variety of evolutionary questions, much of biodiversity may remain hidden in highly variable species complexes, which can have impact on the design of reserves to capture the most phylogenetic diversity (Rosauer et al. 2018). In this instance the resolution of the reddishbrown spotted Gehyra provides further evidence of the now well established distinctiveness and high endemism of the Pilbara (Powney et al. 2010; Doughty et al. 2011; Pepper et al. 2013), but it also reveals patterns of endemism and richness within the Pilbara that had not been previously appreciated. With at least an initial understanding of the spatial distribution of the species treated in this study we can begin to evaluate the ways in which body size and microhabitat use are associated with lineage diversification in what we now know to be a relatively species rich radiation of Gehyra.

\section{ACKNOWLEDGEMENTS}

We thank the numerous field workers who have collected and discussed with us the Gehyra punctata species complex over the years, especially the environmental consultants who have grappled with Gehyra identifications (particularly G. Harold and R.J. Teale, Biota Environmental Sciences), M. Adams (formerly of the South Australian Museum) for his unpublished extensive allozyme surveys and participants in the Pilbara Biodiversity Survey (particularly J.K. Rolfe, P. Oliver and P.G. Kendrick). We thank C. Stevenson, B. Maryan and R. How for support during the early phases of the project, P. Sawers (Biota Environmental Sciences) for preparing the distribution maps, L. Kealley and R.J. Ellis for image preparation and specimen sorting, T. Parkin for logistical help, K. Date for providing photographs of the Museum Victoria specimens from the Horn Expedition, M. Sistrom, M. Hutchinson, C. Moritz, P. Oliver, G. Shea, J. Huey,
M. Kearney and M. Heineke for helpful discussions, A. Amey and L. Grismer for critical reviews, and B. Maryan, G. Shea and R.J. Ellis for photos in life. For financial support we thank N.L. McKenzie of the Department of Environment and Conservation (WA) for funding the initial allozyme analysis, the Australia and Pacific Science Foundation, and the Winston Churchill Memorial Trust for PD's residency at Villanova University in 2011 where the bulk of the morphological analyses were carried out. The Gerald M. Lemole Endowed Chair funded AMB's travel to Perth.

\section{REFERENCES}

Adler, K. (2007). Contributions to the history of herpetology, part 2. Society for the Study of Amphibians and Reptiles: Saint Louis, U.S.A.

Ashman, L.G., Bragg, J.G., Doughty, P., Hutchinson, M.N., Bank, S., Matzke, N.J., Oliver, P.M., and Moritz, C. (2018). Diversification across biomes in a continental lizard radiation. Evolution: in press.

Bauer, A.M., Jackman, T., Sadlier, R.A. \& Whitaker, A.H. (2006) A revision of the Bavayia validiclavis group (Squamata: Gekkota: Diplodactylidae), a clade of New Caledonian geckos exhibiting microendemism. Proceedings of the California Academy of Sciences 57: 503-547.

Bergmann, P.J. and Russell, A.P. (2007) Systematics and biogeography of the widespread Neotropical gekkonid genus Thecadactylus (Squamata), with the description of a new cryptic species. Zoological Journal of the Linnaean Society 149: 339-370.

Börner, A.R. and Schüttler, B.I. (1983). An additional note on the Australian geckos of the genus Gehyra. Miscellaneous Articles in Saurology 12: 1-4.

Bourke, G., Pratt, R.C., Vanderduys, E. and Moritz, C. (2017). Systematics of a small Gehyra (Squamata: Gekkonidae) from the Einasleigh Uplands, Queensland: description of a new range restricted species. Zootaxa 4231: 85-99.

Bush, B., Maryan, B., Browne-Cooper, R. and Robinson, D. (1997). Reptiles and frogs in the bush: Southwestern Australia. University of Western Australia Press, Crawley, Western Australia.

Bustard, H.R. (1965a). The systematic status of the Australian gecko, Gehyra variegata punctata (Fry). Herpetologica 21: 157-158.

Bustard, H.R. (1965b). The systematic status of the Australian geckos Gehyra variegata (Duméril and Bibron, 1836) and Gehyra australis Gray, 1845. Herpetologica 20: 259-272.

Camargo, A. and Sites, J.W., Jr. (2013). Species delimitation: a decade after the Renaissance (pp. 225-247). In: Pavlinov, I. Ya. (ed.), The species problem - ongoing issues. InTech Publishing: Rijeka, Croatia.

Chrapliwy, P.S., Smith, H.M. and Grant, C. (1961). Systematic studies of the gekkonid lizard genera Gehyra, Peropus, Hoplodactylus and Naultinus. Herpetologica 17: 5-12.

de Queiroz, K. (1998). The general lineage concept of species, species criteria, and the process of speciation (pp. 57-75). In: Howard, D.J. and Berlocher, S.H. (eds), Endless forms: species and speciation. Oxford University Press: Oxford, United Kingdom.

de Queiroz, K. (2007). Species concepts and species delimitation. Systematic Biology 56: 879-886. 
Doughty, P., Oliver, P. and Adams, M. (2007). Systematics of stone geckos in the genus Diplodactylus (Reptilia: Diplodactylidae) from northwestern Australia, with a description of a new species from the Northwest Cape, Western Australia. Records of the Western Australian Museum 24: 247-265.

Doughty, P., Ellis, R.J. and Oliver, P.M. (2016). Many things come in small packages: Revision of the clawless geckos (Crenadactylus: Diplodactylidae) of Australia. Zootaxa 4168: 239-278.

Doughty, P., Rolfe, J.K., Burbidge, A.H., Pearson, D.J. and Kendrick, P.G. (2011). Herpetological assemblages of the Pilbara biogeographic region, Western Australia: ecological associations, biogeographic patterns and conservation. Records of the Western Australian Museum, Supplement 78: 315-341.

Doughty, P., Palmer, R., Sistrom, M.J., Bauer, A.M. and Donnellan, S.C. (2012). Two new species of Gehyra (Squamata: Gekkonidae) geckos from the north-west Kimberley region of Western Australia. Records of the Western Australian Museum 27: 117-134.

Doughty, P., Bourke, G., Tedeschi, L.G., Pratt, R.C., Oliver, P.M., Palmer, R.A. and Moritz, C. (2018). Species delimitation in the Gehyra nana (Squamata: Gekkonidae) complex: cryptic and divergent morphological evolution in the Australian Monsoonal Tropics, with the description of four new species. Zootaxa 4403: 201-244.

Duméril, A.M.C. and Bibron, G. (1836). Erpetologie générale ou histoire naturelle complete des reptiles. vol. 3. Libr. Encyclopédique Roret: Paris.

Edgar, R.C. (2004). MUSCLE: multiple sequence alignment with high accuracy and high throughput. Nucleic Acids Ressearch 32: 1792-1797.

Ellis, R.J., Doughty, P. and Bauer, A.M. (2018). An annotated type catalogue of the geckos and pygopods (Squamata: Gekkota: Carphodactylidae, Diplodactylidae, Gekkonidae, Pygopodidae) in the collection of the Western Australian Museum. Records of the Western Australian Museum 33(1): 51-94. doi: 10.18195/issn.0312-3162.33(1).2018.051-094.

Frost, D.R. and Hillis, D.M. (1990). Species in concept and practice: herpetological applications. Herpetologica 46: 87-104.

Frost, D.R., Kluge, A.G. and Hillis, D.M. (1992). Species in contemporary herpetology: comments on phylogenetic inference and taxonomy. Herpetological Review 23: 46-54.

Fry, D.B. (1914). On a collection of reptiles and batrachians from Western Australia. Records of the Western Australian Museum and Art Gallery 1: 174-210.

Fujita, M.K., Leaché, A.D., Burbrink, F.T., McGuire, J.A. and Moritz, C. (2012). Coalescent- based species delimitation in an integrative taxonomy. Trends In Ecology \& Evolution 27: $480-488$.

Gamble, T., Greenbaum, E., Jackman, T.R., Russell, A.P. and Bauer, A.M. (2012). Repeated origin and loss of adhesive toepads in geckos. PLoS ONE 7(6):e39429

Gray, J.E. (1834). Characters of two new genera of reptiles (Geoemyda and Gehyra). Proceedings of the Zoological Society of London 1834: 99-100.

Gray, J.E. (1845). Catalogue of the specimens of lizards in the collection of the British Museum, $1^{\text {st }}$ edition. British Museum: London, xxviii + 259 pp.

Heinicke, M.P., Greenbaum, E., Jackman, T.R. and Bauer, A.M. (2011). Phylogeny of a trans-Wallacean radiation (Squamata, Gekkonidae, Gehyra) supports a single early colonization of Australia. Zoologica Scripta 40: 584-602.

Heineke, M.P., Jackman, T.R. and Bauer, A.M. (2017). The measure of success: geographic isolation promotes diversification in Pachydactylus geckos. BMC Evolutionary Biology 17: 9.
Horner, P. (2005). Gehyra koira sp. nov. (Reptilia: Gekkonidae), a new species of lizard with two allopatric subspecies from the Ord-Victoria region of north-western Australia and a key to the Gehyra australis species complex. The Beagle 21: $165-174$.

Hutchinson, M., Sistrom, M., Donnellan, S. and Hutchinson R. (2014). Taxonomic revision of the Australian arid zone lizards Gehyra variegata and G. montium (Squamata, Gekkonidae) with description of three new species. Zootaxa 3814: 221-241.

Kealley, L., Doughty, P., Pepper, P., Keogh, J.S., Hillyer, M. and Huey, J. (2018). Conspicuously concealed: Revision of the arid clade of the Gehyra variegata (Gekkonidae) group in Western Australia using an integrative molecular and morphological approach, with the description of five cryptic species. PeerJ 6: e5334.

King, M. (1979). Karyotypic evolution in Gehyra (Gekkonidae: Reptilia) I. The Gehyra variegata-punctata complex. Australian Journal of Zoology 27: 373-393.

King, M. (1981). Notes on the distribution of Gehyra nana Storr and Gehyra punctata (Fry) in Australia. Australian Journal of Herpetology 1: 55-56.

King, M. (1982a). Karyotypic evolution in Gehyra (Gekkonidae: Reptilia). II. A new species from the Alligator Rivers region in northern Australia. Australian Journal of Zoology 30: 92-101.

King, M. (1982b). A new species of Gehyra (Reptilia, Gekkonidae) from central Australia. Transactions of the Royal Society of South Australia 106: 155-158.

King, M. (1983). Karyoptic evolution in Gehyra (Gekkonidae: Reptilia). III. The Gehyra australis complex. Australian Journal of Zoology 31: 723-741.

King, M. (1984a). The Gehyra australis species complex (Sauria: Gekkonidae). Amphibia-Reptilia 4 (1983): 147-169.

King, M. (1984b). A new species of Gehyra (Reptilia: Gekkonidae) from northern Western Australia. Transactions of the Royal Society of South Australia 108: 113-117.

Lanfear, R., Calcott, B., Ho, S.Y.W. and Guindon, S. (2012). PartitionFinder: Combined selection of partitioning schemes and substitution models for phylogenetic analyses. Molecular Biology and Evolution 29: 1695-1701.

Lesson, R.P. (1830). Description de quelques reptiles nouveaux ou peu connus. In: M.L.I. Duperrey (ed)., Voyage Autour du Monde Execute par Ordre du Roi, sur la Corvette de La Majeste, La Coquille, exécuté Pendant les Annees 1822, 1823, 1824 et 1825. 2. Zoologie 2 (1). Arthur Bertrand, Paris: 1-65.

Loveridge, A. (1934). Australian reptiles in the Museum of Comparative Zoology, Cambridge, Mass. Bulliten of the Museum of Comparative Zoology 77: 243-283.

Low, T. (1978). A new species of gecko, genus Gehyra (Reptilia: Gekkonidae) from Queensland. Victorian Naturalist 96: 190-196.

Lucas, A.H.S. and Frost, C. (1896). Reptilia. In: Spencer, W. B. (ed.) Report on the work of the Horn Scientific Expedition to Central Australia. Part II. - Zoology. Dulau and Co., London and Melville, Mullen and Slade, Melbourne, pp. 112-175.

Macey, J.R., Schulte, J.A., Ananjeva, N.B., Larson, A., Rastegar-Pouyani, N., Shammakov, S.M. and Papenfuss, T.J. (1998). Phylogenetic relationships among agamid lizards of the Laudakia caucasia species group: testing hypotheses of biogeographic fragmentation and an area cladogram for the Iranian Plateau. Molecular Phylogenetics and Evolution 10: 118-131.

Macey, J.R., Schulte, J.A., Larson, A., Ananjeva, N.B., Wang, Y., Pethiya- goda, R., Rastegar-Pouyani, N. and Papenfuss, 
T.J. (2000). Evaluating trans-Tethys migration: an example using acrodont lizard phylogenetics. Systematic Biology 49: 233-256.

Macleay, W. (1877). The lizards of the Chevert Expedition. Second paper. Proceedings of the Linnaean Society of New South Wales 2: 97-104.

Maddison, W.P. and Knowles, L.L. (2006). Inferring phylogeny despite incomplete lineage sorting. Systematic Biology 55: 21-30.

Mayden, R.L. (1997) A hierarchy of species concepts: the denouement in the saga of the species problem (pp 381424). In: Claridge M.F., Dawah H.A. \& Wilson M.R. (eds), Species: the units of biodiversity. Chapman and Hall: New York.

McKenzie, N.L., van Leeuwen, S. and Pinder, A.M. (2009). Introduction to the Pilbara Biodiversity Survey, 2002-2007. Records of the Western Australian Museum, Supplement 78: 3-89.

Mitchell, F.J. (1955). Preliminary account of the Reptilia and Amphibia collected by the National Geographic SocietyCommonwealth Government-Smithsonian Institute Expedition to Arnhem Land. Records of the South Australian Museum 11: 373-408.

Mitchell, F.J. (1965). Australian geckos assigned to the genus Gehyra Gray (Reptilia, Gekkonidae). Senckenbergiana Biologica 46: 287-319.

Moritz, C. (1986). The population biology of Gehyra (Gekkonidae): chromosome change and speciation. Systematic Zoology 35: 46-67.

Moritz, C., Pratt, R.C., Bank, S., Bourke, G., Bragg, J.G., Doughty, P., Keogh, J.S., Laver, R.J., Potter, S., Teasdale, L.C., Tedeschi, L.G. and Oliver, P.M. (2018). Cryptic lineage diversity, body size divergence and sympatry in a species complex of Australian lizards (Gehyra). Evolution 72: 54-66.

Oliver, P.M., Bourke, G., Pratt, R.C., Doughty, P. and Moritz, C. (2016). Systematics of small Gehyra (Squamata: Gekkonidae) of the southern Kimberley, Western Australia: redescription of G. kimberleyi Börner \& Schüttler, 1983 and description of a new restricted range species. Zootaxa 4107 : 49-64.

Oliver, P.M., Adams, M. and Doughty, P. (2010). Molecular evidence for ten species and Oligo-Miocene vicariance within a nominal Australian gecko species (Crenadactylus ocellatus, Diplodactylidae). BMC Evolutionary Biology 10: 386.

Oliver, P.M., Adams, M., Lee, M.S.Y., Hutchinson, M.N. and Doughty, P. (2009) Cryptic diversity in vertebrates: molecular data double estimates of species diversity in a raditation of Australian lizards (Diplodactylus, Gekkota). Proceedings of the Royal Society B 276: 2001-2007.

Padial, J.M., Miralles, A., De la Riva, I. and Vences, M. (2010). The integrative future of taxonomy. Frontiers in Zoology 7: 16. doi: 10.1186/1742-9994-7-16

Pepper, M., Doughty, P. and Keogh, S.J. (2013). Synthesis: Geodiversity and endemism in the iconic Australian Pilbara region: a review of landscape evolution and biotic response in an ancient refugium. Journal of Biogeography 40: $1225-1239$.

Powney, G.D., Grenyer, R., Orme, C.D.L., Owens, I.P.F. and Meiri, S. (2010). Hot, dry and different: Australian lizard richness is unlike that of mammals, amphibians and birds. Global Ecology and Biogeography 19: 386-396.

Rambaut, A. (1996). Se-Al: sequence alignment editor software. $<\mathrm{http} / / /$ tree.bio.ed.ac.uk/software/seal $>$

Read, K., Keogh, J.S., Scott, I.A.W., Roberts, J.D. and Doughty, P. (2001). Molecular phylogeny of the Australian frog genera
Crinia, Geocrinia and allied taxa (Anura: Myobatrachidae). Molecular Phylogenetics and Evolution 21: 294-308.

Rodriguez, F., Oliver, J.L., Marin, A. and Medina, J.R. (1990). The general stochastic model of nucleotide substitution. Journal of Theoretical Biology 142: 485-501.

Rosauer, D.F., Byrne, M., Blom, M.P.K., Coates, D.J., Donnellan, S., Doughty, P., Keogh, J.S., Kinloch, J., Laver, R.J., Myers, C., Oliver, P.M., Potter, S., Rabosky, D.L., Afonso Silva, A.C., Smith, J. and Moritz, C. (2018). Realworld conservation planning for evolutionary diversity in the Kimberley, Australia, sidesteps uncertain taxonomy. Conservation Letters: early on-line view.

Sistrom, M.J., Hutchinson, M.N., Hutchinson, R.G., Donnellan, S.C. (2009). Molecular phylogeny of Australian Gehyra (Squamata: Gekkonidae) and taxonomic revision of Gehyra variegata in south-eastern Australia. Zootaxa 2277: 14-32.

Sistrom, M.J., Edwards, D.L., Donnellan, S. and Hutchinson, M. (2012). Morphological differentiation correlates with ecological but not genetic divergence in a Gehyra gecko. Journal of Evolutionary Biology 25: 647-660.

Sistrom, M., Donnellan, S. and Hutchinson, M. (2013). Delimiting species in recent radiations with low levels of morphological divergence: A case study in Australian Gehyra geckos. Molecular Phylogenetics \& Evolution 68 : 135-143.

Sistrom, M., Hutchinson, M., Bertozzi, T. and Donnellan, S. (2014). Evaluating evolutionary history in the face of high gene tree discordance in Australian Gehyra (Reptilia: Gekkonidae). Heredity 113: 52-63.

Sites, J.W., Jr. and Marshall, J.C. (2003). Delimiting species: a Renaissance issue in systematic biology. Trends in Ecology and Evolution 18: 462-470.

Sites, J.W., Jr. and Marshall, J.C. (2004). Operational criteria for delimiting species. Annual Review of Ecology and Systematics 35: 199-227.

Stamatakis, A. (2006). RAxML-VI-HPC: maximum likelihoodbased phylogenetic analyses with thousands of taxa and mixed models. Bioinformatics 22: 2688-2690.

Storr, G.M. (1978). Seven new gekkonid lizards from Western Australia. Records of the Western Australian Museum 6: 337-352.

Storr, G.M. (1982). Two new Gehyra (Lacertilia: Gekkonidae) from Australia. Records of the Western Australian Museum 10: $53-59$.

Storr, G.M., Smith, L.A. and Johnstone, R.E. (1990). Lizards of Western Australia. III. Geckos and pygopods. Western Australian Museum Press: Perth.

Sukumaran, J. and Knowles, L.L. (2017). Multispecies coalescent delimits structure, not species. Proceedings of the National Academy of Sciences 114: 1607-1612.

Thackway, R. and Cresswell, I.D. (1995). An interim biogeographic regionalisation of Australia. Australian Nature Conservation Agency: Canberra.

Wells, R.W. and Wellington, C.R. (1983). A synopsis of the Class Reptilia in Australia. Australian Journal of Herpetology 1: 73-129.

Wilson, S.K. and Swan, G. (2008). A complete field guide to reptiles of Australia, 2nd edition. Reed New Holland: Sydney, $512 \mathrm{pp}$.

Wiens, J.J. and Penkrot, T.A. (2002). Delimiting species using DNA and morphological variation and discordant species limits in spiny lizards (Sceloporus). Systematic Biology 51: 69-91.

Zietz, F.R. (1920). Catalogue of Australian lizards. Records of the South Australian Museum 1: 181- 228.

MANUSCRIPT RECEIVED 26 MAY 2018; ACCEPTED 28 JUNE 2018. 


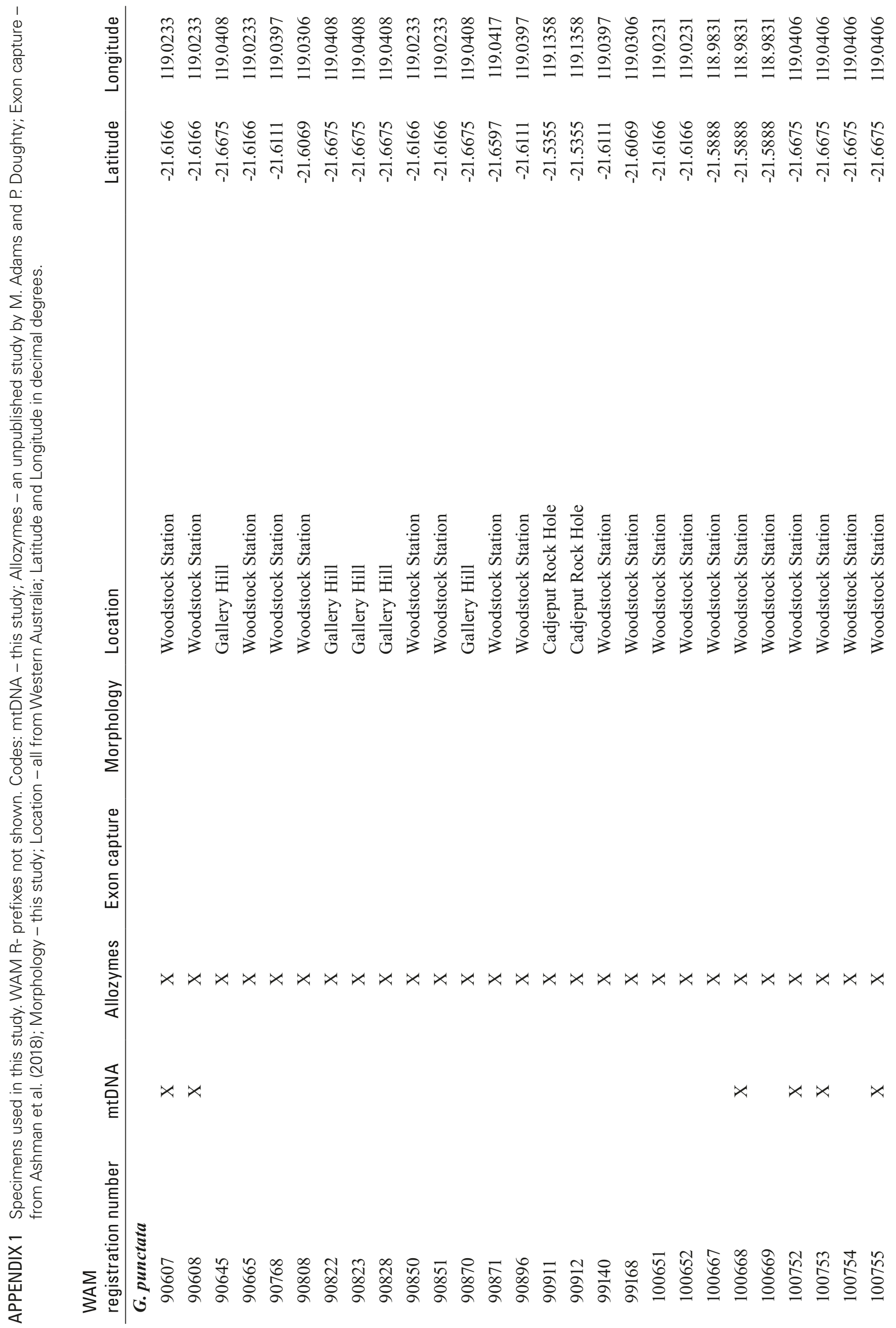




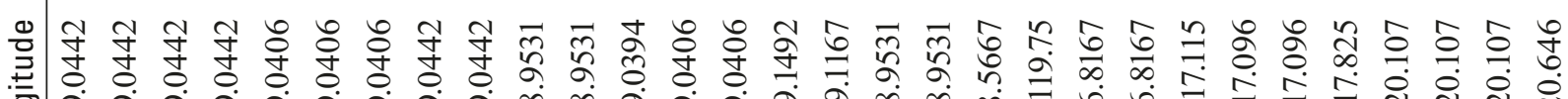

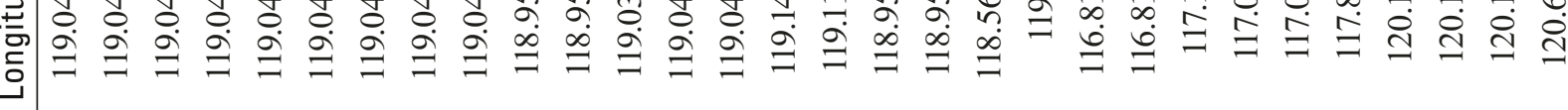

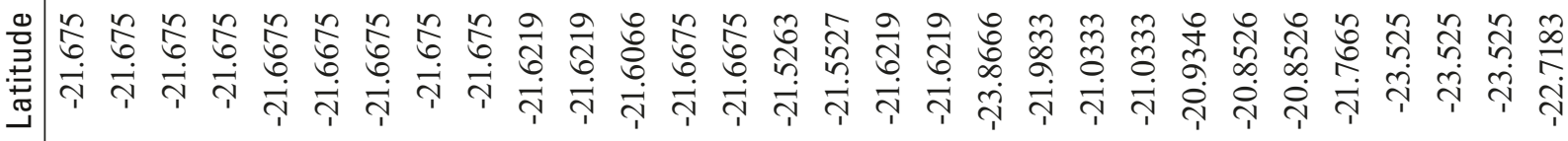
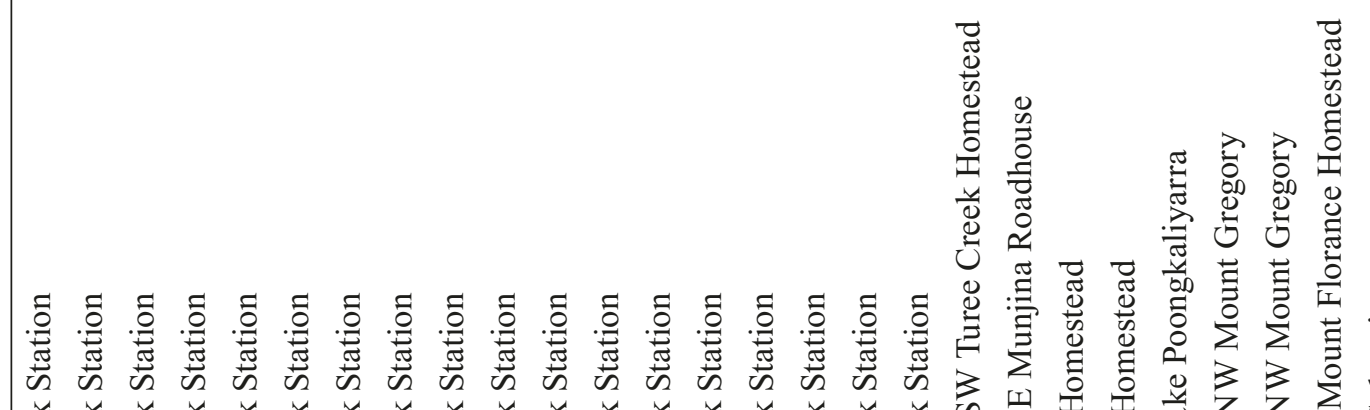

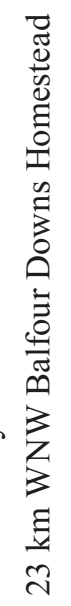

$\stackrel{\infty}{\stackrel{\infty}{\&}}$

(x)

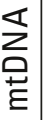

$$
x
$$<smiles>C1CC2CCCC2C1</smiles>
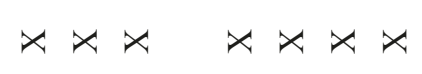

㐫

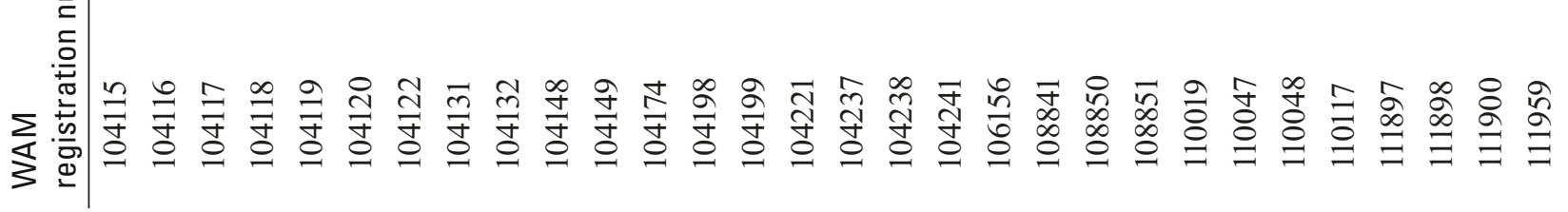




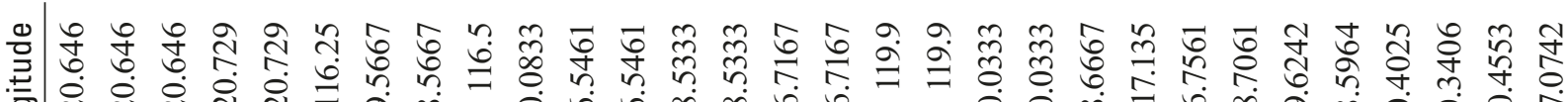

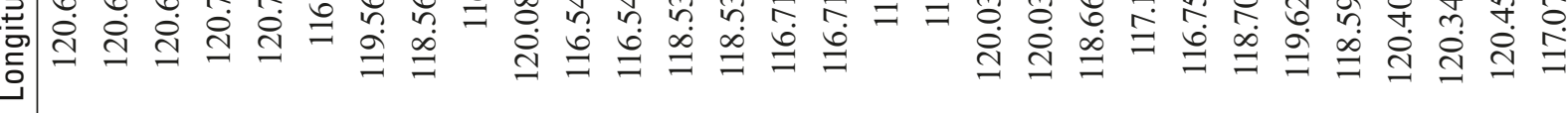

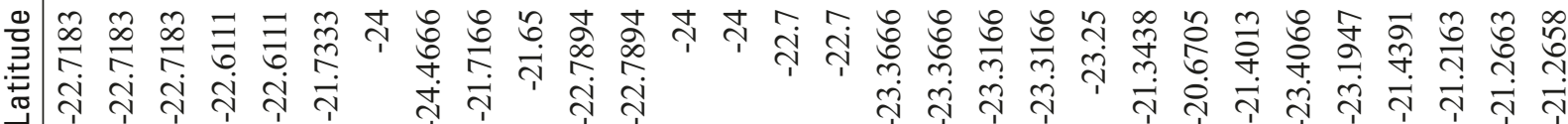

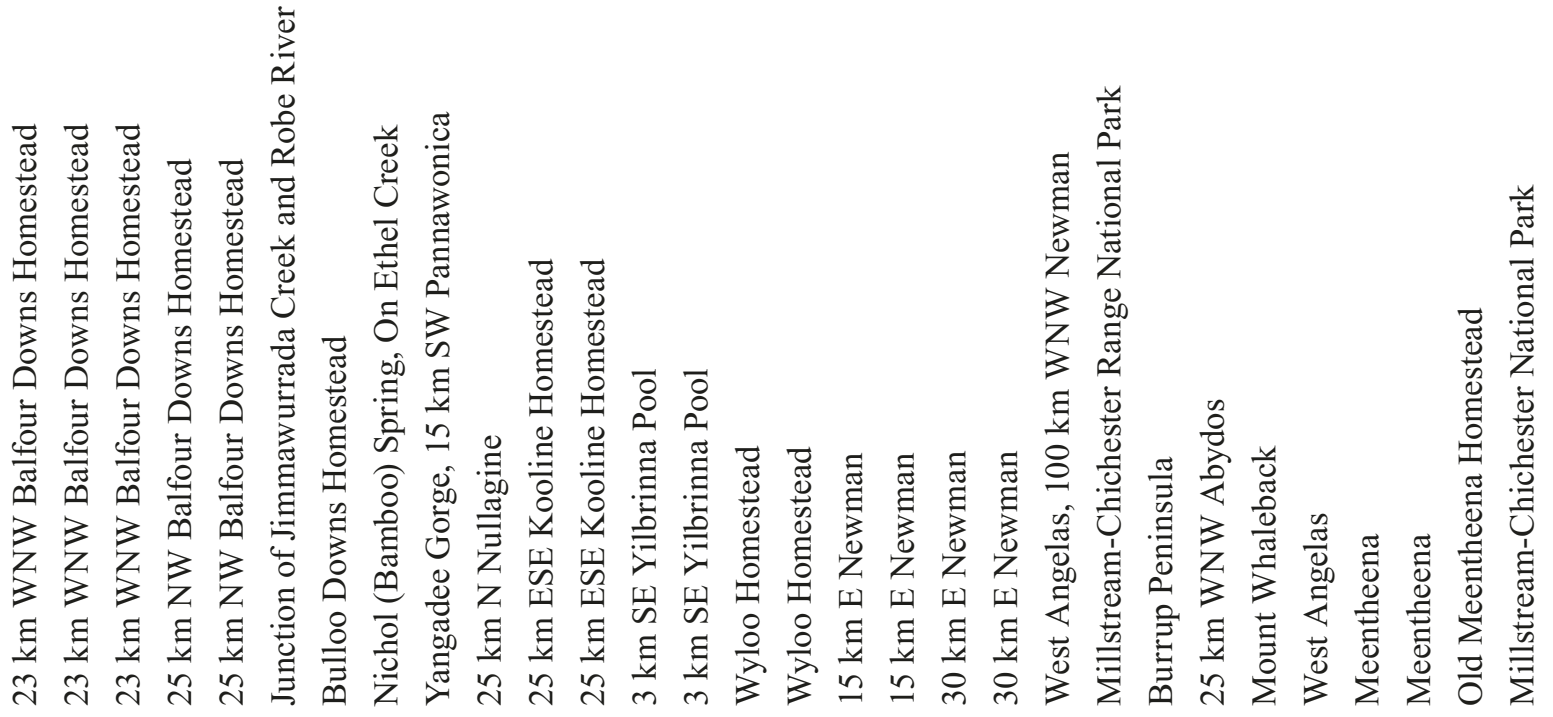

흥

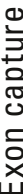

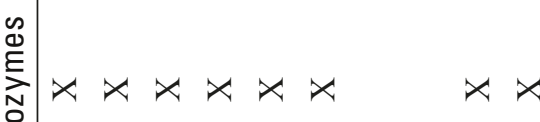

자

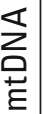<smiles>[Y][Y]=[Y][Y]</smiles>

है

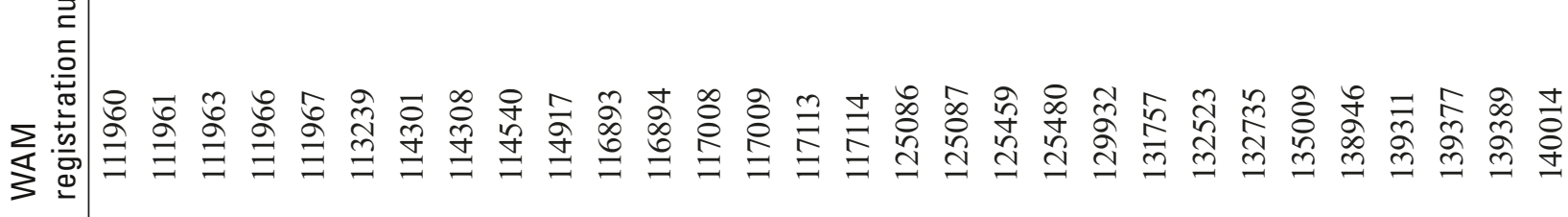




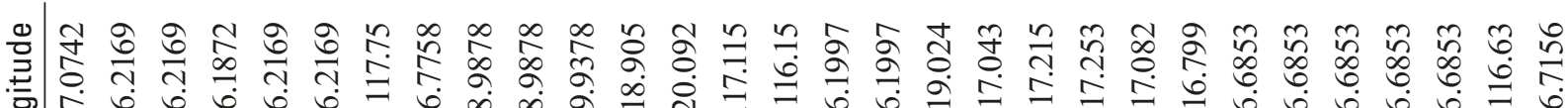

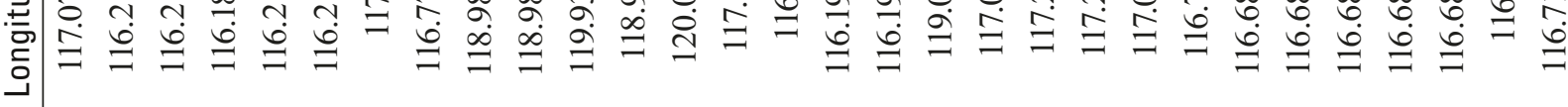

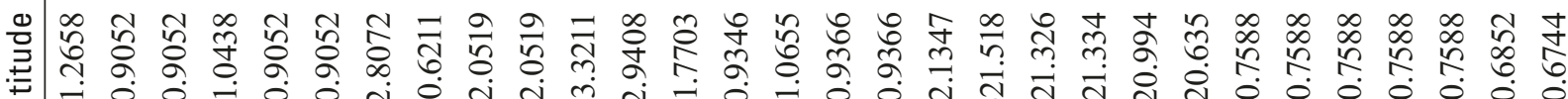

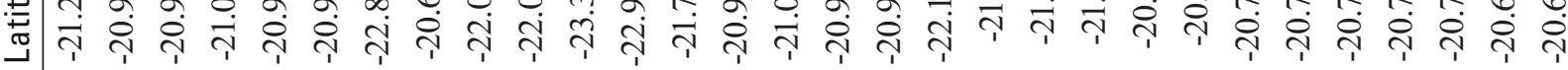

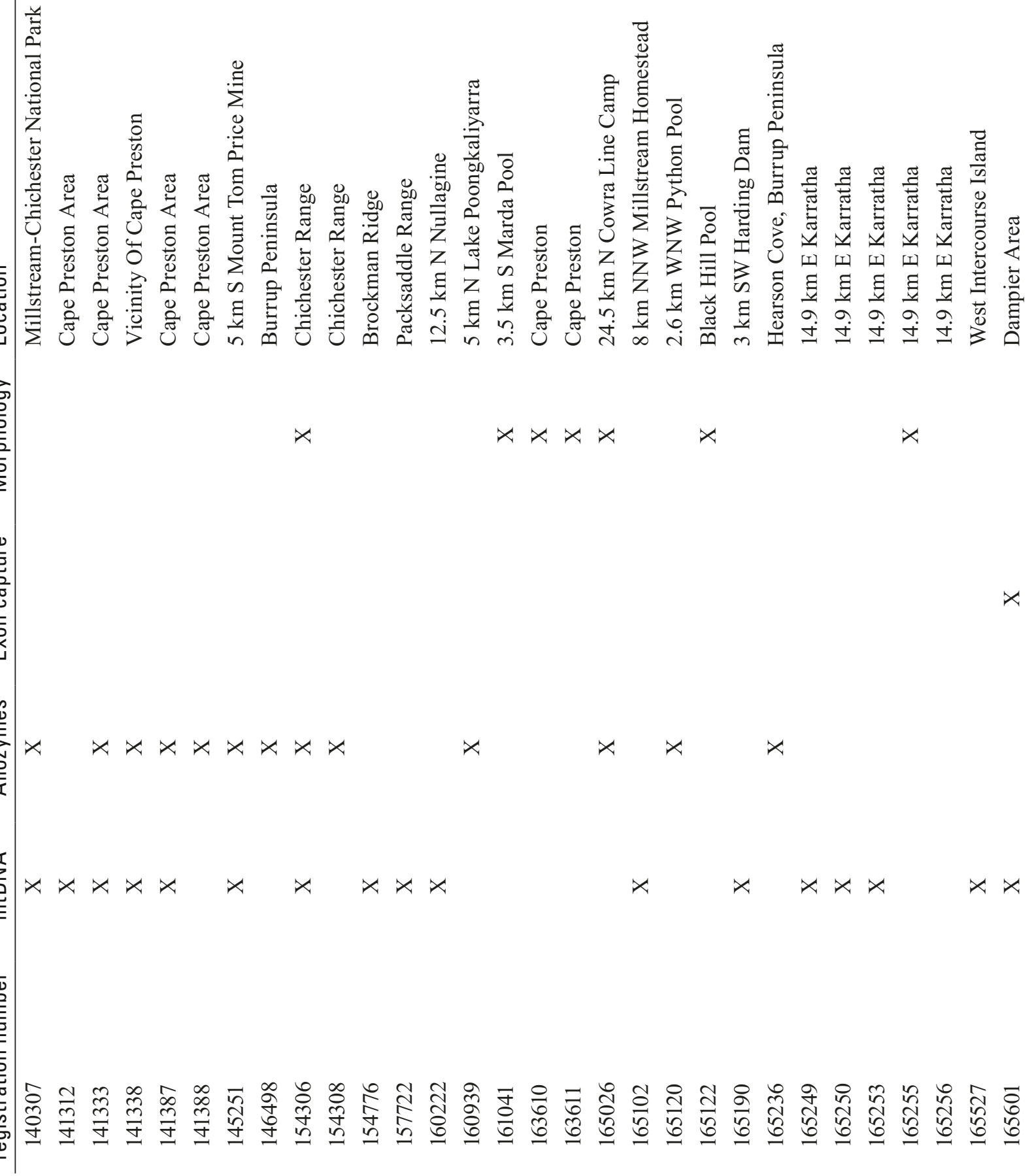




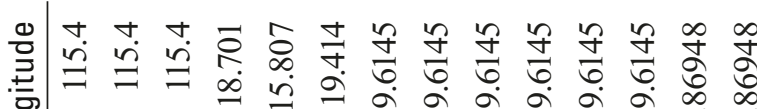
高

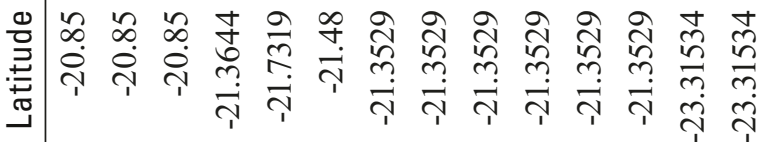

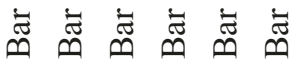

象

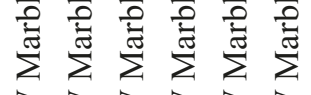

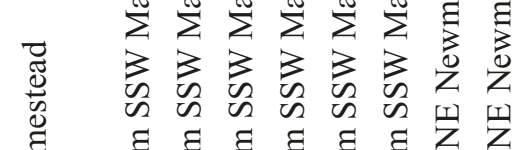

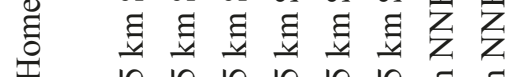

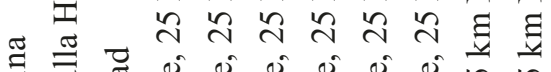

劳

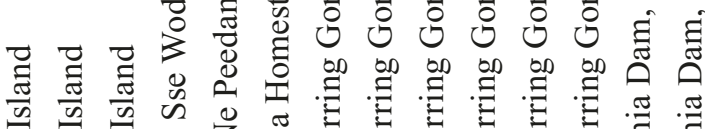

ᄃ

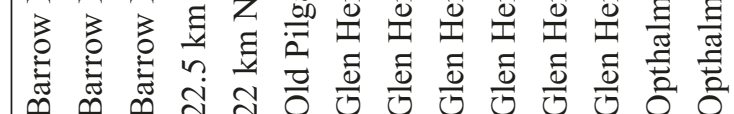

흠

$x x x$

$\sum$

咅

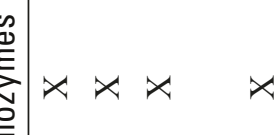

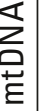

$x x x \quad x x x x$

$x x$

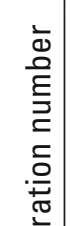

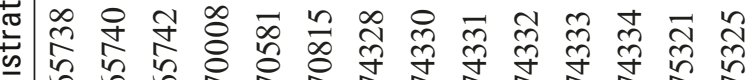

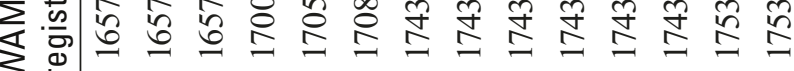

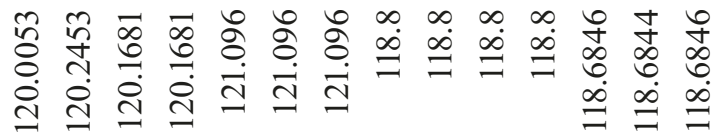

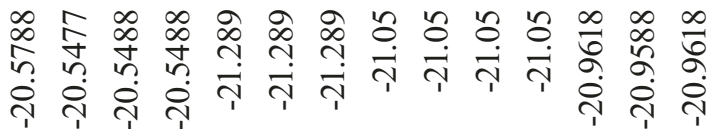

चี च]

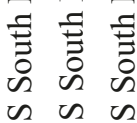

छ $\Xi$

$\frac{5}{6} \frac{1}{6}$

क्षे हो 2

窟

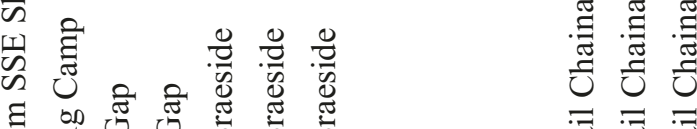

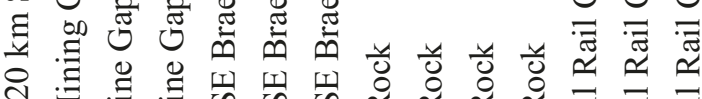

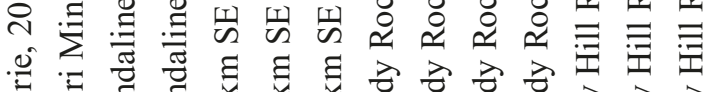

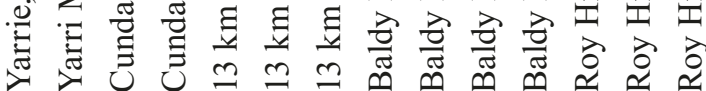
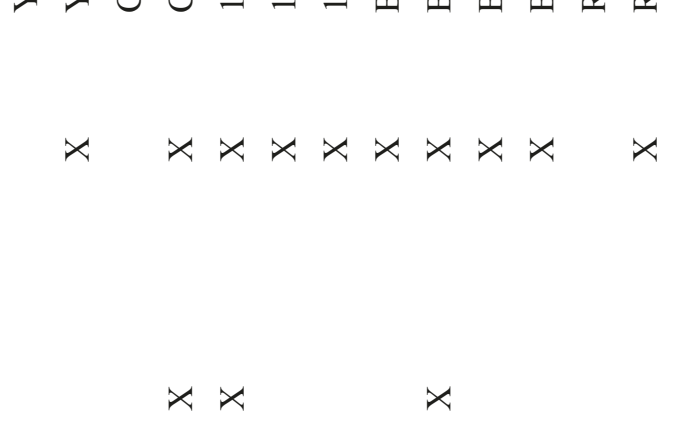

$x \times x \times x \times x \times$

$x x x x x x x \quad x \quad x x x$

$\dot{\vec{\theta}}$

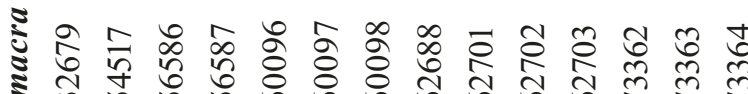

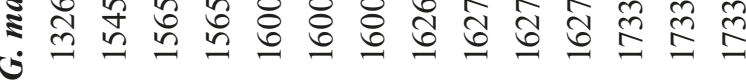




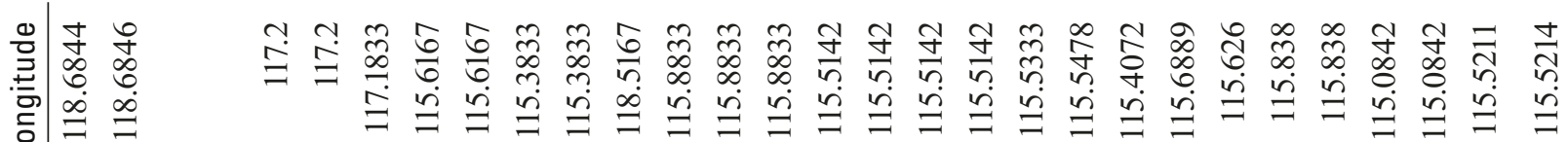

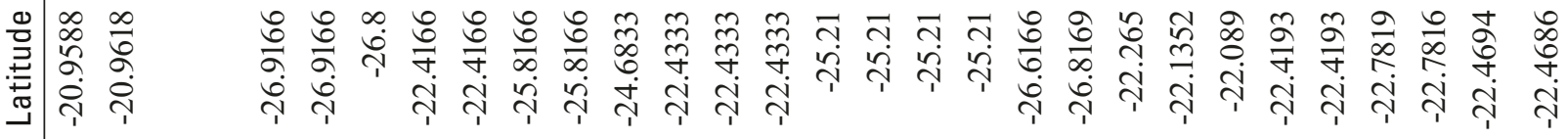

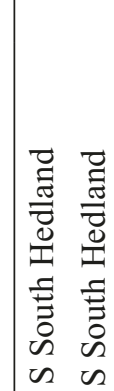

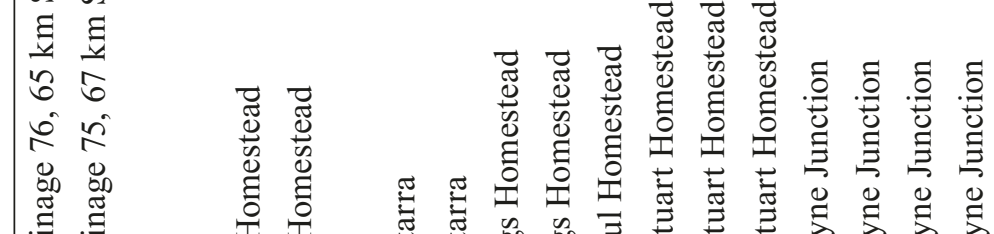

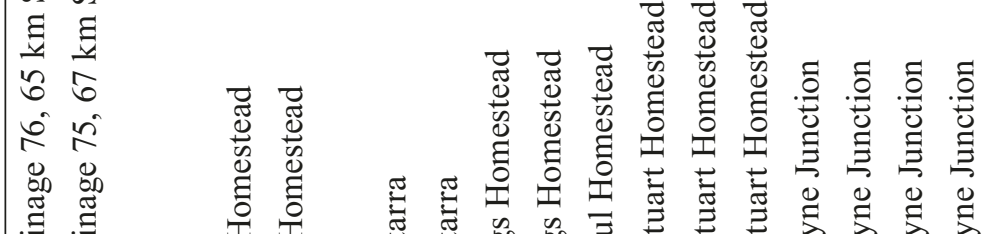

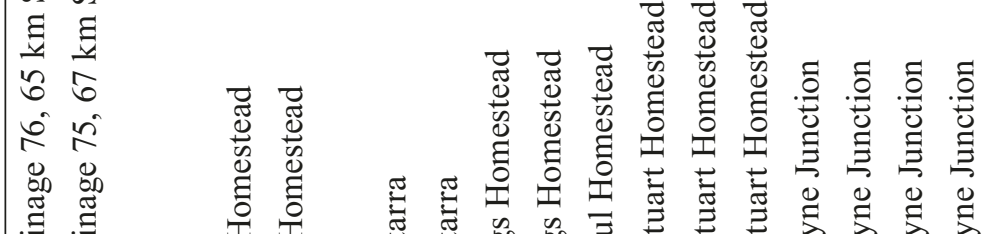

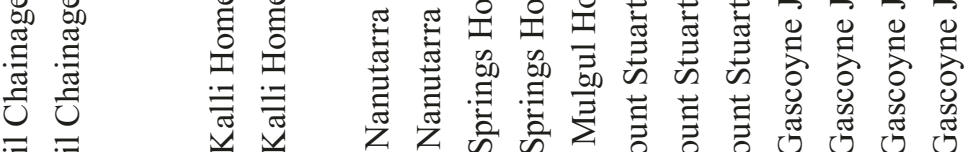

त)

总恶焉

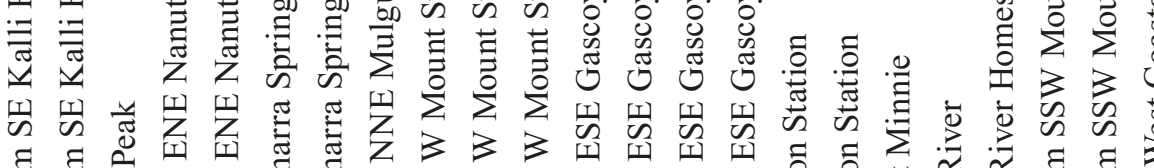

遍

떠

五

守牙

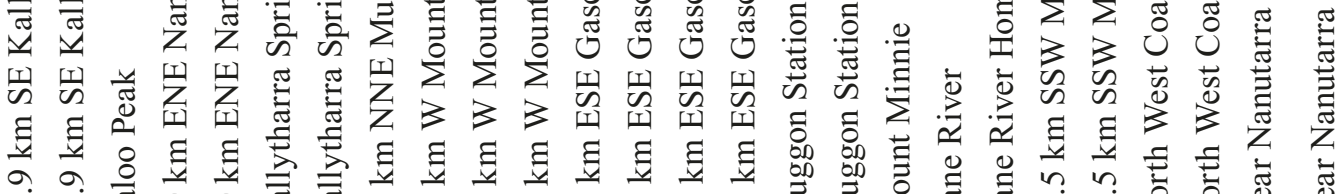

完

仓े

흥

$x \times$

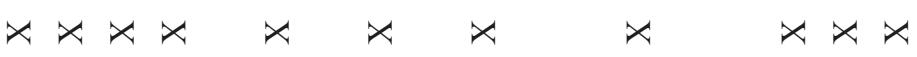

章

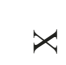

ते

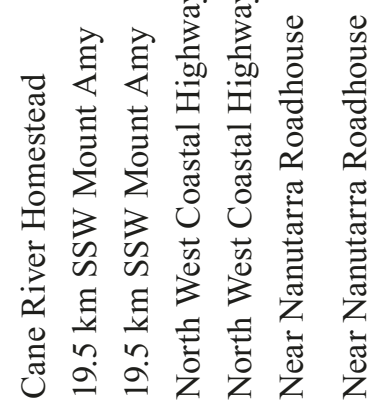

突

离

$x x x$

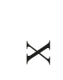

$x$

$x x x x$

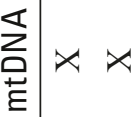<smiles>[Y][Y]</smiles>

$x$

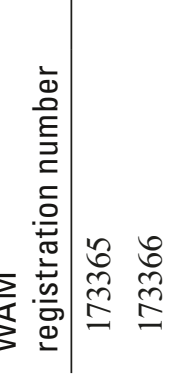

ثิ

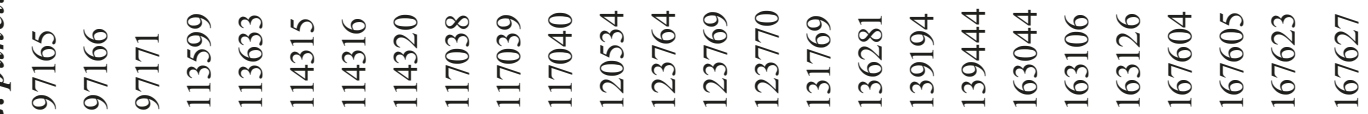




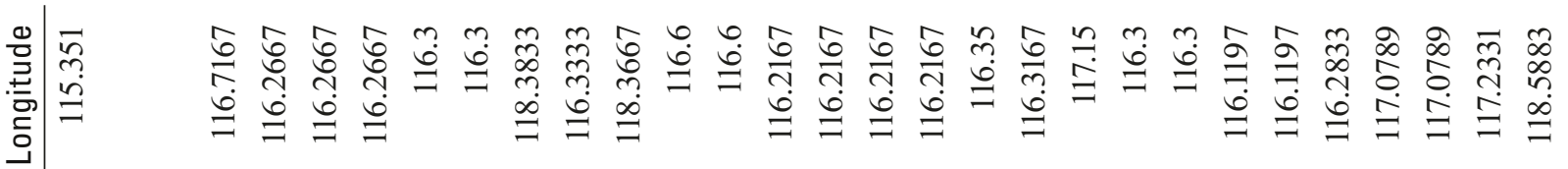

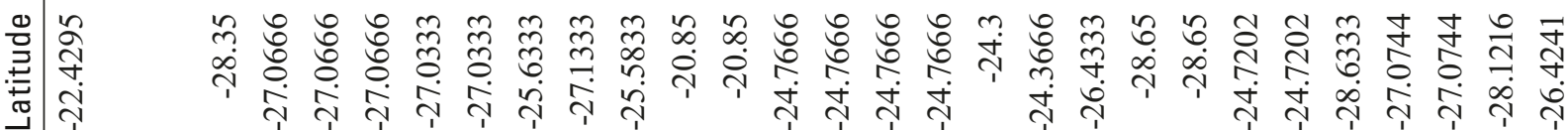

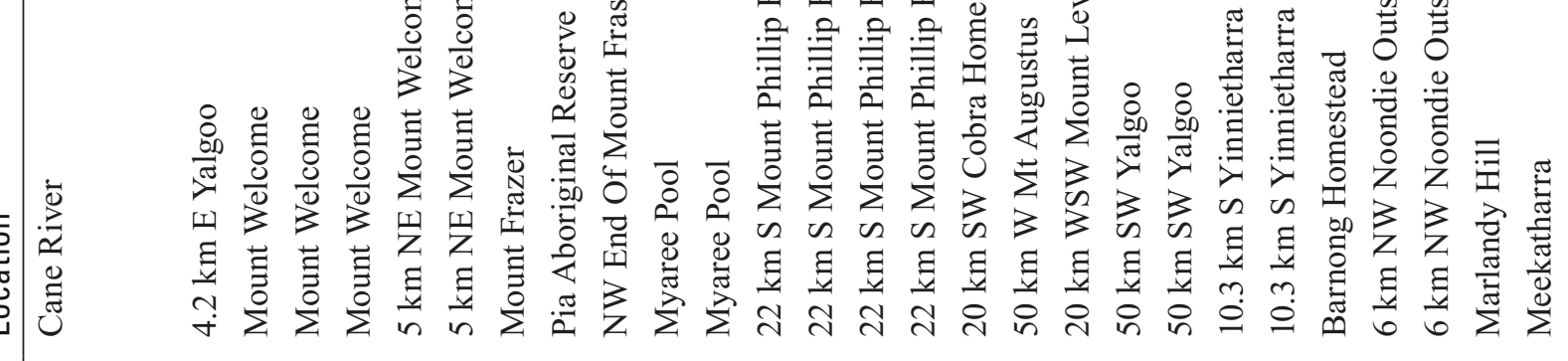

के
$\frac{0}{0}$
$\frac{0}{0}$
$\frac{0}{2}$

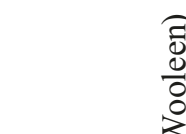

$\frac{\overparen{8}}{\frac{0}{8}}$
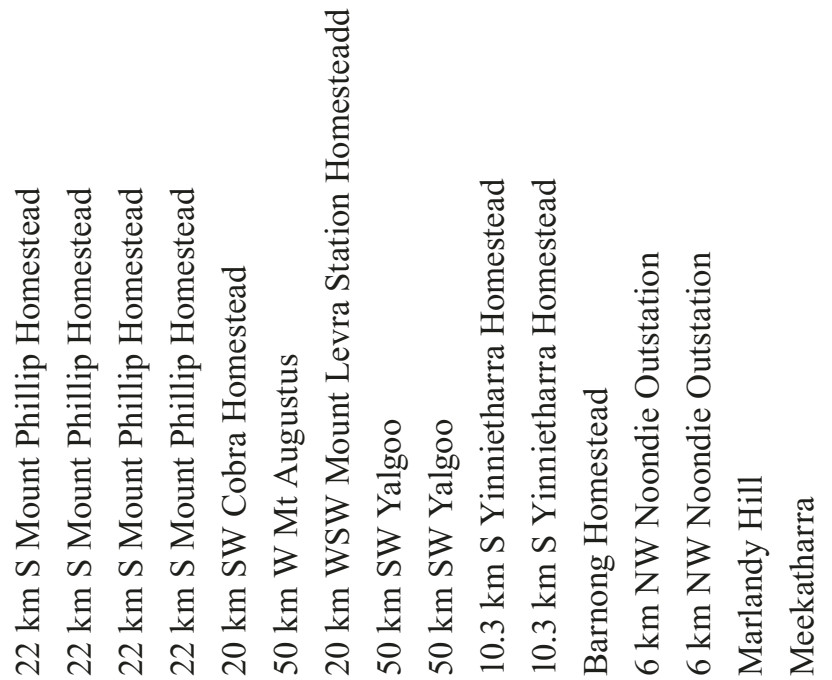

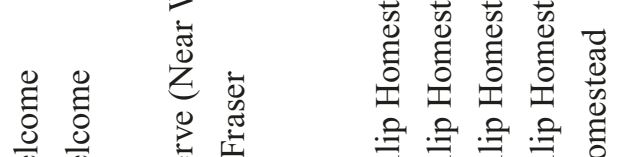

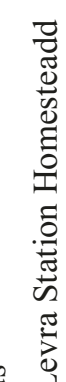

$x x x$

$x$

$x \times x \times x \times x$

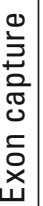

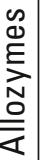

$x x x x x$

$x \times x$

$x x x x x x x$

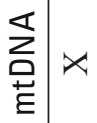

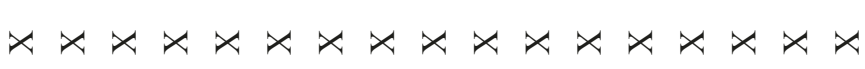

$x \times x \times x \times$

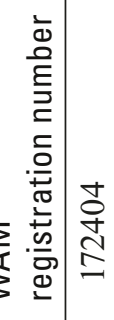

$\stackrel{\text { : }}{a}$

के

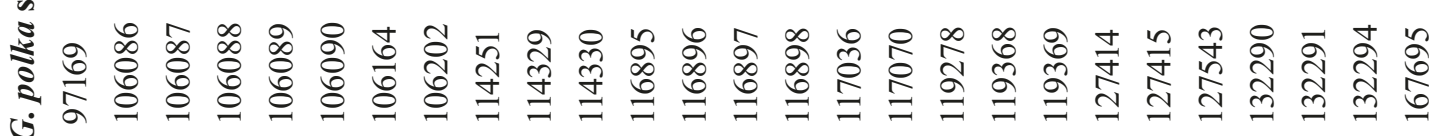




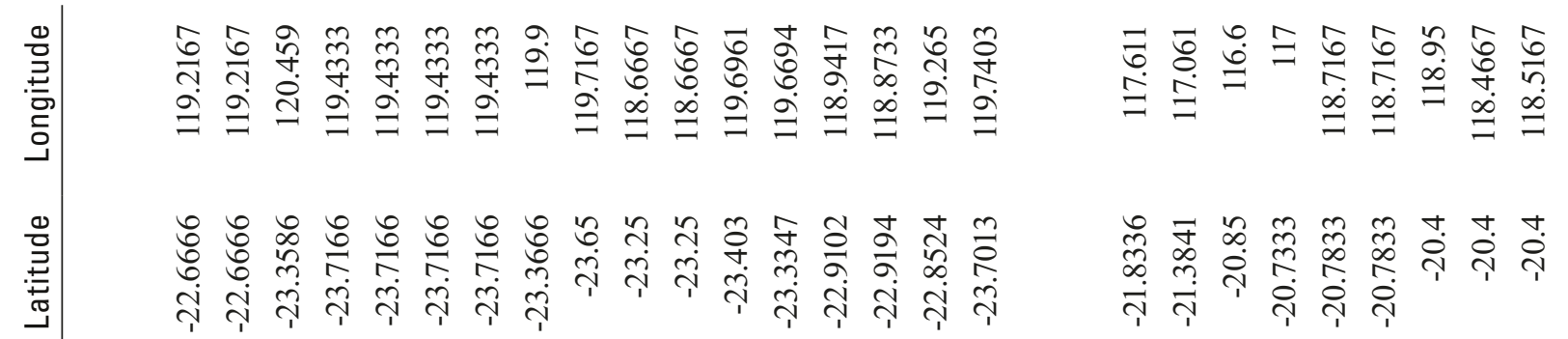

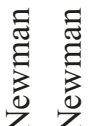

$\begin{array}{ll}\vec{\Xi} & \overrightarrow{0} \\ 0 & 0 \\ 0 & 0 \\ 0 & 0 \\ 0 & 0\end{array}$

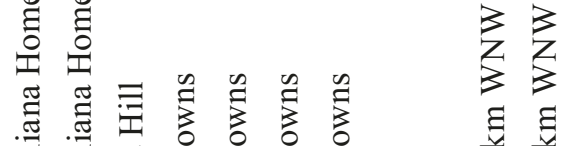

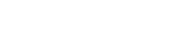

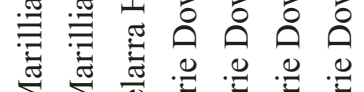

छ

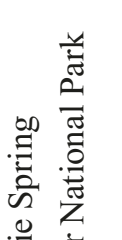

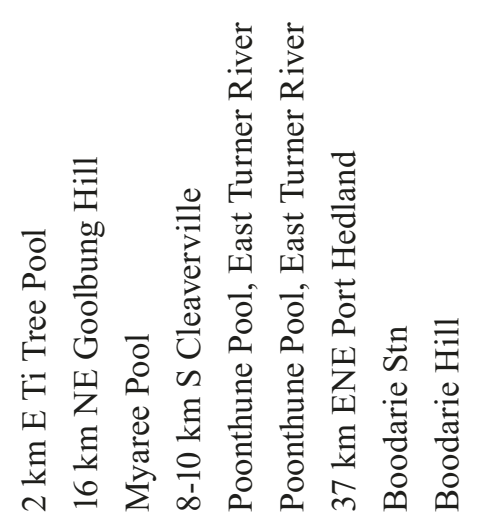<smiles>[Y][V]</smiles><smiles>[Y][Y][Y]([Y])([Y])[Y]</smiles><smiles>[Y][Y][Y]</smiles><smiles>[V][V]</smiles>

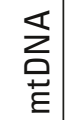

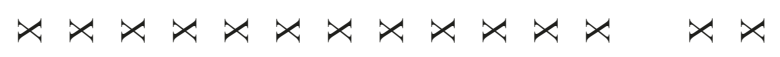<smiles>[Y][Y][Y]</smiles> 


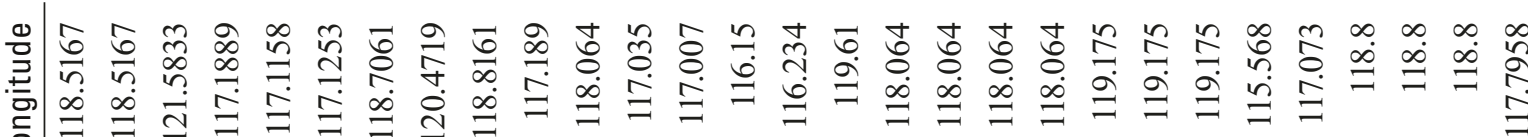

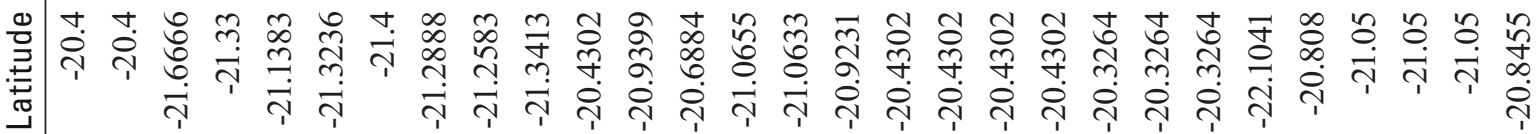

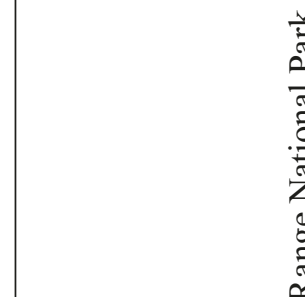

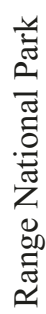

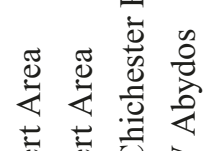

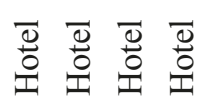

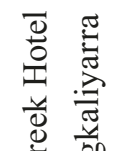

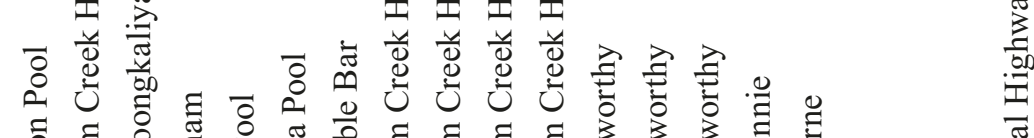

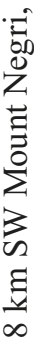

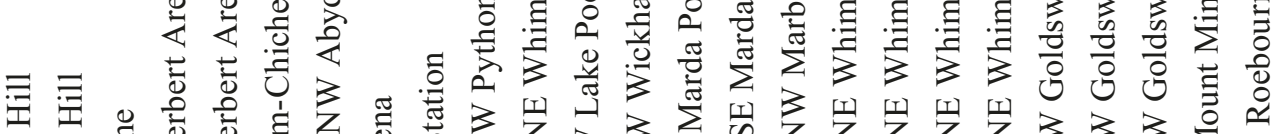

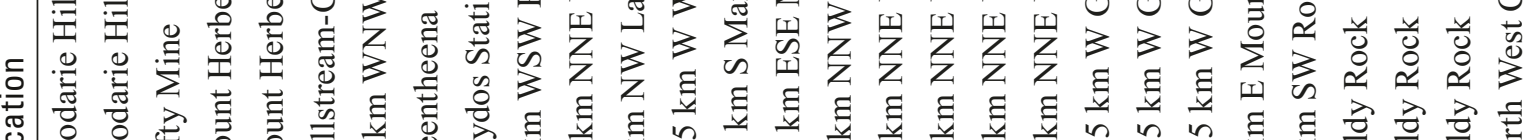

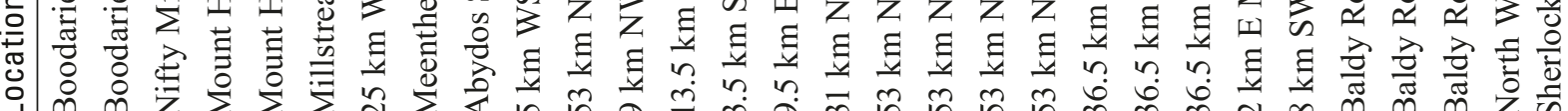
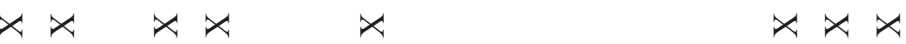

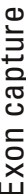

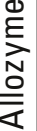
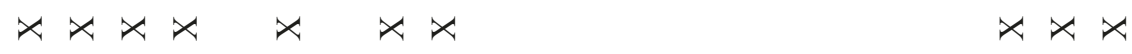

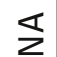

$\stackrel{+}{E}$

$\stackrel{\bar{d}}{\mathrm{E}}$

.

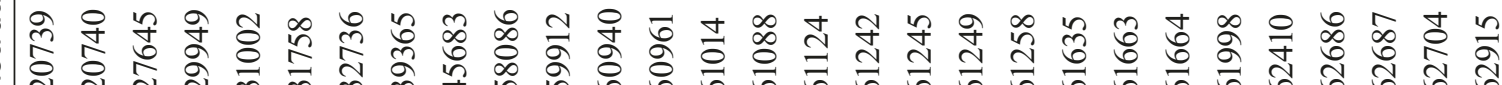

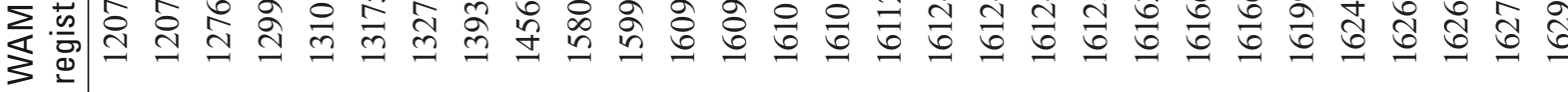




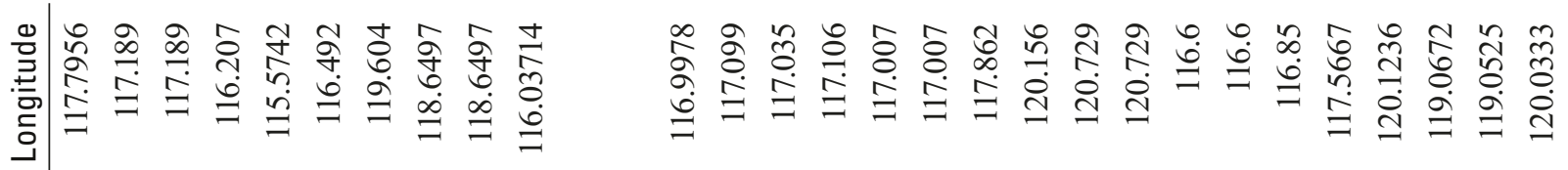

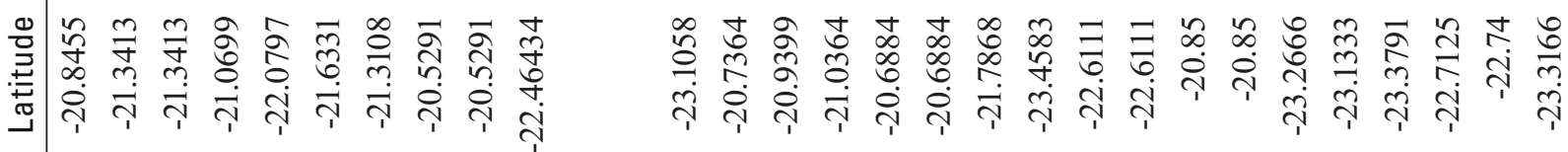

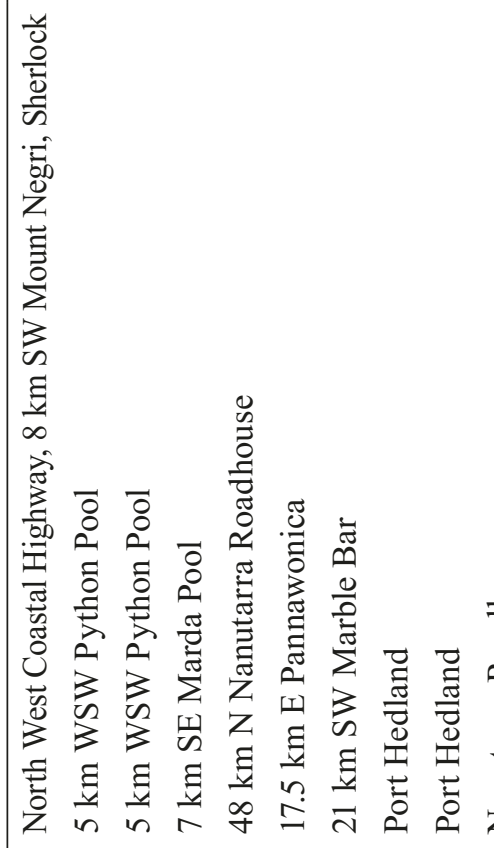

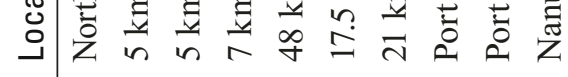

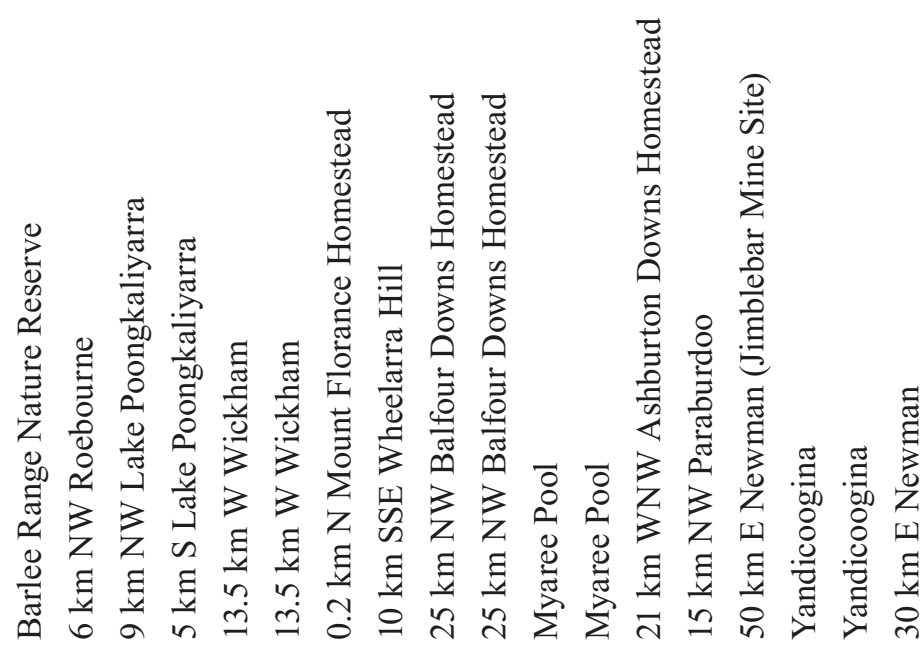

के
$\frac{0}{0}$
$\frac{0}{2}$
$\frac{0}{2}$

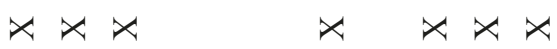

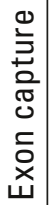

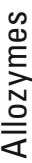

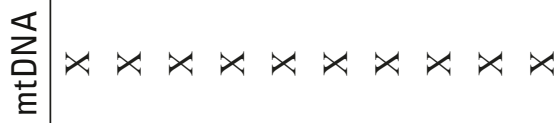<smiles>[Li]</smiles>

$x \times x \times x \times x \times x \times x \times x \times x$

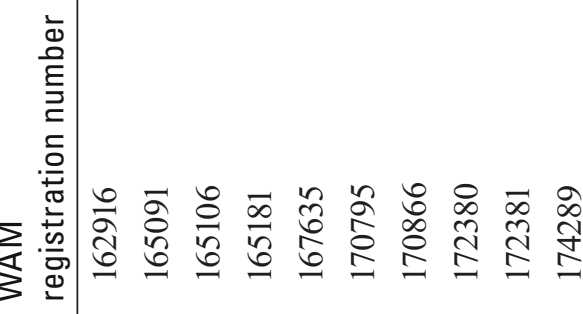

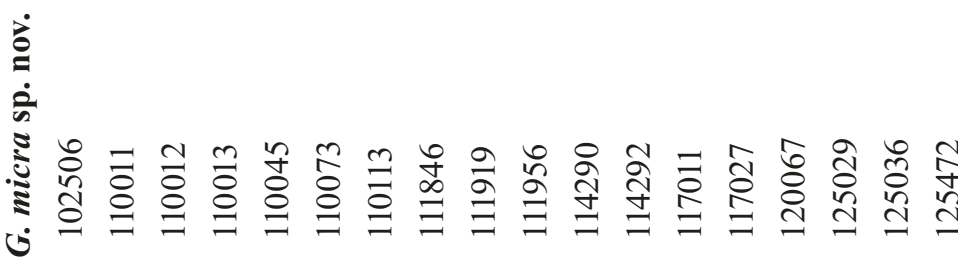


节 ঢั)

站 节 तิ

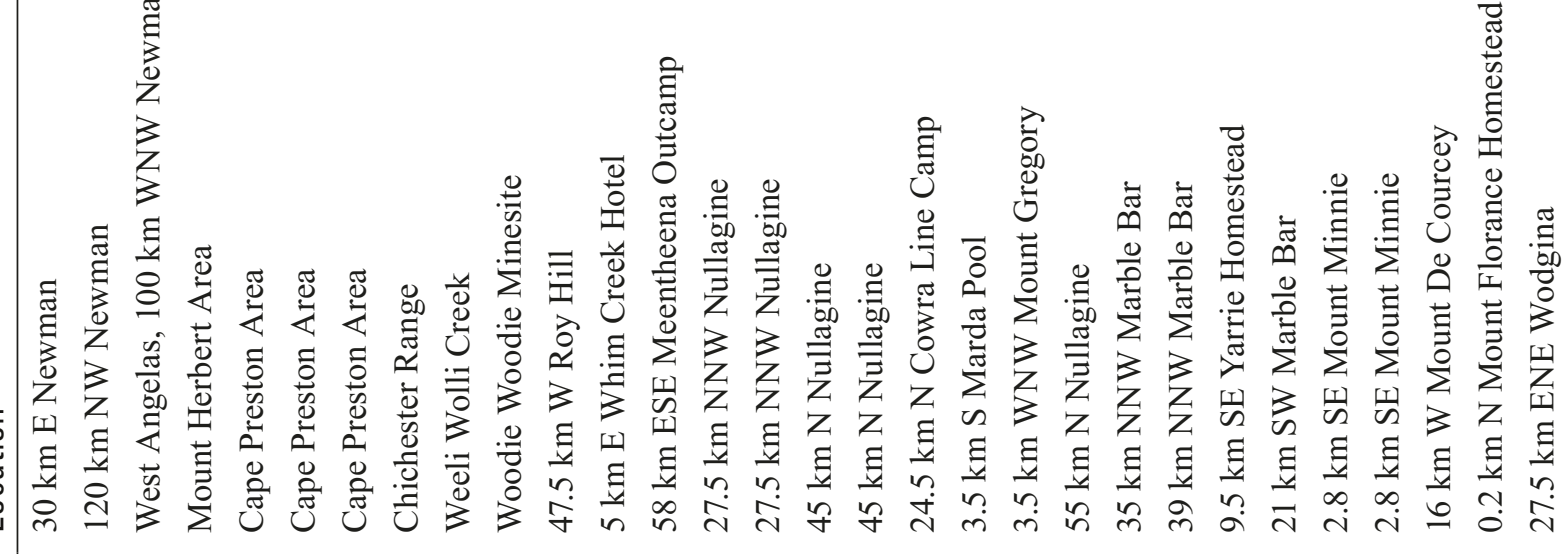

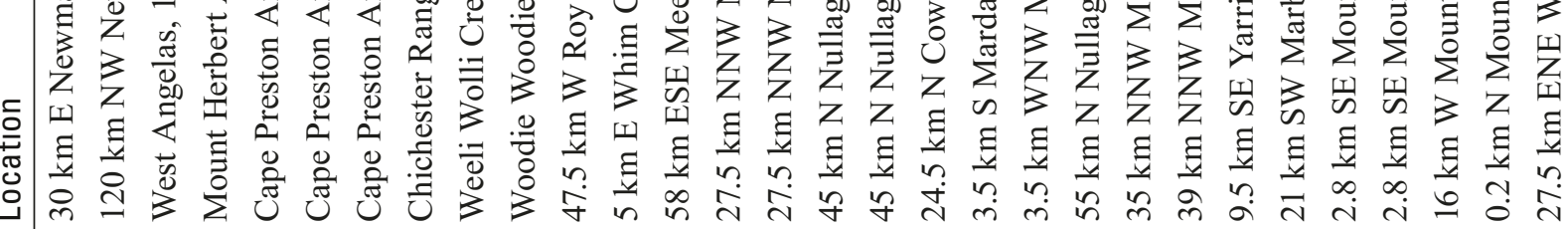

흥

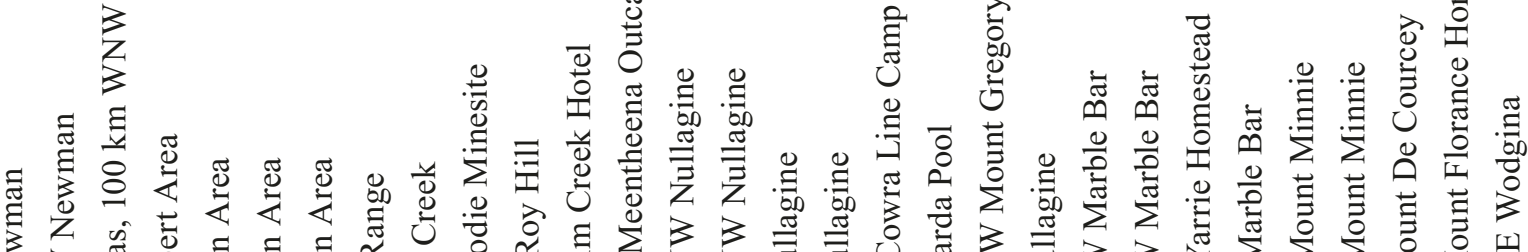

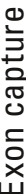

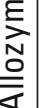

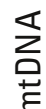

हี
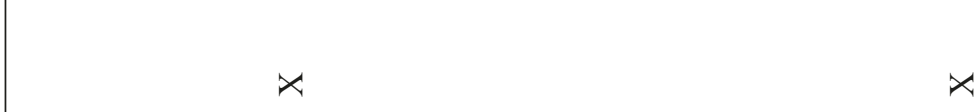

$x$

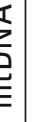

흘

듬

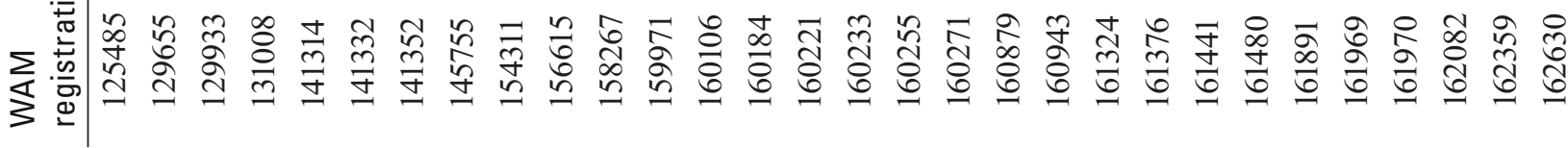




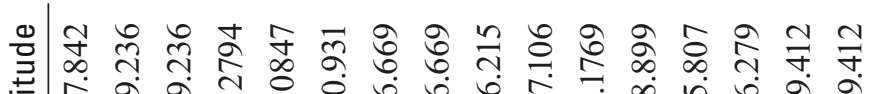

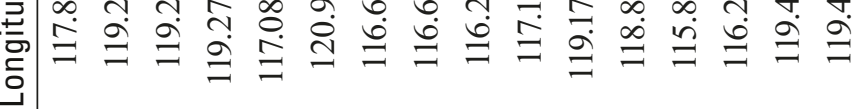

mº 它

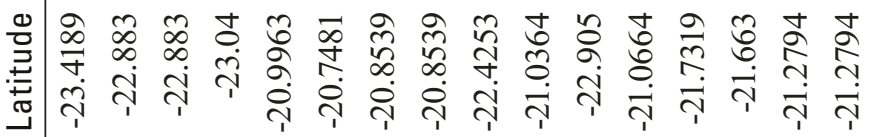

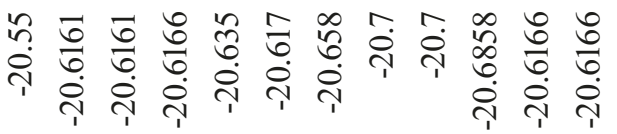
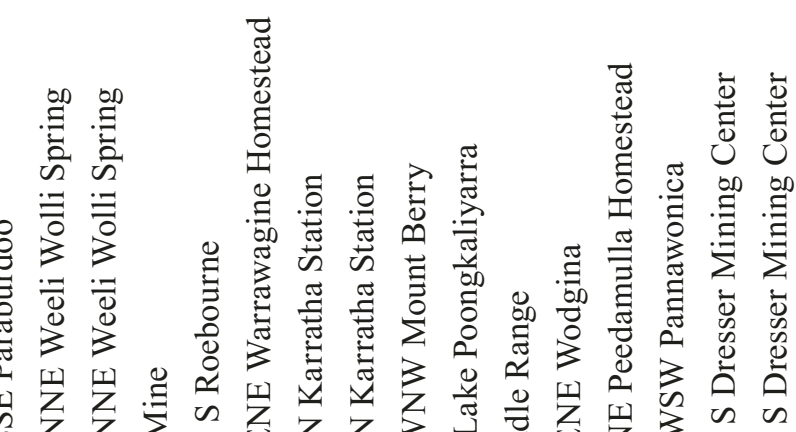

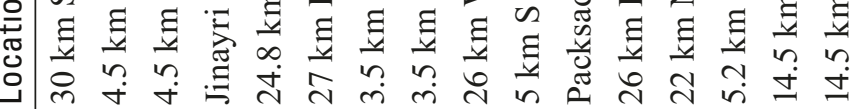

항
$\frac{0}{0}$
$\frac{0}{2}$
$\frac{0}{2}$
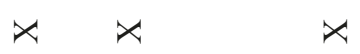

$x x x x$

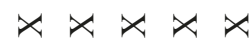

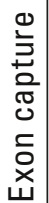

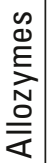

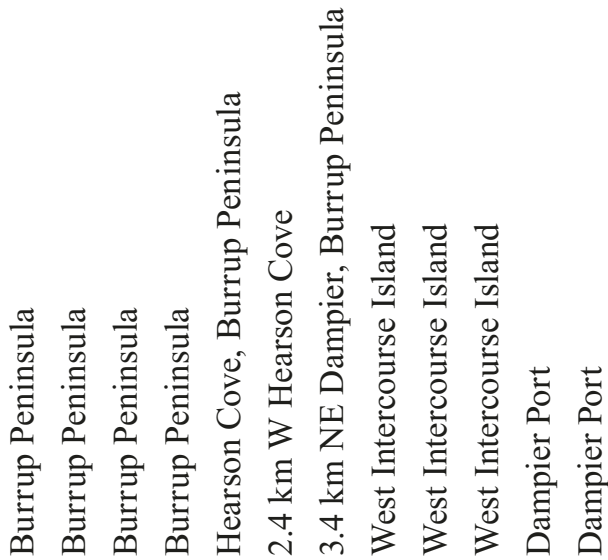

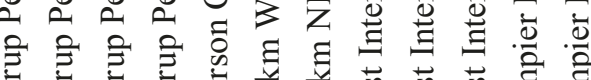

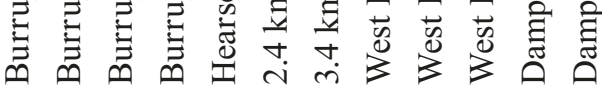

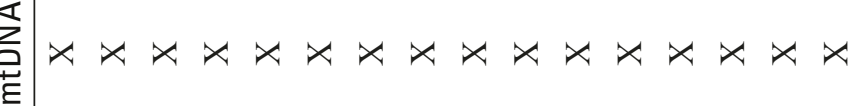

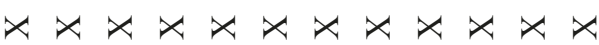

ळ亠े

至

অ $\infty$ oे तै

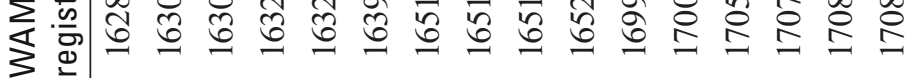

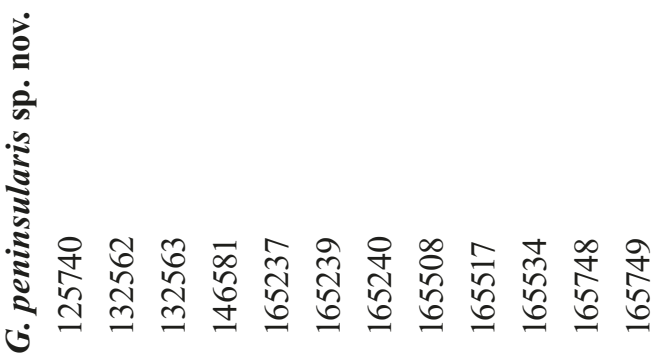




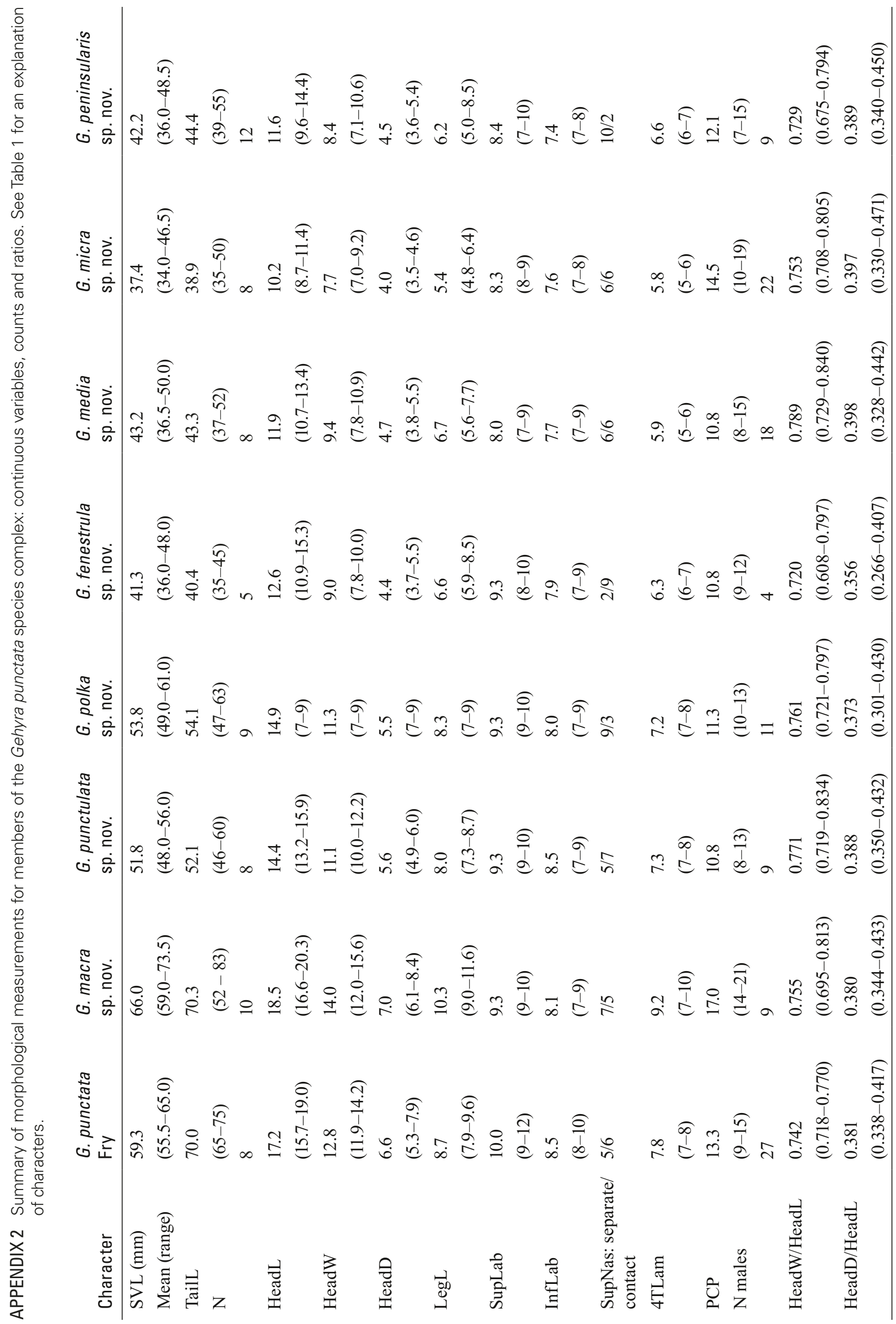

